\title{
NBSIR $73.285(R)$
}

\section{Structure Analysis and Program Planning Study of the Army Nurse Corps (ANC)}

Part I

John W. Rowen, Ralph B. Swisher, Patsy B. Saunders

Technical Analysis Division Institute for Applied Technology

$N$ ational Bureau of Standards

Washington, D. C. 20234

October 1,1973

F inal Report: Project No. 4314487

(The findings in this report are not to be construed as an official Department of the Army position.)

Prepared for

The Department of the Army Office of The Surgeon General Washington, D. C. 20314 

NBSIR 73-285

\section{STRUCTURE ANALYSIS AND PROGRAM \\ PLANNING STUDY OF THE ARMY NURSE \\ CORPS (ANC)}

Part 1

John W. Rowen, Ralph B. Swisher, Patsy B. Saunders

Technical Analysis Division

Institute for Applied Technology

National Bureau of Standards

Washington, D. C. 20234

October 1, 1973

Final Report: Project No. 4314487

(The findings in this report are not to be construed as an official Department of the Army position.)

Prepared for

The Department of the Army

Office of The Surgeon General

Washington, D. C. 20314

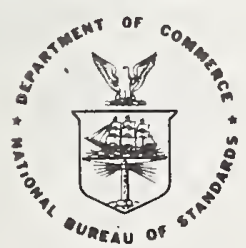

U. S. DEPARTMENT OF COMMERCE, Frederick B. Dent, Secretary

NATIONAL BUREAU OF STANDARDS, Richard W. Roberts, Director 
A number of persons contributed to the Structure Analysis and Program Planning Study of the Army Nurse Corps. It would be virtually impossible to acknowledge the efforts of all those who have supported the project and study. The authors would, however, like to place on record their appreciation for the specific assistance of several individuals.

Colonel Irene R. Pishak served as the study sponsor's representative during January through June 1972. Colone1 D. S. Frazier assisted Colonel Pishak and the National Bureau of Standards staff in the development of the questionnaire and survey instruments. The authors particularly wish to mention the support, suggestions and continuing guidance of Lieutenant Colonel Cassandra M. Smith, who served as the sponsor's representative during the period of June 1972 to October 1973, and who worked long and hard to bring every phase of the study to successful completion.

A very special acknowledgment must go to Dr. Robert J. Cunitz, who served as co-project leader (representing the Behavioral Sciences Program Area) during the period January through August 1972. During this time Dr. Cunitz contributed much to the original study design, the development and field validation of the survey instruments, and the format for final data analysis and reporting.

Dr. Michael E. Thomas, currently Professor at the University of Florida, and Dr. Neal D. Glassman, now at the Office of Naval Research, both former members of the Bureau staff, were instrumental in early stages of development of the force structure simulation model. Dr. June R. Cornog, 
Program Manager, TAD, for Behavioral Sciences, Elaine Bunten and Dr. Lynn Llewellyn were all instrumental in formulating, testing and validating the worldwide questionnaire and MEDDAC survey instruments.

The authors gratefully acknowledge the participation of the following persons during the study:

- Dr. Julius Lieblein and James A. Lechner, who wrote, edited, and rewrote most of Section 4, Part I, and all of the statistical sections in Annex II. Dr. Dennis Eisen provided support to those sections in Part I dealing with the quality of patient care and the treatment of the MEDDAC data.

- The authors were provided with programming support by Janet A. Yellen, Elizabeth E. Leyendecker, Walter D. Urban, Richard H. Jackson and John Scotch.

- Mary L. Friend, with the aid of Roy P. Mullinax, Carol R. Naas and Arthur I. Cohen spent many hours in preparing drafts of the final report for review and made a variety of contributions including style, figures and format. Elizabeth A. Robertson assisted in Behavioral Sciences tasks including those relating to instrumental format development and validation, and supervising the manual processing of questionnaire data.

- John C. Flannagan, Dr. Alan J. Goldman, and Peter W. Finkel all read the entire report and spent many hours reviewing and discussing all parts of the report with the authors. In addition, Mr. Finkel assumed overall responsibility for the study in September 1972, coordinating the efforts of his staff (Public Policy and Program Analysis Area), the Behavioral Sciences staff and interacting with the sponsor. 
1.0 Introduction ............... . 1-1

1.1 Study Goals . . . . . . . . . . . 1-2

1.1.1 Organization of Report...... I-3

1.2 The Army Nurse Corps Force Structure Model (ANCFSM)............ . 1-3

1.3 The Quality of Patient Care. . . . . . 1-4

1.4 Data Base. . . . . . . . . . . . . 1-5

1.5 Preface of Accomplishments, Findings,

and Results... . . . . . . . . . 1-5

1.5.1 The Force Structure Model. . . . . 1-5

1.5.2 The MEDDAC . . . . . . . . . 1-6

1.5.3 The Worldwide Questionnaire. . . . 1-7

2.0 Method and Issues. . . . . . . . . . . 2-1

2.I The Survey Instruments. . . . . . . . 2-3

2.2 Field Testing and Modification of

Questionnaires. . . . . . . . . . 2-4

2.3 Use of Models in Force Configuration

Analysis, Calculations, and Simulation. . 2-6

3.0 Analysis of the ANC Worldwide Questionnaire. . 3-1

3.1 The Corps in Profile........... 3-14

3.1.1 Age, Sex, and Grade Distribution. 3-14

3.1.2-3 Marital Status and Dependents. . . 3-16

3.1.4 Professional Qualifications

(Education and MOS)....... 3-16

3.1.5 Professional Orientation:. . . 3-18

3.1.6 Programs Through Which Army Nurses

3.1.7 Enter the Corps. • · Patterns: • • 3-2I

3.2 Attrition, Personnel Policies, and

Attitudes Toward Aspects of Army Nursing. • 3-22

3.2.1 Response to Policy Proposals... . 3-27

3.2.2 Aspects of Army Nursing. . . . . . 3-43

3.3 Current Assignment. . . . . . . . 3-79

3.4 Assignment Preference . . . . . . . . 3-79

3.5 Summary of ANC Officer Worldwide

Questionnaire. . . . . . . . . 3-80 
$\underline{\text { Page }}$

4.0 The MEDDAC - The Operating Environment of

the ANC. . . . . . . . . . . . 4-1

4.0.1 Original Survey Instruments. . . . 4-2

4.0.2 The MEDDAC Data Base... . . . 4-4

4.1 Staff/Workload/Quality-of-Care

Relationships . . . . . . . . . . 4-7

4.2 MEDDAC Relationships and the Army Nurse

Corps Force Structure Model . . . . . . 4-9

4.3 The MEDDAC Regression Model. . . . . . 4-10

4.4 Examples of Results . . . . . . . . . 4-12

4.4.I Several Variables. . . . . . . 4-12

4.4.2 One Variable......... . 4-14

4.4.3 The MCCU Variable. . . . . . 4-16

4.5 Data Analysis . . . . . . . . . . . 4-19

4.5.1 Analysis of MOS Data... . . . 4-19

4.5.2 Graphical Relationships. . . . . 4-26

4.5.3 Geographical Distribution. . . . 4-32

4.6 Quality of Care... . . . . . . . 4-34

4.6.1 Theory ........... 4-35

4.6.2 Application. . . . . . . . 4-38

5.0 ANC Force Structure Simulation Model (ANCFSM). - 5-1

5.1 Input Data and Output Formats . . . . . . 5-3

5.2 ANCFSM Model Structure and Description. . 5-10

5.3 Validation and Initial Results of

Simulation.

6.0 Discussion and Conclusions. . . . . . . . 6-1

6.1 Future Uses of Models and Data.. . . . .6-1

6.2 The ANC Force Structure Simulation Model: $6-5$

6.2.1 Model Projections of Future Staffs

6.2.2 Model Variables, Corps Profile, and Policy Testing... . . . . 6-6

6.3 The MEDDAC. . . . . . . . . 6-7

6.3.1 Hospital Requirements. . . . . 6-7

6.3.2 Quality of Patient Care... . . 6-8 
6.4 The Worldwide Questionnaire . . . . . . 6-8

6.4.I Retention--Staying or Leaving. . . . 6-8

5.4.2 Minimizing the Major

Dissatisfactions of ANC Officers . . 6-9

6.4.3 Nursing and Army-Wide Officer

Selection for Promotion. . . . . 6-10

6.4.4 Professionalism: Military and

Nursing. . . . . . . . . 6-12

6.5 Specific Configurations via Education

and Training. . . . . . . . . . . 6-13

6.6 Accomplishments, Findings, and Conclusions. 6-15

6.6.1 The Force Structure Model. . . . 6-15

6.6.2 The Worldwide Questionnaire. . . . 6-17

6.6.3 The MEDDAC .......... . 6-18 


\section{LIST OF FIGURES}

Part I

Figure

Number

Title

Page

$2-1$

ANC Promotion System.

$2-9$

$3-1$

Professionalism in Nursing and the Military.

$3-2$

ANC Sex Distribution by Age

Primary MOS Distributed According to Sex, Service Component, and B.S. Degree. . .

Staying or Leaving by Age

Program of Entry by Staying or Leaving.

$3-25$

$3-6$

Four Patterns of ANC Response to Policy Proposals by How They Feel About an Army

Career.

How Army Nurses Feel About Staying or Leaving Related to Whether They Agree That Nursing Questions Are Settled by Rank Instead of Professional Knowledge.

3-8 How Army Nurses Feel About Staying or Leaving Related to Agreement with Assuming Responsibility for Additional Medical

Procedures. . . . . . . . . 3-55

3-9 ANC Feelings as to whether Advancement Depends Too Much on Formal Education Related to Staying or Leaving . . . . 3-64

3-10 Whether ANC Officers Agree That They Do Not Have Enough Opportunities for Direct Patient Care Related to How They Feel About Staying or Leaving. . . . . . . 3-68

3-11 How Army Nurses Feel About Staying or Leaving Related to Whether They Agree That the More Rank ANC Officers Obtain the More They are Concerned with Promotion instead of Patient Care 
Figure

Number

$3-12$

$4-1$

$4-2$

$4-3$

$4-4$

$4-5$

$4-6$

$4-7$

$4-8$

$4-9$

$4-10$

$4-11$

$4-12$

$4-13$

$4-14$

$4-15$
Title

Page

Army Nurses Feelings about Staying or

Leaving Related to Agreement with

Dissatisfaction over Dependency and

Benefit Differences between Male and

Female Officers . . . . . . . . 3-76

Three Variable Predictor Equation

for Nurses.

$4-13$

Fitted Value of Number of Professional

Nurses (Single Variable). . . . . . 4-15

Old MCCU Predictor Equation . . . . . 4-17

New MCCU Predictor Equation . . . . . 4-18

Requirements for MOS 3442 (Pediatrics). . 4-22

MEDDAC Mos Required Current and Future. . 4-24

Nurses vs. Number of Beds Staffed. . . 4-28

Nurses vs. Average Number of Beds

Occupied. . . . . . . . . . . 4-29

Nurses VS. M.D.'S......... . . 4-30

Hospital Infection Rate vs. Hospital

Size............ . . 4 4-39

Average Stay, All Procedures

vs. Hospital Size

$4-40$

Average Stay, General Surgery,

vs. Hospital Size . . . . . . . 4-4l

Average Stay, Appendectomy,

vs. Hospital Size.

$4-42$

Average Stay, Hernia, vs. Hospital Size . 4-43

Average Stay, Cholelithiasis,

vs. Hospital Size. 
Figure

Number

$\cdot 4-16$

$4-17$

$4-18$

$4-19$

$4-20$

$4-21$
Title

Page

Care Complaints vs. Hospital Size. . . 4-45

Unusual Occurrences vs. Hospital Size • 4 4-46

Quality of Patient Care, ANC Officers

Opinions vs. Hospital Size.

$4-47$

Overall Quality of Care vs. Hospital

Size. . . . . . . . . . . . 4-49

Alternative Overall quality of Care

vs. Hospital Size. . . . . . . 4-52

Overall Quality of Care vs. Residual

Nurses. . . . . . . . . . . . 4-53

$5-1 A \quad)$

5-1B ) Selected Sheets of Inputs and

5-1C ) Outputs of the ANCFSM

$5-1 D \quad)$

$5-1 E \quad)$

5-2 Overview of Steps in the Simulation of ANCFSM . . . . . . . . . . . . 5-11

5-3 Projection of Structure of Corps--Total ANC Officer Strength--Initial. vs. 1975. . 5-17

5-4 Projection of Structure of Corps-Army Nurse Corps Profile

$$
\begin{aligned}
& 5-4 \\
& 5-6 \\
& 5-7 \\
& 5-8 \\
& 5-9
\end{aligned}
$$

$5-19$ 
Table

Number

3-1 Measures of Personal and Professional Orientation of Army Nurse Corps Officers. . . . . . . . . . 3-19

3-2 Reasons for Joining the Army Nurse Corps and Reasons for Deciding to Stay. . . . 3-28

3-3 Interest in Clinical Nursing Courses Reported by ANC Officers with Different MOS'S . . . . . . . . . . 3-4I

$4-1$ Data Matrix of MEDDAC in Columnar Format. . 4-5 $4-2$ $4-3$ $4-4$ $4-5$ MEDDAC MOS Requirements Compared with Available Nurses (Under Two Specific Policies)........... . . 4-2I ANC Duty MOS for All Registered Nurses for Each MEDDAC . . . . . . . . . 4-27

Identification and Statistics of MEDDAC Variables. . . . . . . . . 4-33 Rank-Ordered Composite Quality of Care. . 4-50 
AFMS - Active Federal Military Service

- AFCS - Active Federal Commissioned Service

AHS - Army Health Service

AMEDD - Army Medical Department

ANC - Army Nurse Corps

ANCFSM - Army Nurse Corps Force Structure Mode1

ASNP - Army Student Nurse Program

AUS - Army of the United States

BOD - Bed Occupied Days

Cat - A category of variables, viz., S, W, QC, OV

COIN - Contract Office Incentive Pay

Configuration - TO Strength

Command

Class I - MEDDAC under field commander

Class II - MEDDAC under surgeon general command

CONUS - Continental United States

COPO-11 Reports - Chief of Personnel Operations, Report No. 11

Corps - Army Nurse Corps

DAC RN - Department of the Army Civilian Registered Nurse

DCSPER - Deputy Chief of Staff for Personnel

FCS - Federal Commissioned Service

FY - Fiscal Year 
IMPRESS - Interdisciplinary Machine Processing for Research and Education in the Social Sciences

MCCU - Medical Care Composite Unit

MEDDAC - Medical Department Activities

MOS - Military Occupational Specialty

MRM - MEDDAC Regression Mode1

NBS - National Bureau of Standards

OTSG - Office of The Surgeon General

OV - Derived and Other Variables

PCS - Permanent Change of Station

PMOS - Primary Military Occupational Specialty

QC - Quality of Care Variables

QOC - Quality of Care

$\mathrm{R}^{2}$ - Correlation Coefficient

RA - Regular Army

RAP - Relative Attrition Propensities

RES - Reserve

RN - Registered Nurse

RNSP - Registered Nurse Student Program

S - Staff Variables

WRAIN - Walter Reed Army Institute of Nursing

TAD - Technical Analysis Division (of NBS)

TO - Table of Organization

TR - Turnover Rate

USAR - U.S. Army Reserve

Variable - A descriptive item of information in the MEDDAC Data Matrix W - Workload Variables 
WW - Worldwide

WWQ - Worldwide Questionnaire 
STRUCTURE ANALYSIS AND PROGRAM PLANNING STUDY ON THE ARMY NURSE CORPS

\subsection{INTRODUCTION}

This report presents an Army Nurse Corps (ANC) force structure plarming model, an analysis of staffing in Army Medical Department Activities (MEDDAC), and an attitudinal survey of Army nurses. The project was conducted by the Technical Analysis Division (TAD) of the National Bureau of Standards (NBS) for the Office of The Surgeon General (OTSG), U. S. Army.

Contemplation during 1967-1970 of restructuring the Army Nurse Corps led the Office of The Surgeon General and the Chief of the ANC to the concept of a multipurpose Structure Analysis and Program Planning Study. In addition to force structure planning, the effort would include a survey of the activities, attitudes, and professional opinions of ANC officers; and a survey of nursing personnel and hospital operations. The project was conceived during a period of manpower transitions and changing personnel policies. In 1967 Congress removed certain inequities and restrictions on women officers, and after reaching a peak in 1967, the level of U. S. military strength in Southeast Asia began to decrease.

Four principal components were developed by the project. The first is an Army Nurse Corps Force Structure Mode1 (ANCFSM), a planning tool which projects alternative future ANC configurations under given policy assumptions, in terms of grade, military occupational specialty (MOS), years of service, and Regular Army (RA), Reserve (USAR), and Army of the U. S. (AUS). The second is an examination of the MEDDAC working environment obtained through regression and correlation analyses which determine the sensitivity of relationships among workload factors, staffing, and quality of care indicators. The third component is the Army nurse attitudinal analysis focused on 
factors affecting attrition, retention, and professionalism in the Army nursing environment. The last component is an extensive computerized, and easily accessible data base.

\subsection{Study Goals}

The OTSG and the ANC are developing a range of nursing policies, plans, and techniques related to six personnel management functions: recruitment, training promotion, retention, separation, and retirement. The study was funded under an approved OTSG program entitled "Structure Analysis and Program Planning Study on the Army Nurse Corps." Representatives of OTSG indicated several basic objectives:

1. Insight into important attitudes, preferences and responses of the ANC to a wide range of proposals on personnel, policies and professional qualifications;

2. Determination of the number of nursing personnel, by specialty, that the U. S. Army utilizes, and the number available under specific statements of policy;

3. Determination of policy alternatives which appear to offer the most effective and efficient control of the recruitment, training, promotion, retention, separation, and retirement of nursing personne1; and

4. Prediction of the effect and impact of specific policy alternatives upon future ANC organization and activities.

These broad, complex goals were investigated at the detailed level of career factors, grade structure, years of service, military occupational specialties, staffing requirements of the medical department activities, and other factors of the ANC. In order to meet these goals, NBS undertook the following tasks:

1. Develop, test, distribute worldwide, and collect responses to a nursing questionnaire and a MEDDAC survey; prepare computerized data bases of nursing personnel information and medical department activities from the responses;

2. Analyze the responses and:

a) extract relationships between nursing personnel and their activities, workloads, and other parameters, and

b) quantitatively describe the ANC Force Structure and the MEDDAC; 
3. Construct and test a methodology using a simulation model which will generate configurations of the ANC, under policy alternatives for study.

1.1.1 Organization of Report

The completed tasks of this study are described in Sections 2-5 and the annexes and appendices to this report. The main results are summarized in Section 1.5 of Part I. Section 2 discusses the issues to be addressed and the methods and techniques developed for responding to these questions. Section 3 is based on the analysis of data obtained in a worldwide survey of all Army Nurse Corps officers as of September 1972. The 50-page survey is an extensive questionnaire which covers some 500 items of interest, with responses from some 3,481 officers of the ANC. Section 4 is a survey of the medical department activities, the organizational environment in which the nurses carry on their professional activities. The MEDDAC is comprised mainly of Army hospitals, dispensaries, and troop medical and health clinics. Section 5 describes a computerized model employing officer data and policy parameters (e.g., year-end strengths) for calculating and simulating the available staff and its specific annual changes in personnel. The annexes are found in Part II; Part III includes a detailed description of the ANC Force Structure Model, and the Appendices. 1.2 The Army Nurse Corps Force Structure Mode1 (ANCFSM)

It is possible to develop alternative force structure configurations under changing missions by use of the force structure flow model developed in this study. However, it is first necessary that the systems analyst comprehend the facets of the total nursing-grade structure system. This system is complex with multiple causal forces, statutory regulations, and 
individual officer decisions all interacting with each other and further described in Annexes II-1 and II-2.

The detailed computer program, ANCFSM, developed to capture the significant factors, including Federal statutes, historical transfers in MOS, Army components, and retention/separation states, integrates a11 the factors into a simulation model which processes observed changes in the force structure over a period of time. The model is discussed briefly in Section 5, and in considerable detail (including programmer instructions) in Part III.

\subsection{The Quality of Patient Care}

It is important to understand the relationship that may exist between the force structure and overall quality of patient care. That is, to what extent does the overall quality of patient care vary with reductions or additions to the ANC? Since it is not possible at this time to make controlled experiments in this area, this question has been formulated along the following lines: Are shortages or surpluses of professional nursing staff, where observed, correlated in any way with individual and overall indicators of quality of patient care used in this study?

To answer this question, it is necessary to arrive at a workable definition of the overall quality of patient care as measured by the indicators of this study. This is done in Section 4.6 where a composite variable approach is taken. There the overall quality of patient care and its components are studied as a function of a number of variables including hospital size and apparent staff shortages and surpluses. 


\subsection{Data Base}

An extensive data base has been created by this study. It is accessible for a far greater range of analyses than were possible or planned for this report. The data can also be used in conjunction with the Officer Master File and Officer Separation File (described in Part III). The data sets, in a sense, constitute a "snapshot" of the ANC and nursing services and departments as of September 30, 1972.

1.5 Preface of Accomplishments, Findings, and Results

The basic results of the study of the Army Nurse Corps can be roughly grouped into three categories:

- The force structure model

- 'The MEDDAC-the operating environment of the ANC

- The worldwide questionnaire

1.5.1 The Force Structure Mode1

The force structure model was designed as a planning tool for forecasting future ANC configurations and officer shortages and surpluses, collectively and by nursing specialty, under alternative policy assumptions.

- Annual Projections of the Force Structure Model

Certain accomplishments and results are indicated in this introduction to the report. The characteristics of cohort groups (groups of nurses with similar service characteristics) of ANC officers comprising the force structure may now be annually projected by a computer model designed and developed at the NBS.

- Relative Attrition Propensities

It was found that attrition, a necessary subroutine in the model required a special approach to minimize simulation model differences with real world fluctuations. It was determined that relative attrition propensities (RAP's) defined by a function of attrition rates are useful and in 
agreement with recent historical data over the period of 19681972. However the RAP's must be used cautiously, further validated with 1973 data, when available, and further updated with the new data made available each year.

- Preliminary Trends in Annual Simulations with Specific "Reduction in Force" Scenarios

Although the computer model has been operated numerous times, and estimates of future shortages and surpluses in nursing specialties have been observed and reported, time has not permitted extensive research of the effects of changing parameters which would operate under contract incentive scenarios.

However, in preliminary testing runs a scenario of "reduction in force" for the next several years with low recruitment levels created a small initial decrease in the number of officers with less than one year of service. It was found that in the model's graphical outputs, which display the force structure (number of officers vs. years of service) for each year being simulated, there appeared a "valley" which "moved" along the horizontal axis (years of service) as the graphs were viewed in chronological order. When the initial (1972) profile of these simulation runs was compared with profiles obtained for 1975 the most pronounced effects of the reduction in force appeared in the 1975 profile for officers with less than seven years of service. The profile of officers with more than seven years of service was relatively unaffected.

\subsubsection{The MEDDAC}

The MEDDAC analysis determined the sensitivity of relationships among workloads, staff, quality of patient care indicators, and other MEDDAC-related variables.

- Increase in Future Hospital MOS Mismatches

Data supplied in the survey of over 70 U. S. Army hospitals worldwide indicate a number of current mismatches between hospital duty MOS's and ANC primary MOS's. Projections of the force structure model indicate this degree of mismatch will possibly widen in the next few years unless appropriate policies of recruitment, training and retention are instituted.

- Fitted Relationships between Staff and Workload Variables

It was found possible to derive a wide range of fitted relationships between staff and workload variables in Army hospitals throughout the world. 
- Bed Occupied Days (BOD) and Medical Care Composite Units (MCCU)

A reliable single indicator of staff requirements is the number of bed occupied days at a given hospital. An improved weighting of the four factors used in calculating the Medical Care Composite Unit (MCCU) resulted in an increase in correlation with nursing staff as a variable.

- Patient Care, Hospital and Nursing Staff Sizes

The observed shortages or surpluses in nurses were found to have little influence on, or correlation with, the study indicators of the quality of patient care. On the other hand, the overall quality of patient care, as measured by the composite indicators of this study was found, in general, to increase with decreasing hospital size.

1.5.3 The Worldwide Questionnaire

Analysis of the officers opinions on 48 proposals revealed those salient proposals of interest to the ANC nurses. The analysis of other parts of the worldwide questionnaire signalled the possibility of continuing high attrition rates among junior ANC officers and revealed the principal issues associated with Army nurses' decisions to leave the service.

- Opinions on 48 Policy Proposals

ANC officers gave their opinions on 48 policy proposals. Analysis showed that basic pay and major allowances and benefits are especially important to those who expect to complete a full career in the Army. Educational requirements and professional status as reflected in appointment criteria and professional pay are important to many, but relatively unimportant to a substantial minority. The introduction of policies removing inequities based on sex and marital status are highly important to female officers. The most salient proposals in this category deal with liberalizing maternity regulations and giving status to civilian spouses of female officers as is the case with male officers.

- Expectation of Staying or Leaving the ANC

Over $70 \%$ of all the younger nurses (20-24 year age group) indicated a high expectation of leaving the service upon completion of their obligation. The highest retention rate, 
by an overwhelming margin, is among $\mathrm{RN}^{\prime} \mathrm{s}$ who enter the service through direct appointment from civilian status. ANC officers view Army nursing as offering excellent professional opportunities, but tend to view Army life and institutions, especially for female officers, as including a number of frustrations and inequities.

- Army Student Nurse Degree Programs

Army student nurse degree programs have lower retention rates than the diploma program. The degree program improves career opportunities and can therefore be assumed to result in greater mobility.

- Professionalism in the MEDDAC-A Dominant Issue

A dominant issue in attitudinal responses was a conflict between professional nursing and military bureaucracy in the MEDDAC environment. The higher the level of professional orientation of an Army nurse the more difficult it becomes to adapt to the system of rank, seniority, and authority in a military organization, especially when that system overrides the nurse's professional judgment.

- The Generation Gap

Both junior and senior officers tend to feel there is a "generation gap" or "communications gap." Most frequently emphasized issues can be interpreted as junior officer reaction to the ways senior officers have adapted to military life, and to changes in the kinds of education and training nurses of differing ages experienced at the beginning of their careers - and whether they show an interest in continuing to update their nursing skills and knowledge.

- Administration, Facilities and Reputation of the ANC

Over half of those who expressed an opinion feel that the Army hospital administration is generally competent, but not particularly responsive to patient's needs. About the same proportion tend to agree that the Army medical facilities and equipment are often obsolete. From submitted material it was learned that most nurses agree that nursing services in their organization enjoy a good reputation and that the quality of patient care is generally good.

- Expanded Nursing Role and Current Assignments

The nurses gave strong support to the expanded role of the nurse and showed an interest in nurse clinician programs. Analysis of questionnaire material related to individual skills 
and current assignments revealed that about two-thirds of the Corps believe that their present assignments utilize their skills properly. Most of the Corps were satisfied with their current work assignments and geographic locations, although a significant proportion indicated they were neither consulted nor given their preference in their current assignments.

These results-the attitudinal analysis, the relationships resulting from the MEDDAC statistics, and the force structure model-will enable management planners to evaluate the future characteristics of the ANC as specified by certain inputs and policies. It is anticipated that management functions will encompass a wide range of military as well as civilian manpower planning decisions with respect to recruitment, training, retention, promotion, separation and retirement. The succeeding sections of Part I, supported by Parts II and III and the data base, provide a more detailed discussion of the study and its results. 

2.0 METHOD AND ISSUES

A basic issue posed by the sponsor was the need to plan an Army Nurse Corps force structure for the future, that is, to project the configuration of the ANC (RA, USAR, and AUS components) by recruiting, training, retaining, promoting, separating, and retiring ANC officers in the various MOS's. A second issue of interest to the sponsor was the relationship, if any, between the nursing staff and the workloads; a third issue was the attitudes, preferences, and professional judgments of the individual Army nurses.

Discussion of the three basic issues during the planning phase led to additional specific and detailed related questions. Resolving the questions further led to a clarification of their precise nature and relationship to the major issues. These related functions tended to affect the choice and development of the methods, techniques, and procedures used to answer the specific questions. Questions related to the three basic issues are:

Category \#1 - Organization of the Nurses (the Force Structure)

1. Is there an effective way to quantitatively describe the annual changes in the ANC grade structure?

2. Is is possible to develop a model of the ANC which can generate specific configurations?

3. How many lieutenants are required for initial entry by phased year to attain and maintain a specific configuration?

4. How long will it take to achieve a specific configuration?

Category \#2 - The Environments in Which the Nurses Work (MEDDAC Data)

1. What is the effect of the hospital size and specific command (Class I and Class II) on the nurse/workload relationships?

2. Is there an effect of the hospital size and hospital staff on the quality of patient care?

3. Are there observable trends in the military/civilian nurse MOS ratio?

4. What is the correlation between workloads and the number of nurses required by the hospitals of the MEDDAC? 
5. Given the current promotion, separation, and retirement policies, will the number of nurses having specific primary MOS's and/or categories of MDS be, in five years, less than or more than the number required by the MEDDAC?

6. Will the attrition and retirement of current nurses in the ANC result in an unacceptable military/civilian ratio in specific instances?

7. Is it possible to identify, in the MEDDAC data matrix, a workload quantity which correlates more highly with the required number of nurses than does the currently employed Medical Care Composite Unit (MCCU)?

Category \#3 - Attitude Questions (Worldwide Questionnaire)

1. How do ANC officers feel about an Army career?

2. What percentage of nurses with less than four years of service plan to leave the service?

3. Why will they leave or remain in the service?

4. What can OTSG do to diminish attrition and to retain needed nurses?

One technique developed in the course of this study for answering questions in both the force structure and nursing environment categories above is, as mentioned earlier, a simulation model. The model will answer several "what if" questions in testing and evaluating proposed changes in regulations and trends. For example, the model can be used to determine the configuration of the ANC projected for five years when: (1) promotions are delayed by one year and (2) attrition increases by a certain percentage. It can also be used to project the important profile (officers vs, years of service) when obligations are extended under incentive contracts. Finally, it can project the ANC configuration when the number of Regular Army appointees are increased by specified increments over a fixed time interval. 


\subsection{The Survey Instruments}

When restructuring of the Army Nurse Corps was being contemplated, it seemed appropriate to the OTSG and to the Chief of ANC to investigate the current attitudes of ANC officers towards many issues that would affect their welfare and working environment. As a result, ANC headquarters personnel began to assemble a list of questions that would form the basis for a survey of nurses' opinions. After two years of work, which included many conferences with and reviews by chief nurses of the MEDDAC, a structured information requirements schedule was ready. The instruments were to include not only nurses' preferences with regard to various policy and usage changes but were also for validating the information in automated personnel files.

The instruments were to obtain information about the attraction value of various recruitment methods, to determine educational interests of ANC officers (both for additional, specialized nursing skills and for general background, degree-directed course work), to obtain some measure of the interest among certain groups of nurses in an Army career, and to characterize those persons most likely to be interested in such a career. Many management and military policies were also broached for consideration to determine officers' attitudes and how these might affect an officer's intent to remain in the service.

Data collected by NBS from the MEDDAC and from individual ANC officers were obtained through mailed questionnaires. The Survey of Nursing Personne1 questionnaires were designed for completion by MEDDAC staff to furnish aggregate data on all nursing personnel and their organization 
and workloads, and to provide input for the development of indicators of the quality of patient care. The ANC questionnaire was completed by virtually all officers of the Corps who had served at least one month of a normal tour of duty after completing officer basic training.

The data obtained from the two kinds of NBS survey instruments and the Army data systems were combined for utilization in the model. Along with the data set created for attitudinal analysis, they constitute a large and valuable data base not only for the present effort but also for future analyses. Where necessary, data have been edited and, in some cases, normalized for use in the force structure model.

\subsection{Field Testing and Modification of Questionnaires}

When NBS was chosen as the task group to study the Army Nurse Corps, the schedule of information requirements was sent to the TAD Behavioral Science group to serve as a guide for the two kinds of final data collection instruments: (1) the Army Nurse Corps Officers worldwide(IWW) questionnaire, to be answered by every ANC officer, and (2) the Administrative Survey of Nursing Personnel, to be completed by MEDDAC staff reporting on hospital organization and facilities, staffing of nursing services, patient and training workload, and indications of the quality of patient care.

The following sequence of steps was then taken to obtain the survey data needed for the study:

(A) The original questionnaires were pre-tested in January 1972 on a small sample of nurses at two hospitals to determine the effectiveness of question formats and whether the kinds of answers received would provide the information desired.

As is to be expected in any kind of survey work, results of this field test indicated a need for revisions to the survey instruments.

(B) Representatives of ANC Headquarters staff met with the NBS social scientists to modify the questionnaires. All items retained 
fulfilled the criteria: Who wants to know this? What level of priority does the information have? How will the answers be used?

Items with low priority or of interest but not of consequence were discarded in an effort to shorten the form, which originally required two to four hours for completion.

(C) The revised questionnaires were pre-tested in April 1972 on a worldwide sample of 12 hospitals, four each in the Orient, Europe, and the U.S. These applications clearly indicated the need for further revisions. The questionnaires were revised with extensive interaction between sponsor representatives and the NBS personnel who had done the pre-testing. Approval for changes was obtained from ANC before fielding the instruments again.

(D) The questionnaires were validation-tested in early August 1972 on nurses at two Army hospitals in the U.S. Final revisions were completed by the end of August 1972 .

(E) The full survey was launched in September 1972, when questionnaire parcels were mailed to non-ANC officers in all hospitals. These individuals had been designated as project controllers who would supervise the distribution of the questionnaires. Sections of the Survey of Nursing Personnel were given to appropriate MEDDAC staff members. ANC WW questionnaires were distributed to all Army nurses. Their personnel records were made available for reference in answering questions. The completed ANC WW questionnaire was individually mailed to NBS by the respondent, a measure adopted to preserve the anonymity of all nurses. Project controllers collected a tally form for each questionnaire completed.

Individual officers were asked to respond to attitude and activity questions in terms of their current assignments. All information was requested as of September 30, 1972, even though a few questionnaires were not completed until November of that year. Completed forms were received from virtually all nurses.

(F) After a majority of the questionnaires had been received, NBS representatives visited three hospitals in the U.S. and three in Germany during November and December 1972. These visits were to validate the manner of data collection and to insure the understanding of selected questions on the worldwide survey.

(G) Responses from the returned questionnaires were key-punched. Members of the NBS staff compiled, edited, and corrected the data to produce the Army Nurse Corps Officer File. All elements 
of the file were categorized and cross-tabulated by use of the IMPRESS (Interdisciplinary Machine Processing for Research and Education in the Social Sciences), a computerized system maintained at Dartmouth College Kiewit Computer Center.

The basic information requirements had been established by ANC Headquarters personnel prior to the time NBS began work on the study. NBS made a contribution in those areas of the final questionnaire devoted to measuring professional values of ANC officers. NBS was also responsible for streamlining the format, eliminating certain low-priority items, and pulling the schedule together into a unified whole.

The results of the individual officer's questionnaire provide a valid accounting of the attitudes, opinions, preferences, and reactions of all ANC personnel to a wide variety of Army policies and projected management activities. The information is provided by rank, age, sex, MOS code, and component (RA, USAR, AUS). The data were cross-referenced so that opinions of small cohort groups can be retrieved. For example, if there is a need to know how male anesthetists with the rank of major feel about increased subsistence pay for overseas areas, this detail can be recovered. Analysis of the data from the questionnaires is discussed in much greater depth in Section 3.

2.3 Use of Models in Force Configuration Analysis, Calculations, and Simulation

This section introduces the future structure of the ANC and describes, in nontechnical terms, the effects of the statutory and regulatory policies, recruitment, training, promotions, changes in MDS, separations, retirements, and other factors upon the structure of the ANC. These career factors 
profoundly impact upon the ANC leadership and nursing skills, thus directly influencing the quality of patient care (discussed in depth in Section 4.6). Rules and precepts characterize the real flow of manpower through the ranks. An Army officer's career through the ranks and through specialized training is determined not only be legislative statutes (10 U.S.C.A.§ 3001), but in large part by the individual officer's capabilities and experience. Some aspects of an officer's service are controlled by legislative requirements and by specific policies imposed by the Deputy Chief of Staff for Personnel (DCSPER). For example, DCSPER sets the zone of consideration, the all-important promotion points and the year-end strength. These rules alone do not directly provide for modelling, training opportunities, voluntary transfer (e.g., from USAR to RA, from one MOS to another), or attrition rates (voluntary separation or retirement).

The force structure simulation model utilizes the rules of these categories of precepts. The first category consists of the statutes and regulations. The second category includes budgetary constraints and annual policies made by DCSPER, OTSG, and/or any other policy-making groups such as the Secretary of the Army, DOD, Congress and OMB. The third category consists of the historical data, properly normalized, and extrapolated into the near future. After this third category has been properly built into the model, annual forecasting is improved by incorporating the latest extrapolations into the input data.

The career flow of an ANC officer usually begins with the rank of lieutenant, moving steadily in an orderly progression through two or all of three systems-RA, USAR, and AUS-until the officer is eventually 
retired. The steps encountered and promotions passed in the long (20-25 years) career of the officers are sketched in Figure 1 (taken from data in Annex II-1). It is necessary that all steps of this process, including the three component systems operated by the Army, described in Annex II-1 be understood so that a higher-1evel flow diagram of a simulation may be prepared. When the calculations involve several thousand individual officers for each annual projection, this becomes a very time-consuming task. It has been reported that a minimum of 2,000 man hours was necessary for the 1967 annual calculation for officers' projection for DCSPER. I/

The model ANCFSM described in this report uses data obtained by computer extraction of pertinent information from the OTSG Officer Master File and/or from the worldwide questionnaire. The input data usually permits the model to present the composition of the Corps in terms of component, permanent and temporary grade, time in permanent and temporary grade, and primary MOS.

The reader will become aware of both the potential and flexibility of the model as a tool. It can and should be modified to approximate any number of situations of interest to the ANC and OTSG. The model can be only as accurate as the input parameters, data, coded regulations, and policies. Since it is impossible to determine exact values for future parameters, it is wise to exercise the model several times, permitting parameters of interest to assume several values within a reasonable range.

1/Leon W. Transeau, User's Guide to a Computer Model for Projecting the Impact of Officer Procurement, Promotion, and Retention Policies, Research Analysis Corporation, McLean, Virginia, December 1967. 
3.0 ANALYSIS OF THE ANC WORLDWIDE QUESTIONNAIRE

\section{$\underline{\text { Introduction }}$}

The voice of the Army Nurse Corps was heard through questionnaires completed by 3,481 ANC officers in the fall of 1972 . Respondents answered nearly 400 questions concerning their attitudes and professional judgements on many aspects of Army Nurse Corps service. In addition, demographic and professional profile data was collected, as well as information on inservice education and training and military status. The Army Nurse Corps Officer Worldwide Questionnaire appears in Annex II-7 of this report.

The principal thrust of the analysis relates the profile variables to attitudes and professional judgements in order to understand better what the members of the Corps are saying to the Office of The Surgeon General. The attitudinal analysis in this report focuses selectively on data related to recruitment and retention of ANC officers. Part of this data concerns ANC responses to some forty-eight current or proposed policies, on which the Corps was asked to comment.

*With a few exceptions, questionnaires were completed during September. Army nurses with less than one month on active duty assignment after basic officer training were excluded from the analysis and are not included in the 3,481 number used in this report. This exclusion introduces a slight systematic bias into the data, especially on demographic variables, since the excluded officers, approximately 300 in number, would swell the reported numbers in the lower age categories, lieutenant grades, the 3449 Primary Military Occupational Specialty (PMOS), and those with not more than $31 / 2$ years service. 
The feasibility of linking the attitudinal data from Army nurses with the projections of the force structure model (ANCFSM) using the officer Master File is one of the potentially valuable results of this project. The linkage allows analysis of the responses of officers to policy changes, that is, permits analyses that include comparisons of ANC officer responses to policies that would be implemented, perhaps to achieve an alternative force structure.

The Army Nurse Corps Force Structure Mode1, presented in Section 5, is a planning tool designed to simulate the effects of current trends and to test the effects of changes in policy decisions on the future configuration of the Corps. That is, what will current trends or trend alterations produce in the future matrix of officer specialties and grades? The model, in other words, is a force structure model responsive to policy decisions.

The interaction of transitions in manpower requirements, changing social values, the attitudes of Army nurses, and the changing roles of different members of the health professions, along with whatever other forces impinge on the process, will influence heavily the future of the Army Nurse Corps. The interaction of policy and personal decisions governs the answers to the questions: Who enters the Army Nurse Corps? Who remains, and for how long? In what specialties do they qualify? Who leaves, and at what point in their military careers? 
In this section we focus on those themes that the individual ANC officer data suggest would affect nurses' career decisions. This will allow comparison with actual attrition propensities, and help to identify means of influencing attrition.

\section{Interpretation and Presentation}

The analysis and interpretation of the individual officer data is quite selective. The data base is exceptionally large and rich. The scope of the analysis reported here was determined on the basis of OTSG priorities and resource limitations.

The discussion of ANC officer responses is based on a virtually $100 \%$ response from the relevant population, and on a great number of analytic tables-far too many to include in the main text.

Some explanations are in order for interpretations unaccompanied by tables in the main text. First, although a large number of statistical tests were made to measure the strength of variations among groups of nurses with particular attributes, the probability that any but the smallest variation is due to chance is ruled out because we have data from virtually the entire corps of Army nurses who have service experience. The statistical probability that any relationship reported is due to chance is less than one in a thousand $(\mathrm{p}<.001)$ throughout Section 3. The adequacy of the sample cannot be an issue.

Second, we have often used words instead of numbers to indicate the approximate degree of difference between responses of different subgroups. 
All of the responses to proposals and the general attitudinal data are on a five point scale from strongly positive to strongly negative. We usually speak of "very slight" differences when the responses of subgroups vary by more than $5 \%$ but less than $10 \%$; "slight" differences if the variation is more than $10 \%$ but less than $20 \%$; "moderate" in the range from 20-35\%; "strong" when differences run from over 35\% to around 55\%; and "very strong" or "intense" differences if the spread is about $60 \%$ or more.

However, these are not precise definitions, and other factors go into the choice of terms. Interpretations consider the distribution between moderate and strong points on the scale. More often than not findings are based on several tables. The terms used reflect in part the consistency of the variation between groups when a series of tables related to the same independent variable form the basis of an interpretation.

Finally, the interpretation often considers the degree of variation in relation to the context of the question. For example, a $20 \%$ difference between the attitudes of two subgroups toward specific medical procedures involved in the changing role of the nurse would be considered more important than a $20 \%$ variation in the numbers in the subgroups who had ever performed the procedure. Statistically, one figure is no more significant than the other, but one is more noteworthy.

Principal Attitudinal Issues: Professionalism, Pay, and Inequities

The dominant issue that emerges from the attitudinal analysis is a conflict of two fields of professionalism, nursing and military, and 
between professionalism and bureaucracy in Army hospitals. The issue is pervasive in the attitudinal data. The higher the level of professional education and orientation a nurse achieves, the more difficult it becomes to adapt to the system of rank and authority in the military bureaucracy, especially when the system tends to use hierarchical authority to override the professional judgement of the individual nurse.

The conflict between professional and bureaucratic norms arises from the inherent noncongruence of the hierarchical structure of authority on the one hand and the division of tasks based on expertise on the other. The problem is not unique to the Army or to the health professions. It is, however, exacerbated by two characteristics of U. S. military institutions: The military bureaucracy is highly articulated in 1) the division of labor and assignment of specific responsibility and accountability, and 2) the authority and mechanisms of control built into the hierarchical system of command and control.

There is no single, definitive statement of what distinguishes a profession from nonprofessional vocations, nor is there consensus on a definition of nursing that clearly discriminates nursing from all other health professions. For our purposes we can use prominent definitions from military sociology and other literature concerning the professions as operating definitions. 
One definition of what constitutes a profession, prominently used by military sociologists, * rests on three distinguishing characteristics: expertise, responsibility, and corporateness. That is, ...The professional... is an expert with specialized knowledge and skill in a significant field...

...the essential and general character of his service and his monopoly of his skill impose...the responsibility to perform the service when required by society.... The responsibility to service and devotion to his skill furnish the professional motive. Financial remuneration cannot be the primary aim of the professional man qua professional man...

The members of a profession share a sense of organic unity and consciousness of themselves as a group apart from laymen. This collective sense has its origins in the lengthy discipline and training necessary for professional competence, the common bond of work, and the sharing of a unique social responsibility.

A fully consistent definition from the fields of education, health, charitable professions, etc., used by William J. McGlothlin, ** rests on seven criteria: 1) intellectual, carrying personal responsibility for choice and judgement; 2) learned, based on a body of knowledge; 3) practical, that is, applied; 4) possesses a body of techniques and skills; 5 ) is organized to foster the profession and regulate practitioners; 6) is guided by altruism or the professional motive; and 7) deals with matters of great urgency and significance for society.

\footnotetext{
*Samue1 P. Huntington, The Soldier and the State. (Cambridge: Harvard University Press, 1957), p.p. T-I1. **William J. McGlothlin, The Professional Schools. New York: 1964, the Center for Applied Research in Education, Inc. p.p. 3-4. McGlothlin draws his first six criteria from Abraham Flexner, "Is Social Work a Profession?," Proceedings of the National Conference of Charities and Correction. Chicago: 1915, Hildmann Printing Co., p.p. 576-590.
} 
Professor Huntington distinguishes the military from other professions in terms of principal function:

The direction, operation, and control of a human organization whose primary function is the application of violence [in the interests of national security] is the peculiar skill of the [military] officer....It distinguishes the military officer qua military officer from the other specialists which exist in the modern armed services...basically auxiliary vocations... (in) relation to the expertise of the (military) officer...

The New York State Nurses Association gives this definition of professional nursing:

The practice of the profession of nursing as a registered professional nurse is defined as diagnosing and treating human responses to actual or potential health problems through such services as casefinding, health teaching, health counseling, and provision of care supportive to or restorative of life and well-being, and executing medical regimens prescribed by a licensed or otherwise legally authorized physician or dentist. A nursing regimen shall be consistent with and shall not vary any existing medical regimen.

For the special case of Army nursing, the subject of this report, the application of the definition is directed toward the protection and conservation of the fighting strength of the Army.

The conflict of nursing, as an auxiliary profession, with the military profession and bureaucracy rests in part on the difference in principal functions, in part on the varying modes of operation inherent in differing sets of skills, and in part on the pervasive noncongruence between professional expertise and hierarchical administrative authority in a bureaucratic institutional setting.

The MEDDAC environment contains elements of both the military and

* Op. cit., p. 12.

** $\overline{R e p o r t}$, The official newsletter of the New York State Nurses Association.

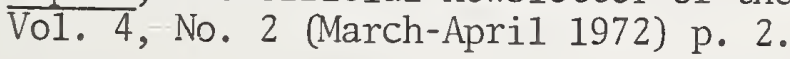


health professions. Military traditions of rank, discipline, and courtesy prevail in tandem witn the military organization's system of command authority. Physicians command the health professions within the MEDDAC. Nurses operate under domination of the military profession and the physician as well as the bureaucracy. The inescapable clash of certain aspects of each is exacerbated by the aspirations of the professionally oriented nurse struggling for full professional status.

It is a complex issue that surfaces most directly in the matter of professional competence versus rank and authority. None of the ensuing discussion should be interpreted as saying that the military are opposed to high professional standards in nursing. Rather, the conflict involves noncongruent professional patterns of expertise and authority.

The pattern of professionalism emerges in a variety of ANC responses. Here we have sketched only the broader frame of reference. The remainder of Section 3 presents the responses to specific proposals and statements about many aspects of Army nursing.

Professionalism is an important factor in two areas of general importance to the future of the Corps: 1) retention of nurses with a highly professional nursing orientation is assumed to be advantageous to the delivery of the best possible health care for the Army; and 2) professionalism in the operational context in which nurses practice in the Army, along with organizational effectiveness in the Army should enhance the effectiveness of those who will provide the Amny Nurse Corps with leadership in the future. Figure 3-1 may be viewed as a.field portraying the two professional areas. The location of any nurse or cluster of nurses would be 


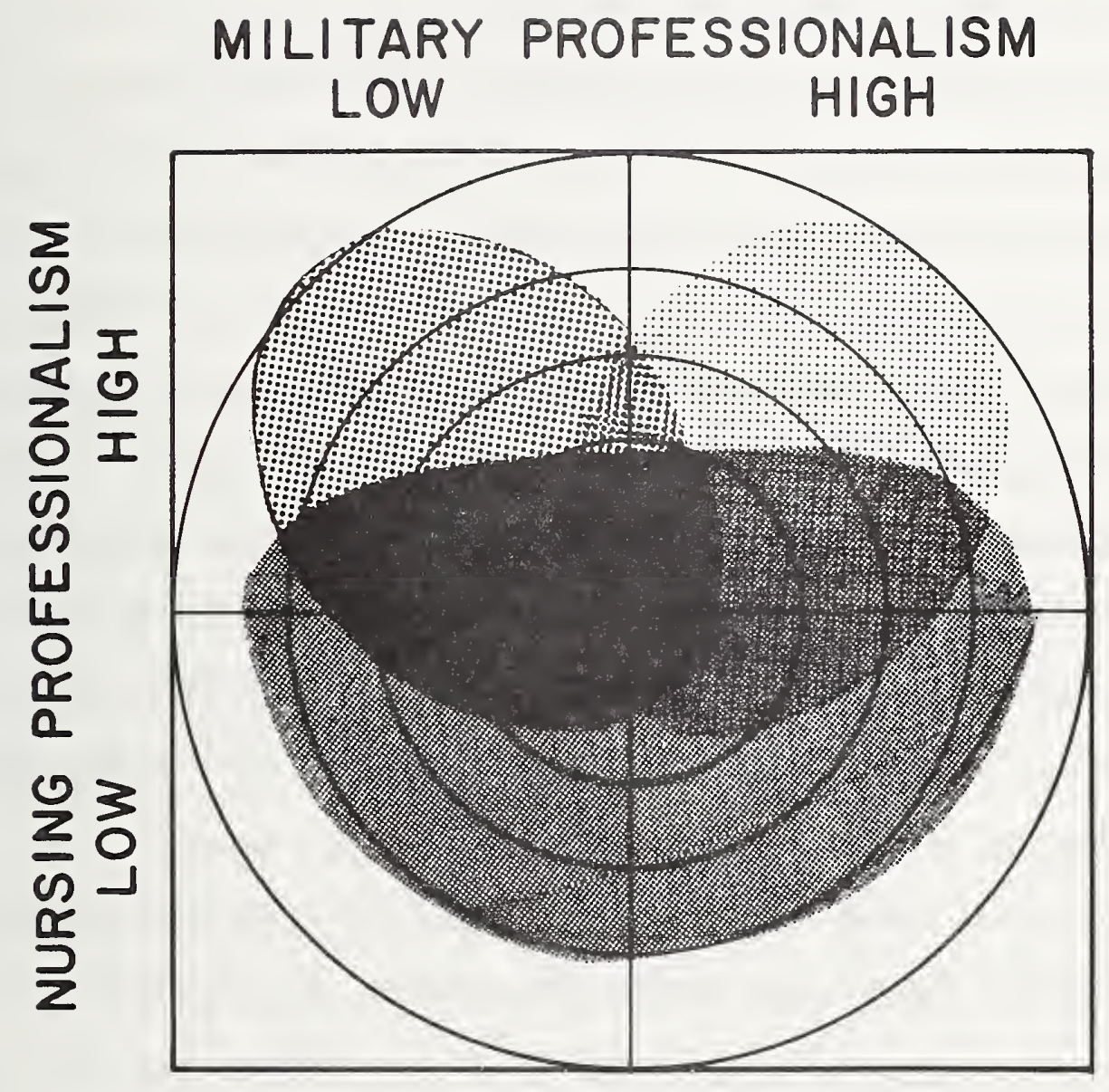

FIGURE 3-1 
a function of measures of professionalism in each-nursing and military. The square is an abstraction of the relationship between the two dimensions. (The shaded areas are for illustration only and do not present actual data.) Empirically, the outer circle probably bounds real cases, although even within the circle nurses who are very low on both professional dimensions are rare in the Army Nurse Corps data.

A general review of the data indicates that a high proportion of nurses who rank high on measures of nursing professionalism but low on measures of military and organizational professionalism reflect their professional mobility and are more likely to leave the service. These nurses tend to have the baccalaureate, show great interest in continuing professional education and specialization, in the nurse clinician specialties, and in the expanded role of the nurse. They experience more difficulty with the military system of rank and authority, and they feel that promotions and advancement depend too little on professional competence. Equal status with other groups in the health professions is important to them.

There is a second group of nurses with high professional orientation both as nurses and as members of the military system. They recognize the conflict between the two but are committed to a career as an Army nurse. They are also likely to have the B. S. degree, often earned subsequent to a diploma, during their military career. They tend to be RA, higher in rank, and are likely to feel that in important respects military values and traditions reinforce the personal dedication needed to bring forth the highest standards of nursing. They tend to believe 
that the military offers excellent professional opportunities. This group also wants equal status within the health professions. Within this group there is considerable variation in opinion about the extent to which the professional emvironment of the hospital should be "demilitarized."

A broad third category of nurses tend to rank lower on both nursing and military professionalism, angling across the diagram in Figure 3-1 but not falling into the extreme low positions in either quadrant. They tend to be diploma nurses. Their values tend to be more narrowly focused on nursing skills than on broader professional perspectives. Their dedication to nursing tends to be quite high; the frame of reference within which they see their profession tends to be more limited. They tend to accept the nurse's role as the handmaiden to the physician. In their military career they are essentially adaptive. From the perspective of the military system, they can expect timely promotions based on competent performance.

The foregoing characterizations should be clearly understood as reflecting aggregate and comparative tendencies only. A variety of factors not analyzed in this study affect the decision of ANC officers to choose an Army career or to serve only an initial tour.

The issue of nursing education, and the related issue of professional orientation, should be approached with particular caution. Certainly, simplistic conclusions must be avoided.

Health care is a field of rapidly expanding technology that calls for the development of new and enhanced skills. However, professionalism calls for a broader and deeper basis for independent judgement and 
decision; the more the development of the professional bases of decision keep pace with skills and technology, the less likely it is that new technology will be inappropriately delegated or utilized.

A principal difference between diploma and degree curricula has been the relative emphasis on skill training in the former and the broader interdisciplinary education in the latter. Baccalaureate education has been seen as providing the individual with a broader base of knowledge from which to draw in exercising professional judgement. The number of variables which a nurse must consider in planning patient care, especially in unfamiliar situations, suggests the need for this type of interdisciplinary approach. Additionally, baccalaureate education provides a foundation for greater mobility entering into management, teaching, clinical specialization and research. This preparation is in consonance with the organizational expectations of nursing in the military. It is no accident, then, that the baccalaureate degree or active work toward it, tends to be correlated with a desire for greater professional autonomy and more equal status for the nurse among health professions.

On the other hand, years of experience will often provide a more or less comparable professional perspective, especially to a nurse who is professionally active. Further, the professional motive, the desire to help protect and preserve life and health, is a shared motivation important to diploma and degree nurses alike. Finally, such other factors as personality, opportunity, and socioeconomic origins normally influence individual decisions and perspectives. 
This report offers only a superficial analysis of the relationship between the dimensions of professionalism on the one hand and the choice of an Army nursing career on the other. Factors such as the higher mobility of baccalaureate nurses, the relative attractiveness of an Army career to young nurses during and following military involvement in Southeast Asia, or the effects of social change are beyond the scope of this study. However, it is safe to assume that those factors do also affect decisions concerning a career in the Army Nurse Corps.

We have attempted to frame the basic issue that attitudinal data indicate to be of most importance to the recruitment and retention of individuals who would constitute a Corps of the highest professional standards. There are other clusters of issues that are also of great importance.

The first of these pertain to financial considerations. For those nurses who have decided on a career in Army nursing or are leaning toward such a decision, financial aspects are very important. However, they are not crucial for most ANC officers making the decision to stay or leave. Only $27 \%$ of those definitely leaving agreed that pay and allowances were a major influence in the decision, whereas $72 \%$ of those definitely staying and $63 \%$ of those possibly staying agreed that these financial considerations were a major influence.

Of great importance to a predominantly female Corps are inequities based on sex. Although current events may have overtaken this study with recent court decisions, there is nevertheless a legacy of inequities clearly reflected in the responses. The issue is of the highest importance to many of those definitely or possibly leaving the service. 
We now turn to a more detailed examination of the data. The remainder of this chapter presents, first, a basic profile of the Corpsdemographic characteristics, military status, professional qualifications and professional values. A discussion of ANC officers' feelings about remaining in the Corps for a normal career is followed by analysis of responses to the policy proposals and to various aspects of Army nursing. The section proceeds to a summary of appeals that influenced the respondents to join the Army and that are among reasons important to them if they are considering staying in the service. Brief comments on satisfaction with current assignments and on future assignment preferences conclude the topics covered in this section.

\subsection{The Corps in Profile}

3.1.1 Age, Sex, and Grade Distribution

Over half of the Army Nurse Corps is under age 27 and approximately $75 \%$ of the Corps are female, as shown in Figure $3-2$. The male $25 \%$ are unevenly distributed by age and grade. While only $8.5 \%$ of the youngest (age 20-24) and of the oldest (50 years of age and over) are male, the middle group from 35-39 are evenly divided between men and women. In actual numbers there are fewer men in the youngest category (20-24) than in any other 5-year age agroup under 40, although there are almost twice as many women in the 20-24 group as there are in the 25-29 bracket, which is the next largest in size.

Not unexpectedly then, men constitute about one-third of the captains and majors, which is about twice the proportion of males in the two lower grades (1ieutenants) and close to two and a half times the percentage of male lieutenant colonels. There were no male respondents in the grade of full colonel. 


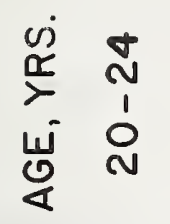

$\begin{array}{cc}\dot{m} & m \\ 1 & 1 \\ 0 & n\end{array}$

$d$
$j$
$d$

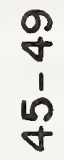

0
1
0
10

opd

نำ

o $\quad m z$

Gั

으

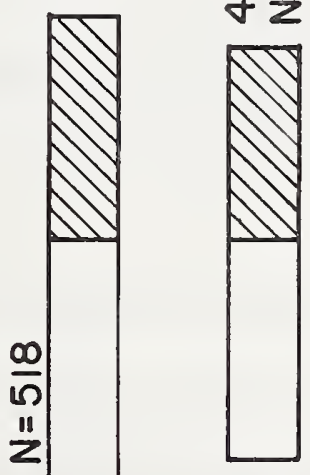

17

.$\infty \mathrm{z}$



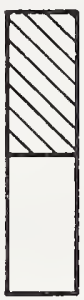

$2 \infty$

ㅇำ ำ

ำㅇำ

iั

ำ

$m z \quad 0 N \quad 0^{N} N$

NI $\quad \stackrel{2}{z} \quad \infty^{\circ} z$

m

in $z$
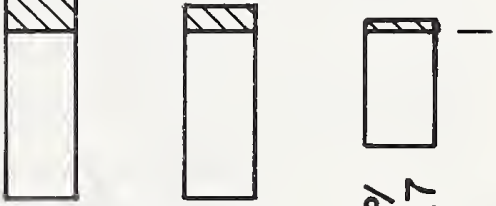

든

ㅇo

ติ

กั

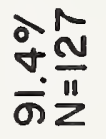




\subsection{2-3 Marital Status and Dependents}

Forty-one percent of the Corps are married; equally, forty-two percent claim dependents on their tax returns; however, twenty-five percent report dependents that do not legally qualify as such under Army regulations in force at the time of the survey.

Inequities based on the difference between legal and actual dependency obligations appear to weigh most heavily against single women. Approximately 150 single officers claim on their tax returns dependents who are not recognized as such by the Army. Of these officers, 123 are single women and 29 are single men.

One hundred and fifteen men over age forty claimed one or more dependents for tax purposes, compared to 106 women in the older age group. Of the 484 single women claiming actual dependents (whether or not they are recognized as such by either the Internal Revenue Service or the Army), 89\% reported dependents not recognized by the Army; among single male officers $83 \%$ also claimed such dependents. For married officers the comparable figures are $43 \%$ of the women in contrast to $21 \%$ of the men.

\subsubsection{Professional Qualifications (Education and MOS)}

Education. Fifty-seven percent of respondents have completed the B.S. or are working toward a baccalaureate degree.

General nursing is predominant in current work toward a baccalaureate degree, followed by medical-surgical and anesthesia.

Seven out of every eight ANC officers expressed an interest in pursuing advanced clinical preparation in such courses as intensive care, nurse clinician specialties, and anesthesiology.

Military Occupation Specialty. Figure 3-3 shows the distribution of PMOS's according to sex, and RA or reserve component, and degree program 


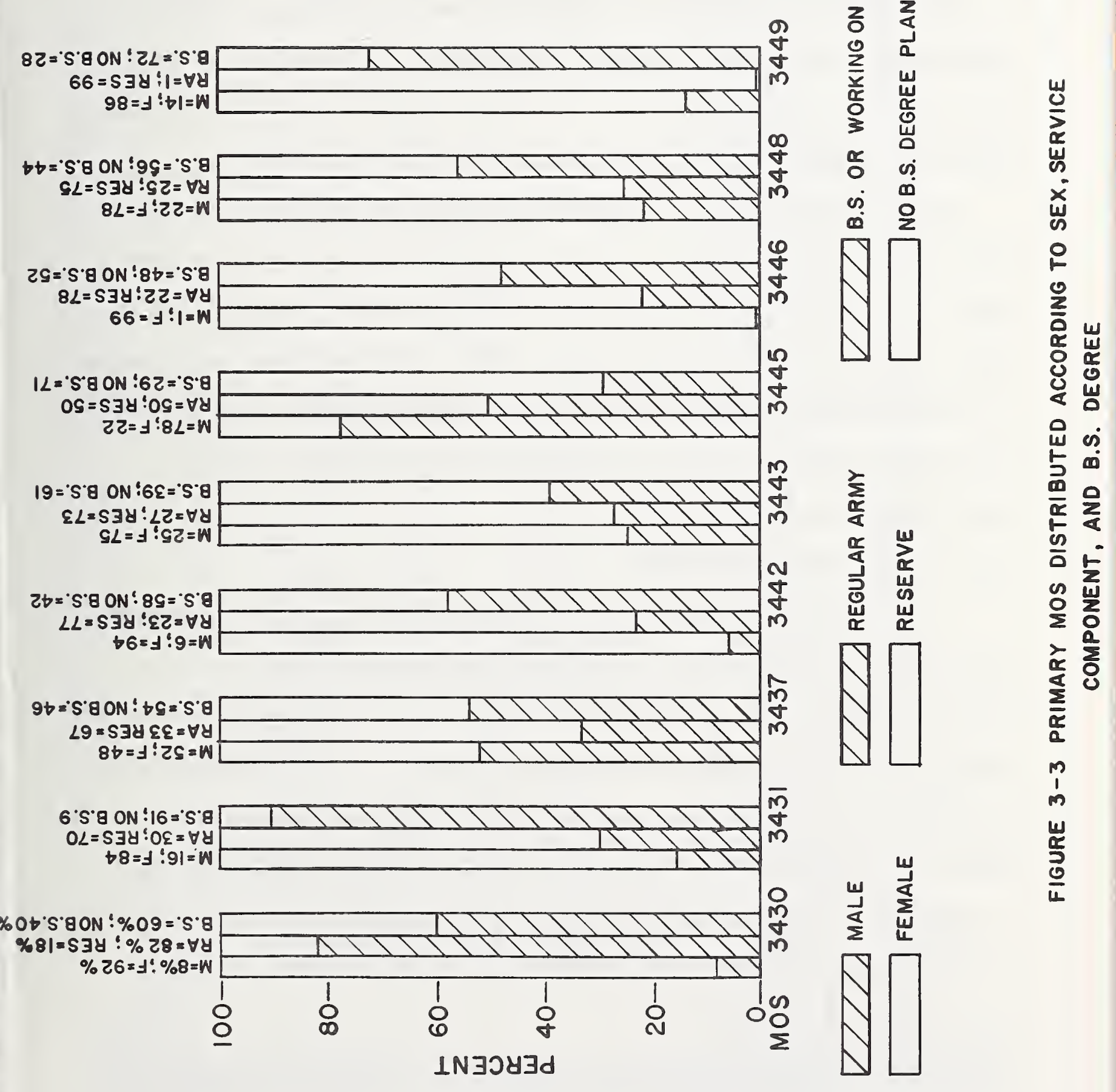


education. Among RA men the greatest percentage, 36\% each are anesthetists and medical-surgical nurses (3448). Among women, the ratio of RA officers to reserves is highest for the administrative MOS 3430 (54 RA/12 RES) followed by anesthetists (3445) (43 RA/28 RES).

The distribution of male and female nurses among MOS's is markedly different. Although men comprise only one quarter of the Corps, they constitute just over three quarters of nurse anesthetists (MOS 3445) and slightly over half of the neuropsychiatric nurses (MOS 3437).

Three quarters of the respondents say they are satisfied with their present PMOS. Three closely grouped sets express the greatest satisfaction: 3431 - Army Health Service nurses (94\%); 3445 - nurse anesthetists $(94 \%)$; and 3430 - nurse administrators (93\%). Only the first year, general duty nurse (3449) was significantly below other MOS groups at $45 \%$. Other than 3449 s, the lowest level of satisfaction reported was at $78 \%$ by medical-surgical nurses (3448).

\subsubsection{Professional Orientation}

The analysis included a set of 21 questions designed to determine what aspects of Army nursing and personal-professional image were of greatest importance to ANC officers. (See Table 1.) Questions were divided into two sets, one tending to reflect the tone of an autonomous person and the other reflecting greater concern for the opinion or appreciation of others. In general, three quarters of the Corps chose responses stated in autonomous or self-reliant terms; only six percent chose the referentoriented answers, and nineteen percent* gave mixed choices.

*These questions were selected as a general set of indicators, and would require retesting and refinement to quality as a valid and reliable scale. 


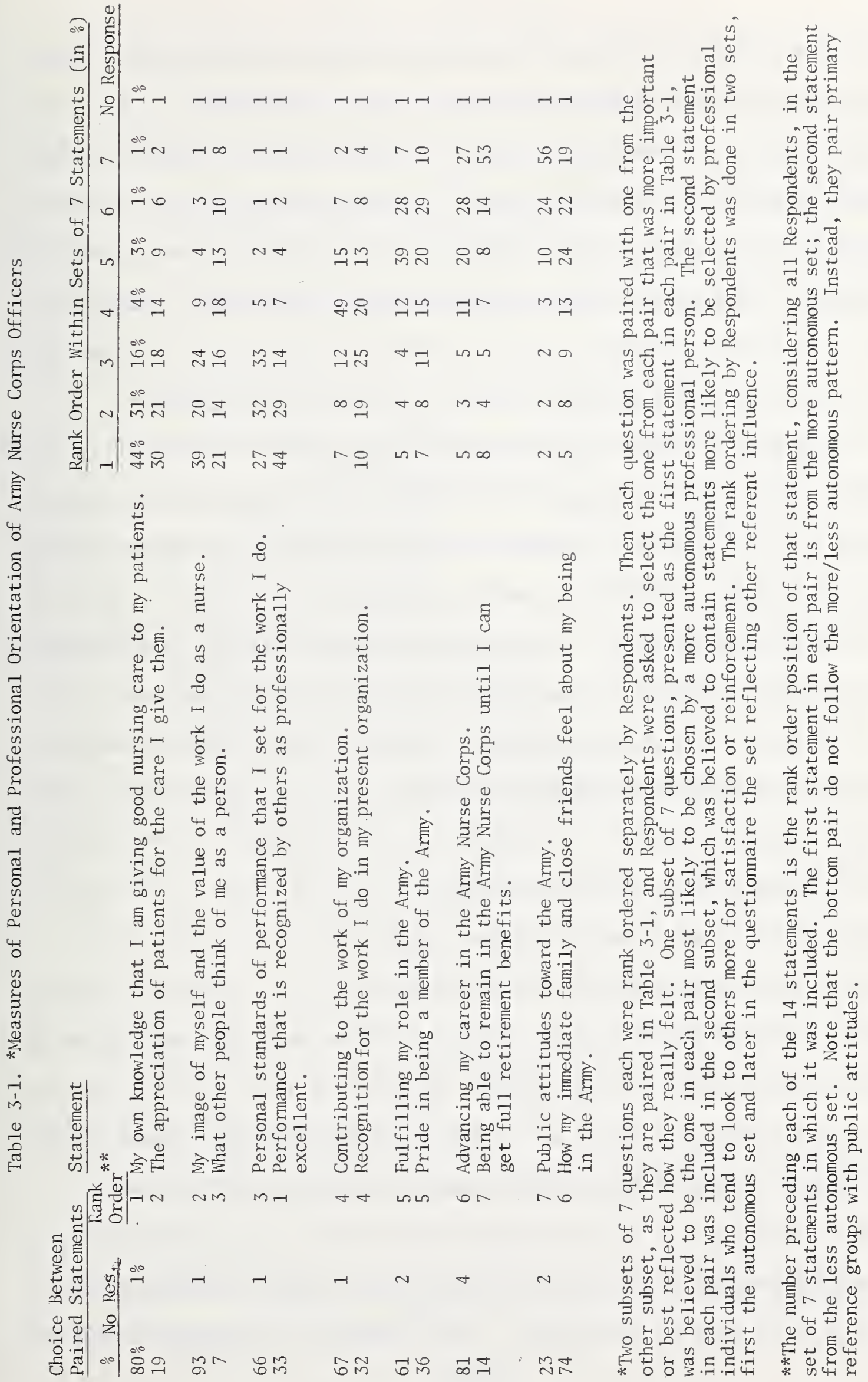


Further analysis indicated that female officers appear to be slightly more independent and self-assertive than males (77\% to $68 \%$ ). The greatest contrast emerges within the older group of nurses with no dependents $(80 \%$ female to $64 \%$ male.) Among MOS groups the greatest autonomy is shown by Army llealth Service nurses $(3431=82 \%)$ and nurse administrators $(3430=81 \%)$, while nurse anesthetists (3445) were least autonomous at $70 \%$. None of these variations, however, change the dominant self-reliance of Army nurses; all groups appear substantially more self-reliant than dependent.

The specific aspects of nursing that respondents say are most important probably approximate the image of the ideal nurse. In the seven item set phrased in self-reliant or autonomous terms, these three elements received unambiguous choice as the three most important:

My own knowledge that I am giving good nursing care to my patients; My image of myself and the value of the work I do as a nurse;

Personal standards of performance that I set for the work I do. These same values dominate when we look at the set of items stated more in other-oriented terms:

Performance recognized as excellent. Appreciation of patients for the care I give. What other people think of me as a person. Data was compiled which shows the number of times each item was chosen in each rank order position, from $\underline{1}$ to $\underline{7}$.

In both cases, but especially among the autonomous set, career considerations and organizational aspects ranked well below the "good nurse" image.

Organizational and professional items are slightly more important to the RA officer than to the Reserve. The orientation also varies moderately 
(but significantly) for some MOS groups. For example, professional recognition is considerably higher and personal performance and professional standards lower for nurse administrators and anesthetists in comparison to others, but the opposite relationship holds for Army Health Service nurses and psychiatric nurses. Other MOS's range between the four mentioned. Professional standards and recognition do tend to become more important with age.

3.1.6 Programs Through Which Army Nurses Enter the Corps

The largest number of nurses in the Corps entered by a direct commission. This is true for every MOS group except first year, general duty nurses, the majority of whom do not remain after their first tour of duty. Seventy-six percent of the first year nurses are from the Student Nurse Programs (diploma and degree). The highest proportions of direct commissions are among nurse administrators $(3430,85 \%$ ) and nurse anesthetists $(3445,64 \%)$. A higher proportion of Army Health Service nurses come through the Army Student Nurse Degree Program (42\%) than do any other MOS except 3449. Second highest in proportion, 25\% of Army Student Nurse Degree Program recruits are medical-surgical nurses (3448).

By a slight margin, the Walter Reed Army Institute of Nursing (WRAIN) program also tends to bring nurses into the Army Health Service MOS (12\% of WRAIN nurses), and that MOS is closely followed among WRAIN nurses by neuropsychiatric (10\%) and pediatric nurses ( $9 \%$ ).

\subsubsection{Regular Army Officer Patterns}

The 814 RA respondents became RA officers at the following grades: second lieutenant for $12 \%$, first lieutenant in $37 \%$ of the cases, captain for $46 \%$, major for only $7 \%$, and less than one percent (3 individuals) at lieutenant colonel. 
Fifty-three percent of the RA officers said counseling helped influence them to apply for an RA commission. Twenty-four percent of the USAR officers who reported counseling by senior officers also said that the counseling helped to influence them to apply for RA status. However, most of these RES officers did not report applying for RA. Forty-six percent of those who did report applying said their application was pending; $25 \%$ said they had not applied but still might.

The ages at which RA officers made the transition from the USAR correspond to what would be expected from the transition by grade, as do the years of service.

RA males dominate the nurse anesthetist MOS. The female RA officers constitute a large percentage of the nurses in the following specialties: nurse administrators, Army Health Service nursing, and operating room and obstetrical nurses.

\subsection{Attrition, Personnel Policies, and Attitudes Toward Aspects of Army Nursing}

Staying or Leaving the Service. The questionnaire asked members to indicate their present feelings toward "staying for twenty or more years of active duty." This section discusses their answers and relates them to other factors -- demographic, military status, their responses to policy proposals, and general attitudes toward serving as an ANC officer.

As expected, those who say they are least likely to remain in the Army are the youngest age group. Figure 3-4 reveals a high rate of expected attrition among those officers in the youngest age groups. Only $1.3 \%$ of the women in the 20 to 24 age group say they definitely intend to make 


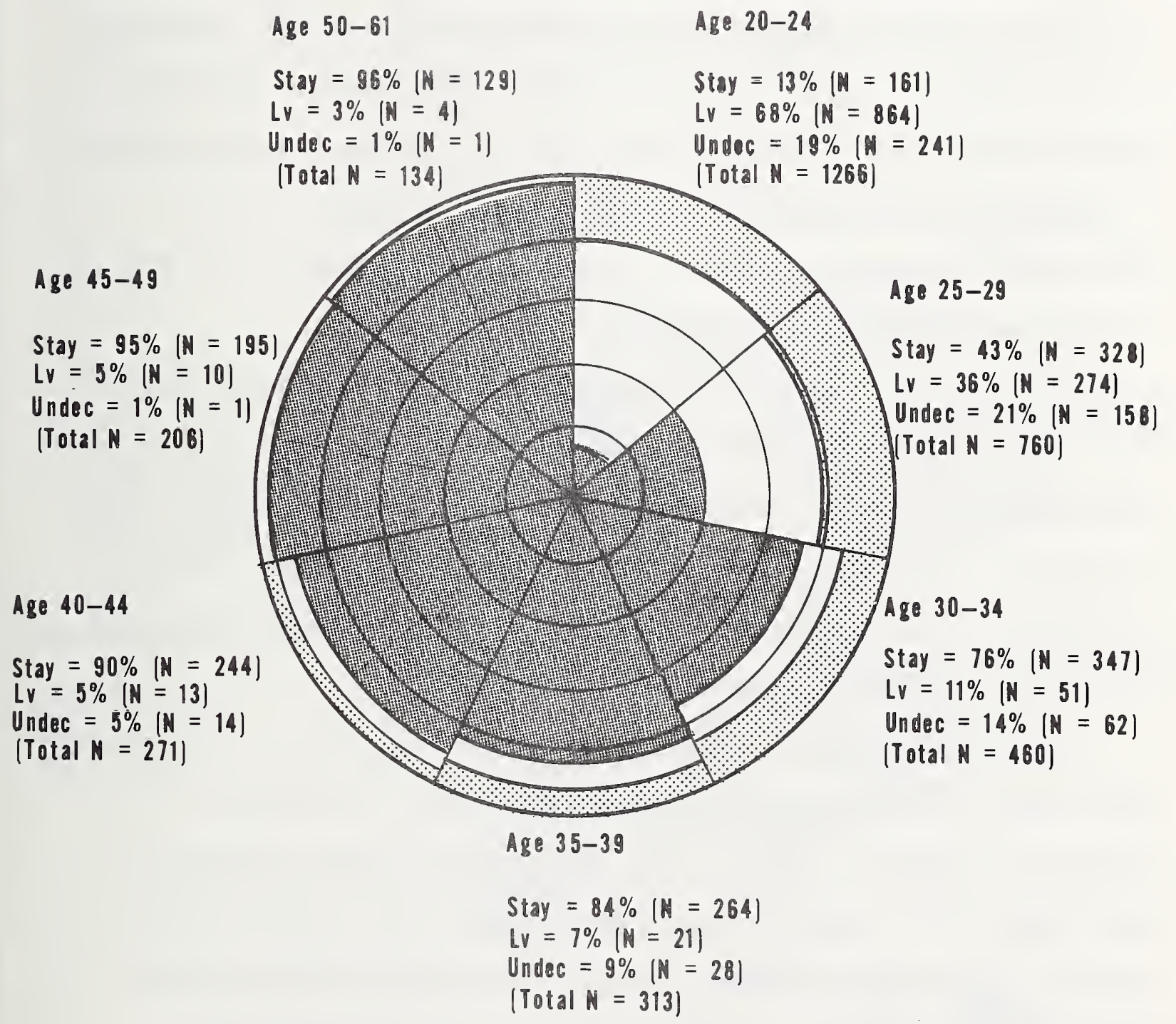

Figure 3-4.

Staying

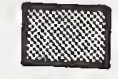

(Percentages rounded]

Loaving

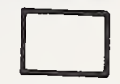

Undecided

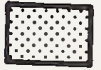


a career of Army nursing, and $9.7 \%$ say they will possibly stay, with another 18. $3 \%$ undecided. Thirty eight percent of this age group say they will definitely leave and $32 \%$ say they will possibly leave. The expected retention figures increase rapidly in older age groups.

In this section we noted that there is a small number of male nurses in the lower grades. However, those men who do obtain an ANC commission are more likely to remain in the service for a full career. Retention appears better among the younger groups of male officers. Male officers in the oldest age group are more likely to leave the Army, possibly reflecting a willingness to begin a second career early (after 20 years) in order to meet family obligations.

Respondents with service agreements in force (or which terminated in 1972) were, as expected, most certain about whether they were staying or leaving; the closer the termination date the more sure they were of their intentions. For example, 1972 service agreement terminations show 52\% definitely leaving and another $24 \%$ possibly leaving, $11 \%$ undecided, only 7\% who will definitely stay and $6 \%$ possibly staying.

There is considerable variation among nurses who entered the Army Nurse Corps through different programs with respect to staying in or leaving the service. (Figure 3-5.) The greatest expected retention rate appears to be among the direct appointments from civilian status, and next highest among entrants through the Army Student Nurse Diploma Program (ASNP: Diploma). Degree programs, such as Registered Nurse 


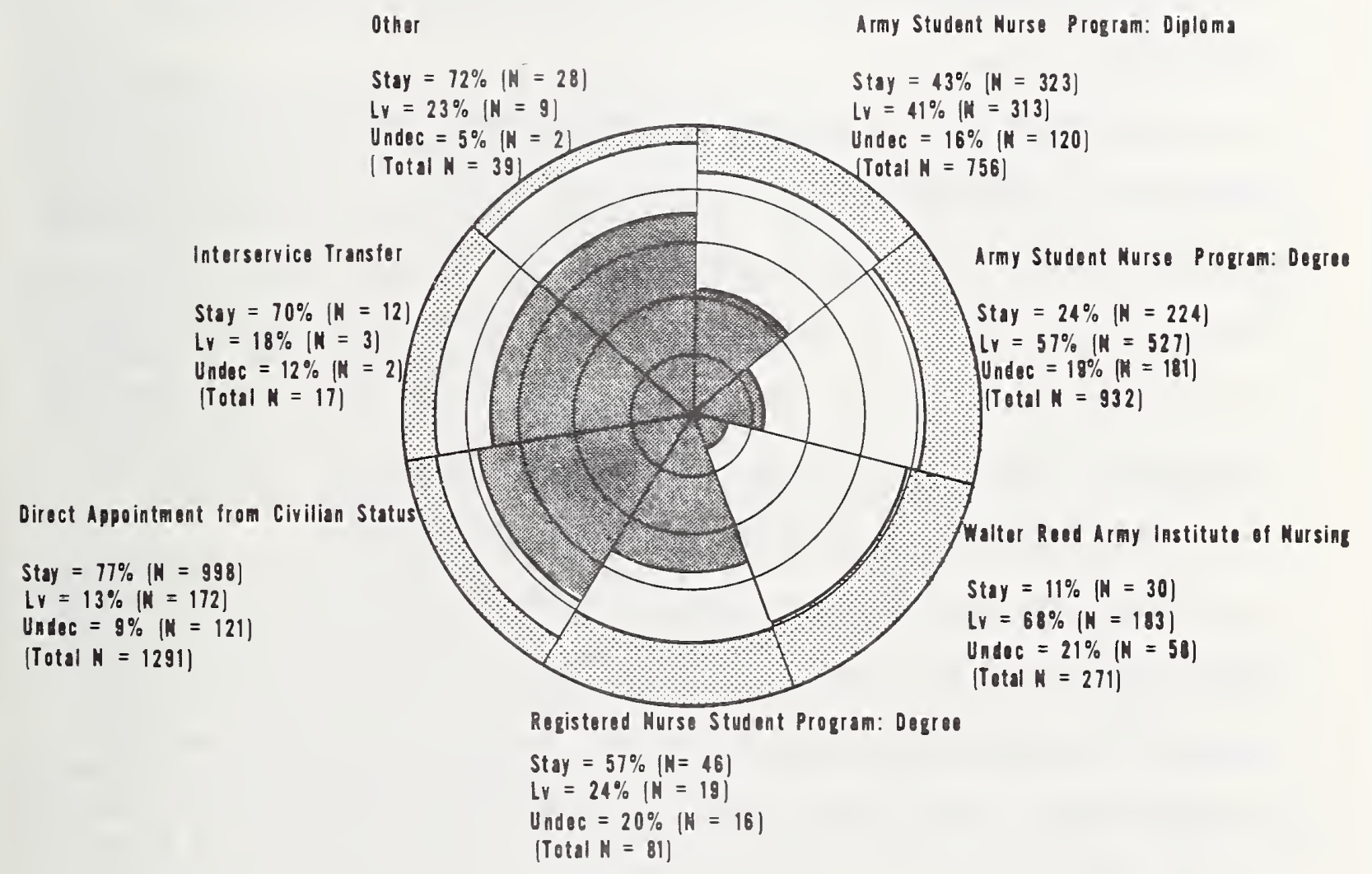

Figure 3-5

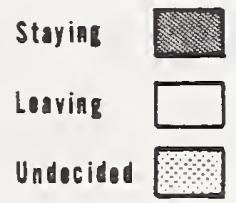


Student Degree Program (RNSP: Degree); and the Army Student Nurse Degree Program (ASNP: Degree) reflect a lower expected retention rate.

A low proportion of all nurses who obtain their nurse's education with the financial support of the Army are likely to serve more than the required obligation incurred to obtain their education. Financial assistance and security may be strong inducements for recruitment, but retention among nurses entering through financial support programs will remain low. However, those who leave active duty do help maintain a reservoir of reserve nurses who could be recalled in a national energency.

A review of expected retention rates among different MOS groups is consistent with other factors. Nearly 93\% of the nurse administrators, $71 \%$ of the nurse anesthetists and $63 \%$ of both the psychiatric and operating room nurses expect to stay. The first two specialties tend to be older, senior grade, RA officers. Other than first year, general duty nurses (14\% will or may stay), pediatric nurses are lowest with only $42 \%$ saying they will or may remain in the service.

Nurses were asked to give their reasons for staying in the Army if they think they might remain. Up to three reasons were cited by each respondent and the pattern is consistent among first, second, and third reasons given. First among reasons given are pay, allowances and benefits, followed closely by professional opportunity. Educational opportunity ranked in the third position, and the belief that the Army would be a good 
place to practice nursing placed fourth. Nurses were more inclined to include "to serve my country" among their second and third reasons than they were as a first reason. (Table 3-2)

The principal reasons ANC officers joined the Corps initially were, above all, the opportunity the Army provided for obtaining a nursing education (1029 nurses gave this reason), followed by professional opportunity (457 respondents) and the pay, allowances and benefits (406 nurses).

Army Nurse Corps recruiting counselors are given unambiguous first place among the sources of information that led Army nurses to apply for an ANC appointment. A variety of other persons such as parents, friends, family physicians, ministers, and nurses with previous military experience, comprise a strong second information source that led to joining the Corps, followed by ANC recruiting mail or brochures.

3.2.1 Response to Policy Proposals

We have mentioned that pay, allowances, and benefits were major advantages to ANC officers if they decided to remain in the service. A group of specific proposals were presented to the nurses concerning pay, allowances, and benefits as well as others concerning educational qualifications, appointments and grade at the time of commissioning. Responses were on a five point scale: major advantage, minor advantage, unimportant, minor disadvantage, and major disadvantage.

Figure 3-6 portrays four types of response patterns to the several proposals: responses to basic economic issues, which tend to be most 


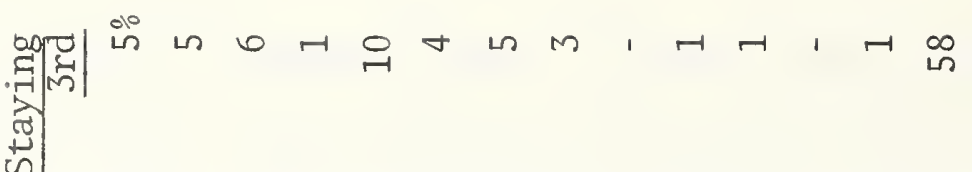

es

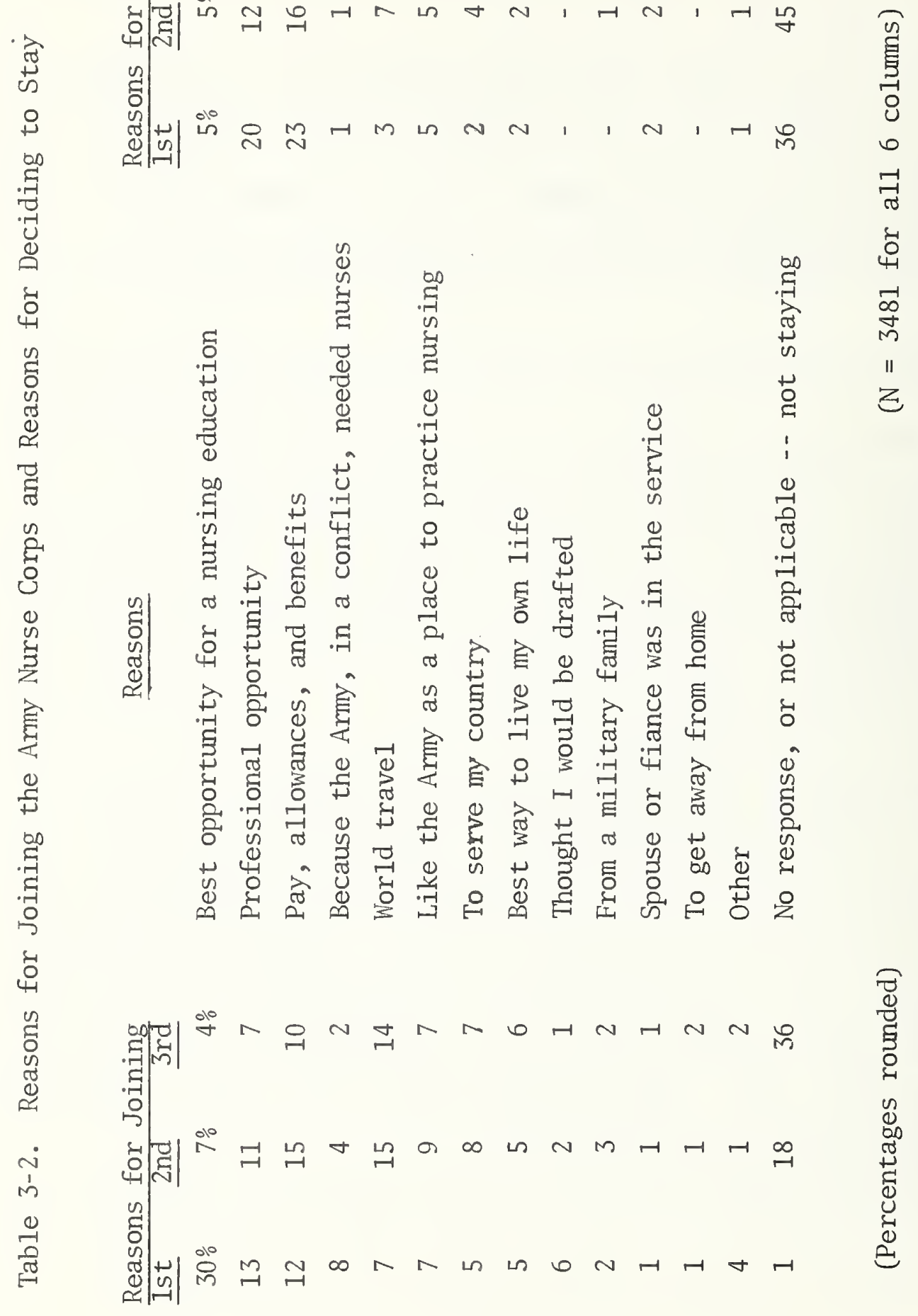




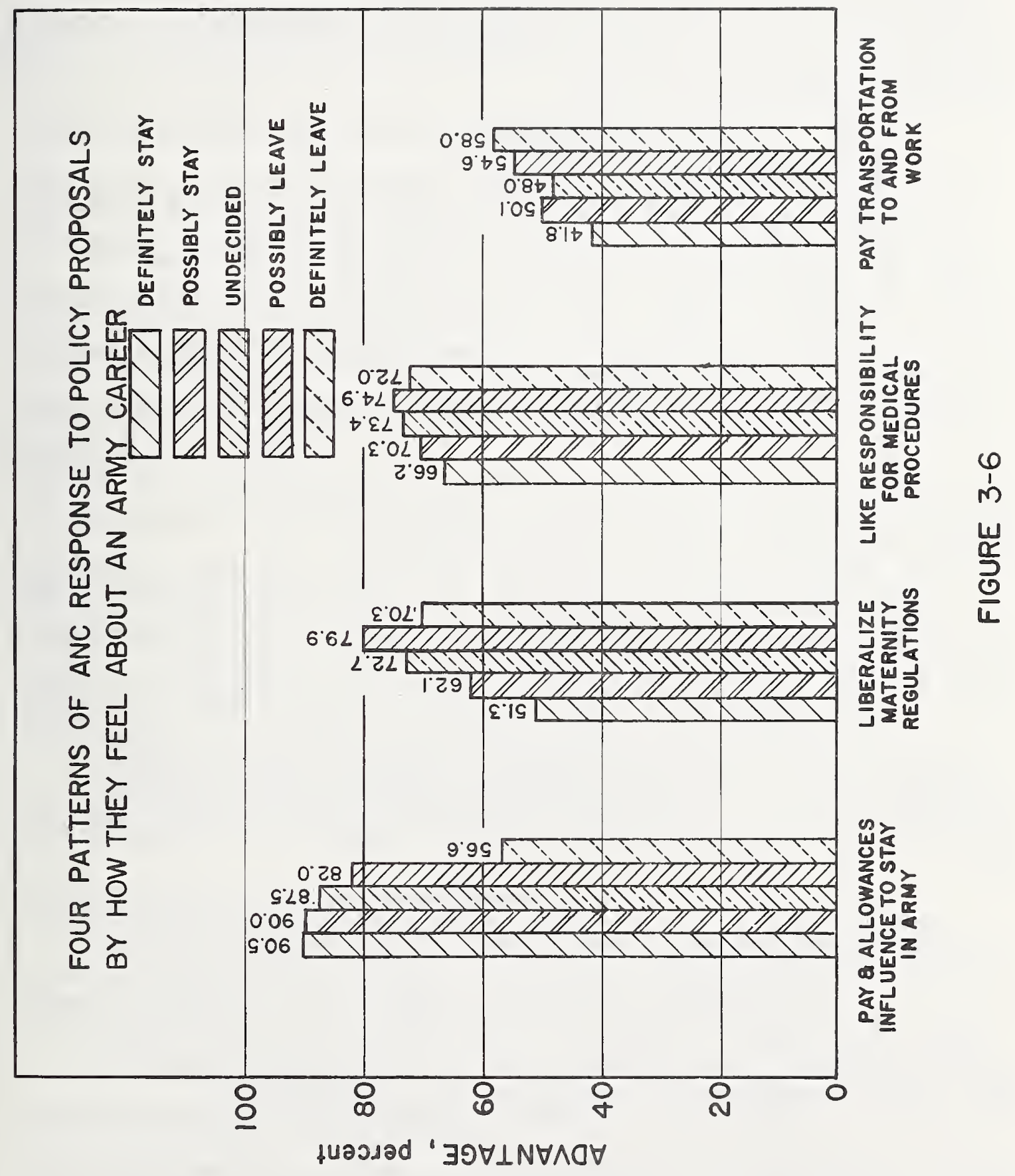


important to those staying in the Army; stronger reaction by those leaving to issues that most affect the female nurses; reactions that are stronger among those leaving which show a professional interest in assuming new responsibilities for medical procedures formerly conducted by physicians; and the pattern in response to a relatively trivial proposal judged unimportant by Army nurses.

1.) Pay, Allowances, and. Benefits

In this and succeeding subsections, responses to specific proposals reflect the basic importance of pay and allowances to the career ANC officer, as shown in Figure 3-6. Al1 proposals received the endorsement of the majority if they proposed to give ANC officers increases in pay, allowances, or benefits. However, the margins of support and the variation between groups that would be most and least affected by the proposal do vary between "gut" issues and minor benefits.

Compensatory time for extra hours is slightly more important to most Army nurses than is differential pay for holidays, weekends and nights. Officers with dependents are more inclined to support compensatory time proposals, while those wi thout dependents are more likely to support differential pay; the differences between the groups is in the order of $10 \%$

Incentive pay for critical MOS's is favored by the Corps, with $90 \%$ of the nurse anesthetists but only $50 \%$ of the Army Health Service nurses calling this a major advantage. Female nurse administrators (12\%) are the only group which sees incentive pay as a disadvantage. 
It may be worth noting that two patterns surface intermittently among the answers of nurse administrators. First, they appear to be the only group whose responses to proposals visibly reflect awareness of budgetary considerations or any limit on the number of proposals that could be implemented. Second, they are the most responsive to proposals that will rectify inequities for other groups of nurses. Males, especially older men, are least likely to be responsive if their own interests are not directly involved. Finally, both sexes, while they are in their thirties, are least responsive to the interests of other groups of ANC officers, while nurses 40 years of age and over tend to be most responsive to proposals that would benefit other nurses but not themselves.

A proposal for military nurses to receive the same pay as civilian nurses tends to have a more even distribution from "advantage" to "disadvantage," perhaps reflecting the pay levels in the geographical areas best known to respondents. The proposal tends to be supported most by nurse anesthetists, by second lieutenants, and by older female nurses.

Inclusion of all benefits in base pay appears to be the greatest disadvantage to male nurses with civilian spouses and least important to female nurses with military spouses.

Pay and allowances rated slightly more important to RA officers than to reserves as an influence to remain in the service.

By nearly twice the margin over reserves, RA officers feel that early retirement with reduced pay would be a disadvantage. Further, the more dependents the greater is the disadvantage. Older nurses in more senior grades also consider this a greater disadvantage. It is only 
slightly less disadvantageous to nurses with military spouses than to those married to civilians, Interestingly, there is virtually no difference between the responses of single officers and those with civilian spouses. The oldest group see the proposal as only slightly less disadvantageous, presumably because they feel less likely to be affected by it. Finally, among younger age groups, the greater the number of dependents, the higher the concern.

2.) Housing, Subsistence, Transportation, Dislocation

These proposals are also in the category of advantages but not crucial criteria for choosing a nursing career in the Army. A proposal to adjust the off-post housing allowance to conform to local prices in high cost areas was heavily endorsed by both married and single officers. Of greatest importance to those 30 years of age or older, the proposal is only slightly less advantageous to middle aged single officers than it is to their married colleagues. The proposal to adjust the subsistence allowance to the cost of living induced a parallel pattern of responses. Among the least important issues is the proposal to pay transportation costs to and from work. The importance attached to this item was lowest among proposals included in the survey.

The proposal to give a permanent change of station dislocation allocation allowance consistent with actual expenses was of less concern to younger officers. A majority see it as advantageous, on the whole, but not important.

The older the officer and the more dependents, the more important is enough government housing for all officers. The issue is especially 
important to the group aged 25 to 29 having four or more dependents, to whom heavy family expenses are particularly burdensome.

The proposal that all ranks should be given the option of off-post housing was very strongly endorsed by all ages and ranks and by both sexes, with no group falling under $85 \%$ support.

3.) Retention Bonus and Retention Pay An annual retention bonus for ANC officers who extend their service is least important to RA women and most important to male reserve officers. However, the basic division is between RA women and others; $59 \%$ of RA females regard the proposal as a major advantage compared to $66 \%$ of the female reserves, $73 \%$ of the male RA's, and $78 \%$ of the male reserve nurses.

Special professional pay to ANC officers is, of course, favored. Men regard the proposal as more important than women, with nurse administrators, anesthetists, and then operating room nurses leading, followed closely by other specialties.

A proposal to prorate professional pay to all of the AMEDD Corps received a slightly lower vote, although all groups support the proposal as a major advantage. The proposal has greatest support among nurse anesthetists and least among pediatric nurses.

\section{4.) Fringe Benefits}

Fringe benefits as a whole do not receive the same level of attributed importance as most of the other proposals. Even so, only among reserves aged 35-39 with military spouses, and among reserves aged 50 or over with civilian spouses does the level of endorsement as a major advantage fall below $50 \%$ to $39 \%$. 
These issues--allowances, retention bonuses, and fringe benefits-may have potential for prolonging a career, but are unlikely to make the crucial difference in choosing a career with the ANC in many cases.

5.) Inequities Among ANC

5a Sex. Proposals that touch on inequities between male and female and between single and married officers tend to induce the greatest variation between the responses of affected groups and those not affected or less directly affected. Proposals in this area have potential for increasing retention of female officers. For example, the proposal to liberalize maternity regulations has only younger females, especially married women, strongly in support.

Response to the proposal that female officers receive the same survivor benefits as male officers shows a parallel pattern, although a larger percentage in each age and sex group responded in strong support of the proposal.

Interestingly, in both cases married females gave the strongest support and married males the least, with unmarried groups falling between. Greater agreement was found on the basis of sex than marital status.

The proposal to establish the same tour provisions for men and women finds more support among older officers, most strongly among older women. Younger women gave it the least support.

5b Marital Status and Dependents. Proposed government housing for female nurses with civilian husbands receives least support from younger, male officers and most support from married women. The proposal to give the housing allowance to both husband and wife if both are military is 
naturally supported most strongly by those who are directly affected, those with military spouses. Single women support the proposal slightly more than single men, and, in contrast, women with civilian husbands are far more supportive than male ANC officers with civilian wives, by a margin of $64 \%$ to $29 \%$

Accompanied tours for civilian husbands gets a resounding $93 \%$ vote from women married to civilians, $82 \%$ with those married to military husbands, $74 \%$ from single women, but only $42 \%$ from male Army nurses with civilian wives. Provisions of medical and dental services for civilian husbands reflect approximately the same response pattern: $95 \%$ from women with civilian husbands, only $45 \%$ from men with civilian wives, and $54 \%$ from single men. Permanent-change-of-station transportation allowance for civilian husbands receives a similar response pattern from women, but this time even less support was forthcoming from those unaffected by the proposal. Further support to the proposal that husbands receive the same benefits as wives of military men came from $96 \%$ of the ANC officers with civilian husbands, but only $46 \%$ of the male nurses with civilian wives supported it.

The proposal to grant the same privileges for post recreation and welfare activities to guests of single officers as to guests of married officers is most important for older single officers. Only those over 30 -both male and female -- register these privileges as a major advantage in more than $50 \%$ of the cases. The proposal is generally rated as unimportant compared to most of the proposals.

Extra pay if marital status or dependents do not limit geographic assignments is another proposal that received only moderate support compared 
to most others. Generally, the proposal is more favored by males than females. There is a slight tendency for single officers with from one țo three dependents to favor the proposal more than bachelors with no dependents. The rationale here may be the same as the apparent reasons for greater male support. That is, although male officers may have dependents, their dependents are unlikely to limit their assignments. Age also appears to influence the pattern of support, with little variation between the sexes. Single ANC officers in their thirties and forties, more likely to have peers with dependent minor children, tend to favor the proposal more than their single colleagues in the youngest or oldest age groups. To a slightly lesser degree, the same differences in response pattern occur among married officers with from one to three dependents.

The related proposal to provide regulatory restrictions for those ANC members whose marital status or dependent relationships do limit geographic assignments received limited endorsement among most groups. Approximately 40 to $50 \%$ of older married officers said the proposal would be a major advantage. Those with no dependents and male nurses were most likely to approve.

6.) Education Proposals

Education proposals touch directly on the professionalism issue. Because educational qualifications vary among nurses, reactions to proposals that would set stiffer requirements or demand additional educational achievement tend to divide the Corps. All such proposals received significant opposition as well as strong support. 
The continuing practice of appointing baccalaureate graduates at a higher rank than graduates of other basic nursing programs was more often considered a major advantage by the very youngest group, by the oldest officers, by nurse administrators, Army Health Service nurses and obstetrical nurses among MOS groups, by those with the B.S. degree more than by those with other qualifications, and was considered a major disadvantage only by comparable numbers of those nurses without the baccalaureate.

A majority of only one group -- diploma nurses who are also nurse administrators -- said it would be a major advantage to limit direct ANC commissions to licensed registered nurses with a baccalaureate degree. Army Health Service diploma nurses also give a majority vote to the proposal when those who say it would be a minor advantage are also counted. Nurses over 40 years of age tend to see the proposal as more advantageous than do younger nurses, perhaps because the senior nurses feel less likely to be affected.

The proposal to require nurses to acquire the B.S. before a specified cut-off date received a generally similar response, although this proposal has more support among younger nurses and reflects less divergence of opinion among MOS groups than the direct commission proposal. The oldest and the youngest respondents are more likely to agree with the cut-off date proposal; those in their late twenties and thirties are less inclined to see it as an advantage.

The proposal to require any ANC officer desiring to remain on active duty longer than five years to obtain a B.S. degree or show satisfactory coursework toward that end received less negative reaction than the 
preceding proposals, which were similarly designed to encourage Army nurses to acquire the baccalaureate. Positive responses also tended to be moderate. Sixty percent of diploma nurses responded positively to the proposal for a five year cutoff to acquire the baccalaureate; $30 \%$ said it would be a disadvantage, and $10 \%$ said it was unimportant. Among all the proposals designed to encourage acquisition of the B.S. degree, the five year cutoff proposal received the greatest number of positive responses from diploma nurses.

Regardless of whether they have already taken courses toward a degree, nurses agree that it would be a major advantage to assign ANC officers where they could attend civilian schools part-time in order to complete the baccalaureate. Support is not affected appreciably by years of active federal military service. However, those with 12 to 24 years service are slightly more in favor of the proposal. Degree nurses see it as somewhat less of an advantage than do nurses without the B.S. The number of credits already earmed appears to have almost no effect on the level of support.

ANC officers who received direct appointments were most likely to say the proposal to eliminate subsidized education and to procure nurses by direct appointment would be a major advantage. Opinion was more divided among officers from other programs of entry, more officers responding that the proposal is a disadvantage than an advantage, and the "unimportant" category received more answers than any other.

There is a slight trend for those who have earned credits toward a degree, and who will or might remain in the service, to say that granting leave without pay to nurses who wish to attend school would be advantageous. 
The fewer credits officers have already earned, the greater merit they see to the proposal, but this trend is also slight.

Senior nurses are more likely to say they strongly disapprove of the proposal to appoint two-year junior college associate degree graduates as warrant officers in the ANC than are their younger colleagues, and women are more inclined to disapprove than men among senior officers. Only scattered and slight variations occur among MOS groups in responding to the proposed warrant officer appointment. Nurse administrators, Army Health Service nurses, and medical-surgical nurses are most opposed.

The alternative proposal to appoint such graduates to the ANC as second lieutenants is most strongly disapproved by the nurse administrators, and most intensely by male but not female second lieutenants. Although, if the "strongly disapprove" and "disapprove" categories are combined, the general percentages are the same for both sexes. There is apparently no difference between the attitudes of diploma nurses and others.

The appointment of hospital diploma school graduate nurses as warrant officers in the Army Nurse Corps is generally opposed by the Corps, although Army Health Service nurses tend to include a larger proportion who approve, followed by first year, general duty nurses. Male second lieutenants strongly disapprove, as do both male and female lieutenant colonels, in comparison to the remaining grades.

Responses to proposals pertaining to educational qualifications and grade of appointments indicate that advanced clinical preparation and continuing education are more important to nurses on active duty than 
educational qualifications for entry (unless the officer is in a group threatened by one of the proposals). About $86 \%$ of the Corps indicated an active-interest in attending advanced clinical courses in nursing specialties (Table 3-3). About 2,000 of the 3,481 nurses have or are working on baccalaureate degrees; 1,084 took courses within the past five years. Approximately 1,875 nurses have a Bachelor degree in nursing, and another 150 nurses have Bachelor degrees in fields other than nursing. There are 400 nurses who have or are working on advanced degrees.

\section{7.) Role Relations}

Professional roles and reactions to proposals for change obviously touch on professionalism and professional status perceptions. Responses to proposals in this area are not clearcut measures of professionalism, but they are indicators of professional perceptions.

Training enlisted personnel to become physicians assistants in the Army is unaffected by differences in ANC educational qualifications, is slightly more favored by women than by male nurses, and supported more by specialist MOS's than by generalists, with the major exception of first year, general duty nurses. Except for the youngest group support for physicians assistants varies little among different ages. When compared to two other attitude questions about physicians assistants (orders from physicians assistants to nurses and assigning to physicians assistants procedures previously done by physicians themselves), negative reactions are consistent in each case. However, it is interesting that those nurses who say they like the expanded role of the Army nurse are also most likely to approve of the role of the physicians assistants. The proposal to appoint physicians 


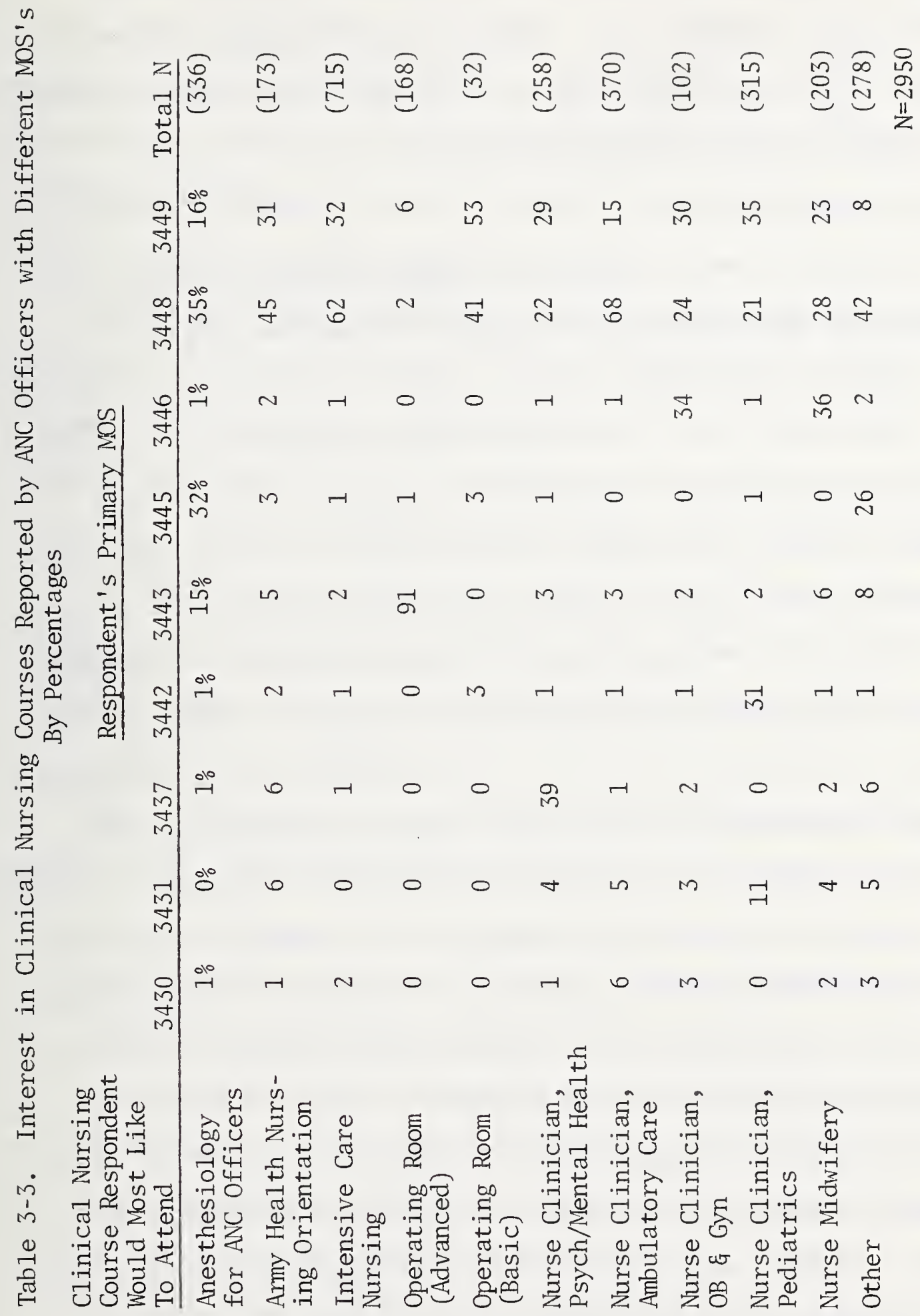


assistants as warrant officers in the Army receives a nearly identical pattern of support and opposition. However, the percentages in favor of the warrant officer appointment tend to be slightly lower across the board than the proposal to train them for the role.

On the proposition that the authority of the Selective Service Act should be extended to permit drafting any group of persons whose skills are essential to the national health, safety and interest, the Corps is divided: $44 \%$ for, $32 \%$ against, and $24 \%$ say that the proposal is unimportant to them. Nurse administrators and anesthetists are most likely to adhere to the proposal, followed by neuropsychiatric nurses. First year, general duty nurses are least enthusiastic about the idea (only 19\% approve). In summary, nurses tend to support all proposals that accrue to their benefit, and to endorse them more enthusiastically when the proposal strikes at basic economic and professional interests and touches on the rectification of inequities that affect them personally. They value educational opportunity more than enforced education standards. Women nurses are more responsive to inequities and hardships among their colleagues than are the men, and those who are either in their twenties or 40 years of age and older are more responsive to the needs of other nurses than are those in their thirties. The nurse administrator is the only respondent that typically considers proposals in the light of scarce resources and options; the anesthetist is least likely to identify with the Corps as a whole, as is the older male officer, who dominates this MOS field. The older nurses often see the emphasis on the B.S. as discriminatory, although nurse administrators tend to support more strongly the proposals to encourage the B.S. degree. 
The next section discusses responses to general topics on aspects of Army nursing, many of which are related to the proposals just considered as well as to the principal themes: Professionalism; military life and institutions; inequities based on sex and marital status; and pay, allowances and benefits.

\subsubsection{Aspects of Army Nursing}

This subsection reviews responses to one hundred and two statements on various aspects of Army nursing. The statements include a broader range of items than the proposals just discussed.

Half of the 102 statements are positive, worded in support of the Army, AMEDD, and so forth, or supporting the status quo. The other 51 are phrased negatively, critical of some aspect of Army nursing. Positive and negative statements are divided as evenly as possible under each subtopic. The words like "complaint" or "support" in the remainder of this section should be interpreted in this context.

Opinions expressed by ANC officers will be related to three characteristics: A composite demographic profile (age: to 28/29 and over; sex; dependents/no dependents); a composite military profile variable (less than/ over three and one half years commissioned service; RA/RES; and a statement of how the respondent feels about choosing an Army nursing career. Responses are on a five point scale: "Strongly agree," "agree," "no opinion," "disagree," and "strongly disagree." Two additional options, not on the scale and not included in the analysis, were given in the questionnaire: "I don't care" and "does not apply." 
A brief explanation of the three compound independent variables will help the reader to understand the responses. The demographic variable combines three measures, and the military profile variable contains two. Each measure was dichotomized to simplify its incorporation into a compound variable. For the demographic variable, age was cut between 28 and 29 years to approximate the line between junior and senior captains. This cut was believed to provide a division in work experience and responsibility. In the military profile variable, commissioned service was dichotomized at three years to approximate the completion of one obligated tour. The categories were designed so that the youngest group included virtually all officers still in their first tour of duty.

The third variable is the nurses' feelings about staying in the Army Nurse Corps. These feelings are probably overstated in the direction of leaving. The question emphasized that respondents were in no way committed to their answers, and the question was probably used by some officers to "let off steam." The margin of overstatement is not known, and can only be ascertained by comparing actual attrition rates from separation files with the data reported here.

The 102 attitudinal questions are discussed under the following seventeen topical subsets.

1) Military Life and Institutions

These measures are among those that most strongly reflect the conflict between nursing professionalism and the military setting. Approximately $70 \%$ of the nurses agree that nursing questions are settled on the basis of rank rather than professional knowledge, with approximately $12 \%$ more of the officers under age 28 agreeing with the statement than those 29 and over. 
Reserves are more inclined to agree with the statement than Regular Army officers serving beyond their first tour. A majority in every category tends to agree with the statement; 58\% of those who will definitely stay say they are bothered by this conflict between rank and professional knowledge, while $78 \%$ of those who will definitely leave take this position (Figure 3-7).

A statement asserting that upper echelons are responsive to the needs of the individual officer received an interesting response pattern, comparing ANC age and sex groups. Disagreeing most strongly that upper echelons are responsive are the older male nurses with no dependents (74\%) and the younger females with dependents $(73 \%)$. Those least critical of upper echelon responsiveness, but still critical in the majority, are the older female nurses with dependents $(51 \%)$ and with no dependents $(57 \%)$. Further, the Regular Army officer, young or old, is less inclined than the reserve officer to rate upper echelons unresponsive. And, not surprisingly, the difference between those who strongly disagree and moderately disagree with the statement is reflected between nurses who will definitely leave and who will definitely stay in the Army Nurse Corps ( $81 \%$ to $54 \%$ ).

A pattern comparable to that just described surfaces throughout this and remaining topics that have to do with general aspects of military life, institutions, regimentation, uniforms, etc. Two points should be made to further qualify this general pattern. First tour Regular Army officers are atypical of their age group in that they tend to react more cautiously to statements reflecting on the Army as an institution, and on rank, authority and so forth. Second, there is a large group of first tour younger officers comprising almost half of the corps -- approximately 
How Irmy Nurses Feal About Staying or Loaving Related to Whather They Agree That Nursing Quastions Are Settlad by Raan Instaad of Professional Knowladge

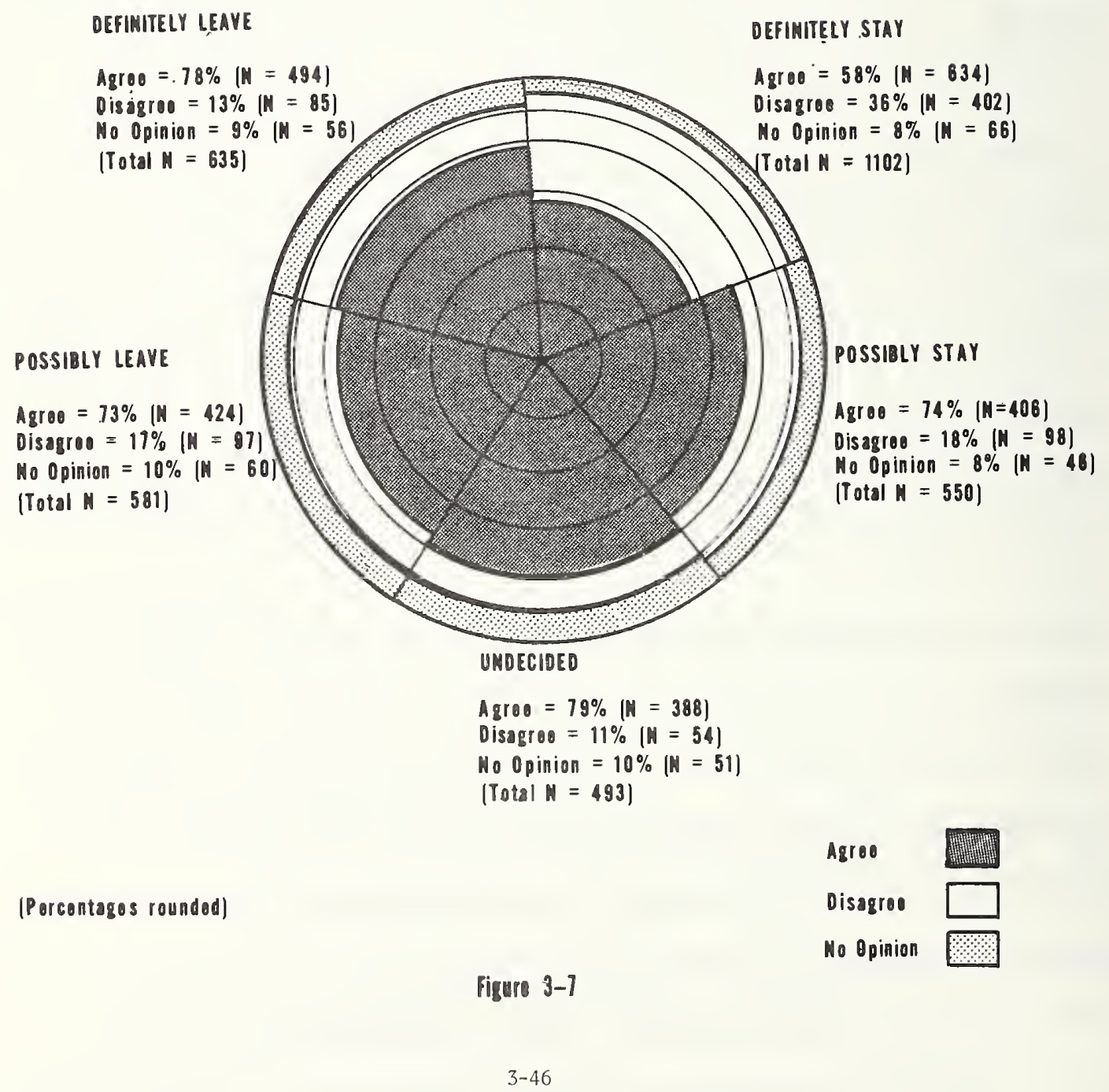


1700 responses - - who tend to react more negatively toward the Army and Army nursing than the rest of the corps. They are also predominant in the groups that say they will definitely leave, possibly leave, or are undecided about remaining for a full career.

The majority of the Corps, by approximately 75\%, finds mandatory social activities unattractive or irritating; they see human dignity and personal privacy suffering in the military. The older women, however, include a strong minority of approximately 20 to $22 \%$ who feel the Army is misinterpreted on the matter of human dignity.

2) Administration-Staffing-Equipment

Items concerning hospital administration, staffing, and equipment tend to relate to a mix of organizational values and nursing professionalism. By a margin of approximately $47 \%$ to $38 \%$ the nurses feel that the administration of Army hospitals is generally competent. However, $73 \%$ feel that hospital administration is not generally responsive to patient needs. Again, the most noticeable spread is between regular and reserve officers, and between those who say they are definitely leaving the Army and those who are definitely staying.

Fifty-six percent of all nurses disagreed with the statement that the number of Army Nurse Corps officers in their organization is adequate. Older male nurses are the only group who tip toward the opposite point of view (44\%); and those whose responses indicate the strongest disagreement with the assertion of adequate Army Nurse Corps officers in their organization are the younger female nurses (63\%). The younger Regular Army officers disagree most strongly with the statement that the number of Army nurses is adequate. Their position here is that there should be proportionately more Army and fewer civilian nurses. 
When responding to a statement on the ratio of military to civilian nurses, the older reserve officers at $86 \%$ assert most strongly that the Army Hospital staff should be more Army Nurse Corps and less civilian. Four fifths of the Corps takes this position, with variations on either side of that figure ruming to less than $10 \%$

Approximately $60 \%$ of the nurses do not feel that there are adequate enlisted nursing personnel in their medical activity. There is little variation among groups on this question, although the older officers do tend to include a small but significant group who feel that there are adequate enlisted nursing personnel. Reserve officers show less concern than the Regular Army nurse about the number of enlisted nursing staff, but again the margin of difference is relatively slight. No important difference emerges in a judgment on the adequacy of enlisted nursing personnel when those who are leaving are compared with those staying.

Forty nine percent of the nurses agree that Army medical facilities are often obsolete, compared to forty-one percent who disagree. The older male officers are most prone to say facilities are obsolete. Little difference shows up when contrasting Regular Army with reserve, or young with old officers on this question. Nor is there a meaningful difference when contrasting those who are definitely leaving with those definitely staying. There is a slightly greater tendency among those who will probably stay in the Army to disagree that facilities are obsolete, but this group ranges only from 11 to $15 \%$ higher than those who will probably leave.

In reponse to an assertion that the equipment in Army Hospitals makes Army nursing satisfying, there is a dispersal of opinion rumning from approximately $10 \%$ who strongly disagree to approximately $16 \%$ who strongly 
agree. The largest proportion of the Corps agrees (37\%); next are those who disagree $(28 \%)$; and $9 \%$ expressed no opinion. Examining the Military profile gives slightly different results. The younger RA officer and the older RA and reserve officer tend to agree, in a range of 60 to $66 \% ; 42 \%$ of young reserves agree, and those who strongly agree are less than half of any other category. There is also a strong positive relation between those remaining in the service and those agreeing that equipment in Army Hospitals makes nursing satisfying. Only $34 \%$ of those definitely leaving agree with this positive appraisal while $70 \%$ of those definitely staying agree.

\section{3) Military Discipline and Uniforms}

Again, these items constitute direct measures of military professional values vis-a-vis those of the nursing profession. Seventy-five percent of the Corps disagrees with the statement that the military system of rank, seniority, and command is the best way of insuring that those with the best professional experience and competence will be given responsibility. The group most likely to agree with the statement are the older women; the younger women are least likely to endorse the military system of rank, seniority, and command. Though very few strongly agree with the statement, an interesting contrast does emerge in the more moderate "agree" category. The young RA officer appears to be the staunchest advocate of the military system; the young reserve is its greatest critic. Not surprisingly, those who are definitely leaving have a stronger tendency to criticize the military system. However, of those definitely staying 63\% are also critical. 
Reactions are more moderate to the statement that military discipline is out of place in a professional environment. Fifty percent of the Corps disagrees with that statement, including about $71 \%$ of the older women, and $32 \%$ of the younger female officers, the lowest figure. Only $18 \%$ strongly agree that military discipline is out of place, and the younger female officers and most numerous among these at $25 \%$, compared to under $10 \%$ of the older women. Young reserve officers are most critical of military discipline in the professional environment, and older RA officers are the most supportive.

Possibly in partial justification of the career decision they have taken, those who are definitely leaving are by far the most critical of military discipline in the hospital environment. Three quarters of those definitely leaving feel military discipline is out of place in an Army hospital, and only $20 \%$ disagree.

Interestingly, only one third of the younger reserve officers agree that military discipline is necessary to insure a high quality of nursing care, compared to two thirds of the older reserves. In one of the several instances in which the proportions differ noticeably, the younger woman with dependents is more inclined to agree that military discipline is necessary to good care than is the younger woman with no dependents. At $67 \%$ and $75 \%$ respectively, the older male and female officers with dependents are most in agreement with the statement that military discipline is necessary to good care.

The corps is divided as to whether regimentation is out of place in today's Army: 43\% say it is and 48\% say regimentation is not out of place. 
Only among the younger female officers, overwhelmingly reserves, does a clear majority agree with the statement. Over $50 \%$ of all of the other groups disagree.

The percentages contrast sharply in relation to the question about how the nurses feel about an Army career. Of those definitely staying only $24 \%$ agree that regimentation is out of place, while $65 \%$ of those definitely leaving are in agreement. Of those possibly leaving $57 \%$ agree, and the undecided group agrees at just a shade under $50 \%$, with $13 \%$ expressing no opinion and $37 \%$ disagreeing.

The older nurses, especially the women, are more inclined to feel that Arny Nurse Corps uniforms are below standards. The Corps as a whole is divided on the statement in a ratio of 51 to $42 \%$. The young reserve officer, who most frequently doesn't expect to wear the uniform long, is least critical of the uniform.

With respect to wearing the uniform, the distribution of responses shifts: $66 \%$ of the nurses agree that headgear should be required only in military formations; $53 \%$ disagree that the white cap should always be worn with the white hospital uniform by female nurses.

\section{4) Quality of Care - Competence}

Professional standards of care in the Army receive generally high marks. Sixty-nine percent agree that the quality of patient care in their organization is generally good; $24 \%$ disagree. Although a majority of no group disagrees with the statement, the young RA officers break their usual pattern of moderation, $29 \%$ disagreeing in this case. Only 21\% of young reserves disagree, compared to $18 \%$ of older reserves, and $14 \%$ of the older RA's. The endorsement of those definitely leaving the Army 
is weaker at $56 \%$ than is that of those definitely staying at $78 \%$.

A majority of the Corps believes that the reputation of nursing service is good in their organization. The figures range from approximately $55 \%$ among the younger women to $75 \%$ among the senior women. By a very slight margin, younger reserve officers are more likely to respond that the reputation of Nursing Services is not good. And a pattern reemerges in which those definitely leaving are most critical -- 35\% of those definitely leaving are critical of Nursing Services' reputation.

Most Army nurses (78\%) agree that in their experience the quality of Army nursing care is very good. The figures range from $65 \%$ for younger women with dependents to $90 \%$ for the older women with dependents. However, those leaving the service are more moderate in their endorsement of the quality of Army nursing care; on 1y 55\% agree that it is excellent.

In response to a statement that the prestige of the Army Medical Department is 10w, 55\% of the respondents disagree and only $29 \%$ agree. Interestingly, the group that was proportionately most willing to agree that the prestige of the Army Medical Department is low were the older single male officers. At $37 \%$, they contrast with the young single males, among whom only $24 \%$ agreed with the statement. A majority of no group agreed with the criticism. Even among those definitely leaving only 33\% agreed with the low estimate of Army Medical Department prestige.

On the whole, however, the Army Nurse Corps does not agree that the Army Health Team esprit de corps is excellent. Only 35\% agree that it is, while $57 \%$ disagree. Only the older women with dependents, at 55\%, agree that the esprit de corp is high. While 45\% of the older Regular Army nurses 
believe that the Army Health Team esprit is excellent, only $22 \%$ of the younger RA officers agree. Three-quarters of those definitely leaving the service disagree, compared to $46 \%$ of those definitely staying. This is probably a reflection of their decision as much as the judgment influencing their decision.

The young single male Army nurse is least complimentary to his colleagues. A majority of each category agrees with the statement that they are impressed by the competence of fellow ANC officers. However, only $53 \%$ of single young men agree with this endorsement; the older single male at $73 \%$ and older RA's at $72 \%$ are most complimentary. There is only a slight difference between those definitely leaving the service and those possibly leaving. Those definitely staying register the best opinion of their fellow ANC officers' competence.

Seventy-nine percent of the older female nurses are impressed by subordinate ANC officers: on $1 y$ $61 \%$ of the younger single male officers and sixty percent of the young RA's are impressed by subordinate officers. However, $82 \%$ of the older RA officers agree with the endorsement of subordinates. The contrast between younger and older reserves is slightly less. Of those definitely leaving $61 \%$ say they are impressed by subordinate officers while among those definitely staying the figure rises to $81 \%$.

Half of the nurses disagreed with the statement that they were, individually, more competent than their supervisors. Only $28 \%$ agreed with the statement, $21 \%$ expressing no opinion. There is little variation among groups. Interestingly, there is no difference on this point between those definitely leaving and definitely staying. 
5) Professional Role and Relations

This set of items relates to the status of the nursing profession. Sixty-four percent of Army Nurse Corps officers like the expanded role of the Army nurse, $17 \%$ do not, and 19\% expressed no opinion. The young RES officer reflects slightly less interest, and those definitely leaving the Army express even less, but even among them the majority approves of the expanded role of the Army nurse by 3 to 2 .

Four out of every five officers say that they like the responsibility for assuming medical procedures previously performed only by doctors in an expanded role. Those apparently most enthusiastic are the young male officers; older women are least enthusiastic. Nevertheless, the percentages in those two cases are $81 \%$ and $58 \%$ respectively - a positive majority in all cases. The young ANC reserve is most enthusiastic (when we compare reserve and regular, and separate first tour and longer service categories). This is one of the very few cases in which the distribution does not reflect very high correlation between those definitely leaving and the young reservists. Those possibly leaving, agreeing at $75 \%$, constitute the largest group. This may indicate that this issue has some appeal for retention. (Figure 3-8)

The older male officer with dependents experiences the least frustration between what he was trained to do and what he actually does. He also tends to be a diploma nurse who has entered either the nurse anesthetist or neuropsychiatric nursing fields. The younger female nurses are most frustrated by this problem. The Corps as a whole is divided on the issue: $52 \%$ not bothered compared to $44 \%$ who are frustrated. Of older males with dependents, only $24 \%$ agree with the complaint. On the other hand, younger 
How Army Murses Feel About Staying or Leaving Related to Agreement with Assuming Responsibility for Additional Medical Procedures

\section{DEFINITELY LEAYE}
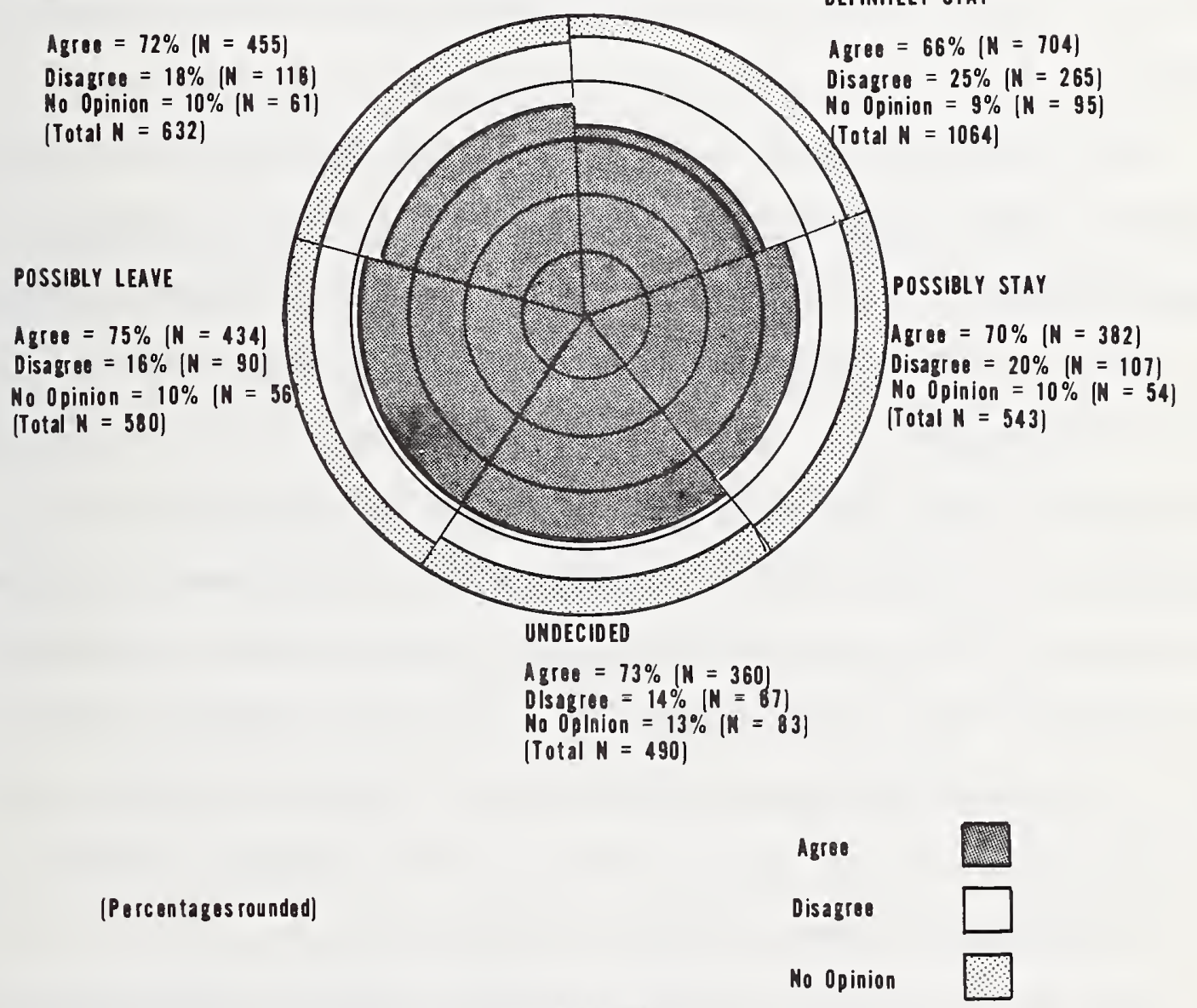

Figure 3-8 
women with dependents agree $59 \%$ of the time. The older Regular Army officer disagrees with the complaint $70 \%$ of the time, compared to the young reserves, of whom $39 \%$ disagree. Forty percent of the young RA's agree with the complaint compared to only $27 \%$ of the older Regular Army officers. The complaint is also positively related with those who are definitely leaving the service although the responses are not overwhelmingly critical among that group. Two thirds of the Corps apparently feel that their assignment utilizes their skills; $30 \%$ say it does not. Variations among groups are relatively meaningless on this question.

Three-fourths of the nurses disagree with the allegation that enlisted men carry out patient care activities that should be done by registered nurses. No group varies from this opinion, although slightly fewer among the young single male nurses take this position than do those in other categories. Only 25\% of the Corps say they do not like assigning physicians assistants to do procedures previously done by physicians, $52 \%$ disagree with that statement and $22 \%$ expressed no opinion. Although only $17 \%$ of the younger females say they don't like the physician assistant's role, approximately $31 \%$ of the older women take this position. Other groups range between the two. However, the young Regular Army officers tend to agree with the older officers; only the young reserves fall in the $17 \%$ range, the figure for that group who are definitely leaving, while the $31 \%$ range holds for those definitely staying. 
In reaction to the statement that orders by physicians assistants would not be acceptable, $40 \%$ of the nurses agree with that statement, $26 \%$ expressed no opinion, and $33 \%$ disagree. The younger single female officer at $30 \%$ is least likely to resent orders by physicians assistants. The older single male officer is most likely to resent them (55\%). About the same difference holds between young reserves at $31 \%$ and old RA's at $53 \%$. Those staying would resent orders by physicians assistants in approximately $50 \%$ of the cases while those definitely leaving would resent them in only $32 \%$ of the cases.

Responses to a set of questions about working relations among ANC officers and with other groups in the Army Medical Department (DA civilian RN's, physicians, enlisted, and other AMEDD Groups) indicated that nurse administrators (3430) are more likely than other MOS groups to say relations are excellent or very good, and neuropsychiatric nurses (3437) are least likely to say so. Army Health Service nurses (3431) usually agreed with the positions taken by psychiatric nurses, that is, relatively less positive about relations among various AMEDD groups. However, nurse administrators change their position with respect to physicians. Only the Army Health Service nurse rated ANC relations with physicians lower than did the nurse administrators. The latter group, as noted, rated the relationships between Army nurses and with all other groups but physicians highest among the MOS groups.

6) Assignment - Location and Facility

Sixty-nine percent of the Corps are satisfied with their present location. Seventy-one percent like their present facility. No important variation occurs among subgroups. Only 18\% say that their assignments 
have been disappointing. Again, there is little variation among groups. The single young male officer, $31 \%$, is a little less satisfied with his assignments than the older single male or the older RA officer in general - in each case approximately $10 \%$ expressing dissatisfaction.

Three quarters of the Corps say they would like more stability in assignments. Although there is not much variation, male officers with dependents are a little stronger in their desire for stability in assignments than other groups. The issue has no apparent relation to the decision to stay or leave.

Eighty three percent of the Corps say they like to travel. The younger male officer with dependents is a little less enthusiastic -only $72 \%$. It does appear to make some difference to those who are definitely staying compared to those definitely leaving the Army Nurse Corps; $93 \%$ of those staying like the opportunities for travel, but only $58 \%$ of those definitely leaving take the same position.

About one-third of the Corps says that working overseas is a difficult experience for them, compared to $61 \%$ who disagree with that statement. Forty percent of those in the Pacific agree that it is difficult, but only 23\% of those in Europe express difficulty. Again, the young male officer with dependents has the most difficulty (58\%), while the older women with no dependents have the least difficulty $(14 \%)$. The younger the officer, the fewer years commissioned service, and the fewer PCS's, the more likely is the response to express difficulty with overseas assignments. The young reserves at $39 \%$ tend to have more difficulty than other groups. About half of those definitely leaving the service agree that working overseas is 
difficult, but only one-fourth of those definitely staying agree with this position. The question was not asked directly, but it can be inferred from other responses that those who have never served overseas were more likely to agree that serving overseas would be difficult. 7) Career Advancement

This set of responses appears to indicate that it is not the lack of nursing experience and challenge that fails to appeal to a nurses's professional and career interests, but the military system of career advancement. The Corps overwhelmingly agrees that Army nursing allows them to work as responsible professionals ( $87 \%$ agree, $10 \%$ disagree). Little variation occurs among groups, although the older and Regular Army officer is most inclined to agree with this statement. Those definitely leaving the service agree to a slightly lesser extent.

Seventy percent of the Corps disagree with the statement that professional accomplishment is limited in the Army. The greatest contrast in opinion on questions of professionalism is between the older women at approximately $18 \%$ and the younger women with dependents, of whom $35 \%$ say that professional accomplishment is limited in the Army Nurse Corps. Approximately the same contrast exists between older Regular Army officers $(13 \%)$ and young reserves $(32 \%)$. Only $15 \%$ of those definitely staying in the Army feel this limitation, while $38^{\circ}$ of those definitely leaving express dissatisfaction.

Three quarters of the respondents agree that the Army gives them an opportunity in their specialty, the highest proportion being the older male officers, probably influenced by the proportion of these who are 
anesthetists and psychiatric nurses. Although still in the majority in their subgroup, only $58 \%$ of the younger women with dependents say they have an opportunity in their specialty, and the younger males with no dependents $(61 \%)$, are next lowest. And while only $55 \%$ of those definitely leaving say the Army gives them opportunity in their specialty, $90 \%$ of those staying say so.

The majority of the Corps, $54 \%$, feel you can get ahead faster in military than civilian nursing. Only $45 \%$ of the young single male officers agree with this statement, but $67 \%$ of the older female officers with dependents agree. The younger reserve officer is less inclined to agree $(46 \%)$, and those who are definitely leaving the Army (27\%) are less likely to agree than those who are definitely staying, of whom $66 \%$ feel they can get ahead faster in the military.

Only the younger women express appreciable reservations about their ability to assume the next higher grade. Four out of every five Army nurses feel they are capable of assuming the next higher grade, but only two-thirds of the younger women do. Considering the general division between younger and older officers, the differences in confidence between those definitely leaving and definitely staying reveals nothing unexpected.

Three quarters of the nurses say that promotions are not made on the basis of professional competence. The strongest minority on this point is among older women with dependents, of whom $36 \%$ disagree with the statement. The greatest contrast occurs between those definitely staying, of whom $64 \%$ agree, and those definitely leaving, of whom $83 \%$ say promotion is not based on professional competence. 
8) Job Satisfaction

Job satisfaction is apparently a more pedestrian reflection of basic reactions to nursing in a military setting. Only $24 \%$ of the respondents say they do not 1ike their present job; $72 \%$ disagree with that statement. There is little variation between older and younger officers, or between Regular Army and reserve - less than $10 \%$. However, while only $17 \%$ of those who will definitely stay in the Army Nurse Corps do not like their present job, 39\% of those definitely leaving say they dislike it.

The figures are almost identical in response to the general statement that job satisfaction in the Army Nurse Corps is high. Three-fourths agree with the statement and $18 \%$ disagree. There is approximately a $20 \%$ spread between the younger males and the older male and female officers approximately $66 \%$ to a range of 86 to $90 \%$. The young reserve is again least inclined to say job satisfaction in the Army Nurse Corps is high, $63 \%$ taking this position, whereas all other groups are over $80 \%$. The figure becomes even lower for those who are definitely leaving the service $(48 \%)$. They are the only group among whom less than $50 \%$ say job satisfaction is high. Of those definitely staying, on the other hand, $93 \%$ say job satisfaction in the Army Nurse Corps is high.

Direct support to the nurse's patients is an important element of job satisfaction: $98 \%$ agree with this statement, $85 \%$ strongly, one percent expressed no opinion, and one percent disagree. Four out of five nurses say they like the challenge in their work. There is only a moderate variation among age groups: approximately $75 \%$ in the younger age group to over $90 \%$ in the older. Even among those who are definitely leaving, 
$65 \%$ say they like the challenge in their work; $92 \%$ of those definitely staying say so.

The nurses also say they have opportunities to use their own initiative in the Army Nurse Corps. Again the spread from younger males with no dependents and young women with dependents, each approximately $70 \%$, and older nurses, $90 \%$, is a difference of approximately $20 \%$ And the young reserve, just under $75 \%$, makes the difference. The figure drops to $\underline{64 \%}$ for those who are definitely leaving the service, compared to $\underline{92 \%}$ for those definitely staying.

Knowing what is expected of them makes their work more satisfying for $75 \%$ of the nurses, with disagreement from only $17 \%$. A small range of $10 \%$ from the younger married women to the older married nurses is the only variation among demographic groups. However, the young RA responds positively to the statement, at $95 \%$ in contrast to $69 \%$ among the young reserves. Those definitely leaving find satisfaction in knowing what is expected of them at only the $58 \%$ level while those definitely staying answer at $85 \%$.

In response to the statement that "I came into the Army to take care of the Military and not civilians or dependents," $73 \%$ of the Corps disagree ( $42 \%$ strongly), $21 \%$ agree with the statement while $6 \%$ expressed no opinion. There is a slightly greater proportion of those who will possibly or definitely stay to agree with the statement ( $26 \%$ and $24 \%$ ) than there is among those who are leaving or undecided (approximately $17 \%$ to $19 \%$ ).

Orientation to their duty station was good for $58 \%$ of the nurses, while $38 \%$ said it was not good. No important variation shows up when looking at other variables. Sixty percent of the nurses say that orientation for their duty position was good. In this case $37 \%$ disagree. And 
again, the only noteworthy variation is a slightly greater tendency among those definitely leaving the service to be critical.

9) Education and Training

Professional education and advanced clinical preparation are issues vital to the Corps and the individual officer. Seventy-seven percent of the Corps feel they are well prepared for their present job; $20 \%$ disagree. There is a range of approximately $10 \%$ from the younger women to the older males, with the most marked difference being the degree of confidence expressed by younger males compared to young women. This is again reflected in a slightly lower figure for young reserves, most of whom say they will definitely leave the Army.

The Corps is almost evenly divided on the proposition that advancement depends too much on formal education. Approximately 43\% agree with the statement while $47 \%$ disagree and $10 \%$ express no opinion. Only $30 \%$ of the young Regular Army officers say advancement depends too much on formal education, while $55 \%$ of older reserves and $42 \%$ of the older Regular Army officers agree. A slightly lower proportion (37\%) of young reserves agree. Those definitely leaving the Army are only slightly more likely to complain about the emphasis on formal education (41\%) than the younger officers as a whole. This does not appear to be an important reason for leaving the service, although it does tend to influence slightly a minority of diploma nurses. Details are graphically displayed in Figure 3-9.

About half $(49 \%)$ of the nurses believe that in-service education at their duty station is limited, while $43 \%$ feel no such limitation. The 


\section{AMC Fodinge as to whather Advancoment Depends Too Much on Forme Edycation Rolated to Staying or Loaving}

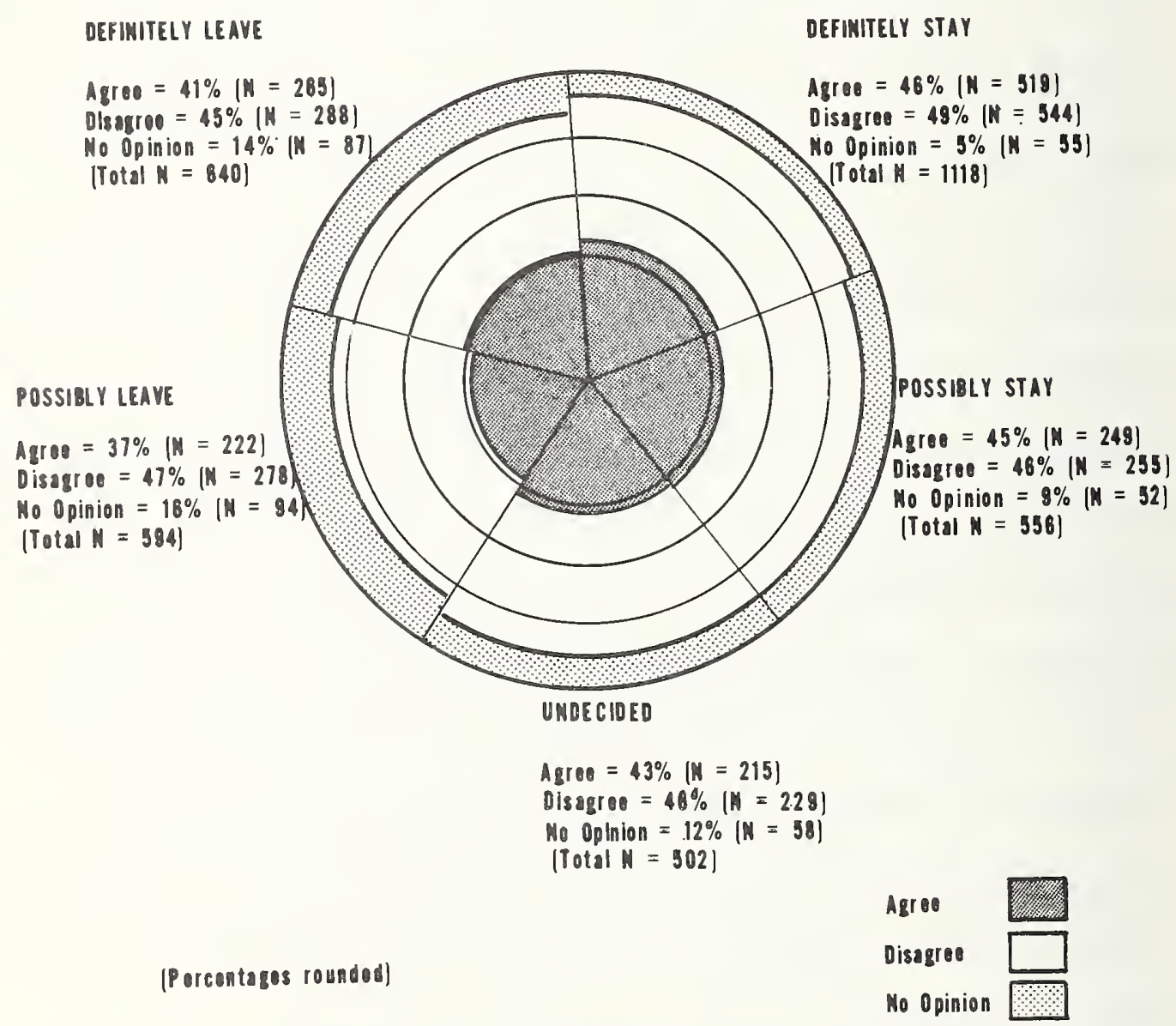

Figure $3-9$ 
percentages run from $60 \%$ among younger single males to $40 \%$ among the older women. No great difference emerges between regulars and reserves, and only a slightly greater proportion of those definitely leaving the service express dissatisfaction with in-service education limitations at their duty station.

By $58 \%$ to $32 \%$ the nurses agree that shift schedules make it difficult to obtain further education. Only $48 \%$ of the older reserves agree with this statement, compared to $63 \%$ of young reserves. Sixty-five percent of those definitely leaving say shift schedules are a problem for obtaining further education, and $50 \%$ of those definitely staying say the same.

However, $66 \%$ of the nurses disagree with the statement that further educational opportunities are limited for an ANC officer. Only $28 \%$ agree with that statement. The biggest spread in opinion, though not very great, is between the older Regular Army and reserve officers: RA 23\%, RES $32 \%$. More than one-third, (36\%) of those definitely leaving express the limitation, supported by $21 \%$ of those who intend to remain in the ANC.

Greater contrast is shown in response to the more positive statement of the issue: formal educational opportumities are better in the Army Nurse Corps than in civilian life. There is a slightly greater spread between the $29 \%$ definitely leaving who agree with this statement and the $52 \%$ definitely staying who feel that formal educational opportunities are better in the military.

10) Authority and Responsibility

Military authority and professional responsibility join in this set of responses. Sixty-two percent of the nurses disagree with the statement that because they cannot be commanding officers, Army nurses cannot really 
assume the responsibility and leadership role that they should. Only $27 \%$ agree, with $11 \%$ expressing no opinion. Young reserves are least inclined to agree that the nurse's leadership role is limited, supported by those definitely or possibly leaving the Corps. Those staying are slightly more inclined to feel that the leadership role of the nurse is limited.

The Corps is evenly divided as to whether the authority they have is too little. Older reserve officers are most likely to agree with the statement, while the young Regular Army officer is least inclined to agree. Interestingly, the figures revert to an even split when comparing those who will definitely leave (48\%) with those who will definitely stay $(48 \%)$.

Sixty-five percent of the Corps agrees that their professional responsibilities are superior to those of civilian nurses working at their duty station. About 24\% disagree; $12 \%$ express no opinion. There is relatively little variation by age group, although the spread between young reserves and older RA officers is $57 \%$ to $78 \%$. Similarly, only half of those definitely leaving say their professional responsibilities are superior to those of civilian nurses at the same duty station, while three fourths of those staying feel they are.

In fact, $80 \%$ of the nurses feel they have an opportunity for responsibility in the ANC that is professionally satisfying, while only $15 \%$ disagree with that statement. The small variation of only $10 \%$ spread between younger and older officers suggests this is not an issue among those saying that they will definitely leave the service. Sixtyone percent of those definitely leaving agree with the statement that 
their opportunities for responsibility in the Army Nurse Corps are professionally satisfying. Only $30 \%$ disagree. While the figure is considerably higher $(90 \%)$ for those definitely staying, the range is not excessive given the difference in age, rank and experience.

According to $56 \%$ of the respondents, Army nurses do not have enough opportunities to practice direct patient care. On the other hand, $40 \%$ of the nurses disagree with that judgment. Once more, the biggest disagreement on the issue is between the older Regular Army officers and the young reservists - $42 \%$ to $65 \%$. Only $44 \%$ of those definitely staying believe nurses don't practice enough direct patient care in the Army, while $71 \%$ of those definitely leaving agree with this statement. Figure 3-10 provides visual display of these statistics.

In response to the statement, "I would prefer to be assigned directly to the doctors of an organizational element (OB/GYN, Medicine, Pediatrics, etc.) rather than the Nursing Department or Service," two-thirds of the nurse anesthetists prefer direct assignment to physicians. A correspondingly high positive response comes from a heavily overlapping group, male officers with dependents - both younger and older. However, 60\% of the Corps as a whole disagrees with the proposition. The greatest contrast is between the older women, among whom only $20 \%$ agree with the statement, and the older men with dependents, $51 \%$ of whom agree.

Army nurses are evenly divided, at $45 \%$, on the statement that the lines of authority in the respondent's present organization are effective. The young reserves (37\%) are least inclined to agree with the statement. About $61 \%$ of those definitely leaving disagree with the statement, while $34 \%$ of those definitely staying disagree and $60 \%$ agree. 
Wheterer AMC Officars Agree that They Do Not Have Enough Opportanitios for Direct Pationt Gare Related to How They Feel about Stajing or Leaving

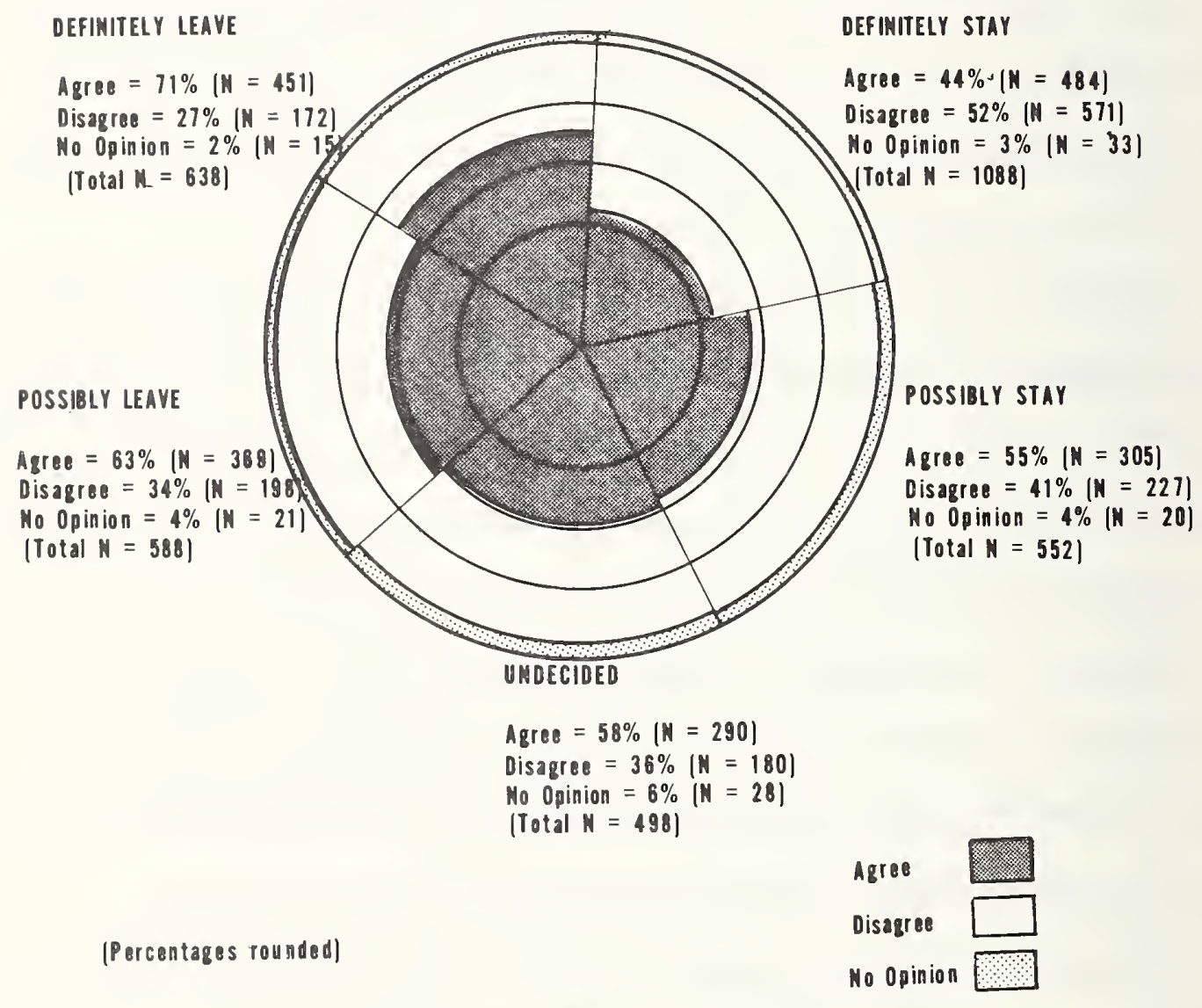

Figure 3-10 
11) Working Conditions

Thirty percent of the Corps say they find working conditions in Army Medical facilities unattractive, while $63 \%$ disagree with that statement. Thirty-six percent of the young reserves say working conditions are unattractive, in contrast to young RA officers, with only $15 \%$ agreeing. The figure rises to $51 \%$ dissatisfaction for those definitely leaving and falls to only $19 \%$ for those definitely staying.

Seventy-one percent of the Corps feel that work schedules are fair; however, $35 \%$ of the young women with dependents disagree with that statement. The greatest contrast is provided by the older males, of whom only $14 \%$ disagree. Young reserves again stand in greatest contrast to both young and old RA officers at $62 \%$ to $85 \%$. And while only $56 \%$ of those definitely leaving the service believe that work schedules are fair, $85 \%$ of those definitely staying believe so.

Two-thirds of the nurses disagree with the statement that the hours they work are more disagreeable than those of civilian RN's. No important variations emerge on this question. However, the single older male officer is a little more inclined to feel that his hours are more disagreeable than those of civilians. The young reserves feel somewhat more dissatisfied than either their older reserve colleagues or the RA officers. The issue is only slightly associated with those definitely leaving the service (35\%) compared to those definitely staying $(20 \%)$.

Irregularity of working hours is a source of dissatisfaction to $56 \%$ of the Corps. Older officers expressed the least dissatisfaction (45\%), while the younger women with dependents agree with the statement in $65 \%$ of the cases. These nurses tend to be young reserves definitely leaving the service. 
While $60 \%$ of the nurses agree that they usually receive compensatory time, $36 \%$ disagree - $20 \%$ of these strongly.

Most nurses $(81 \%$ ) object to being moved from ward to ward without consultation. The issue is expressed a little more frequently, 10\% more of the time, by young reserves than by others. The same $10 \%$ spread exists between those definitely leaving and those definitely staying.

Four out of five nurses like the variety of jobs in the Army, the older nurses a little more than the younger nurses. The difference between those definitely leaving and definitely staying is typical - 66\% to $88 \%$.

\section{2) Efficiency Reports and Promotions}

Virtually all of the Corps (97\%) would like to sign their efficiency reports to prove that they had had an opportunity to read them. No significant variation occurs among different groups. Other items in this set tend to be more relevant to ANC attitudes toward the military personnel rating system.

That rating officers make fair judgments is the opinion of $56 \%$ of the respondents. However, 37\% disagree. Even though $66 \%$ of the older Regular Army officers agree that rating officers make fair judgments, their view is shared by only $50 \%$ of the young reserve officers.

By $57 \%$ to $32 \%$ Army nurses would prefer that their efficiency reports be completed by their supervisors, and not by the doctors with whom they work. Among one group there is an even division: the older males with dependents. This split, at $45 \%$ agree and $45 \%$ disagree, is again probably influenced by the number of nurse anesthetists reponding. 
Only $12 \%$ of the young Regular Army officers agree with the proposal and $68 \%$ disagree. Thirty-nine percent of older reserves agree, $10 \%$ higher than either younger reserves or the older Regular Army officers. A slightly higher percentage among those who will definitely leave the Army Nurse Corps, $38 \%$, also agree with the proposal. However, this figure is only $6 \%$ to $7 \%$ higher than those definitely staying.

Eighty-four percent of the respondents agree that the present system does not contain adequate safeguards against personality conflicts influencing efficiency reports. Younger officers express slightly less concern, and reserves slightly more than RA officers. The issue has no apparent influence on how respondents feel about an Army career. The Corps as a whole is about evenly split in their reactions to the statement that "the more rank Army Nurse Corps officers obtained the more they are concerned with promotion instead of patient care." Forty-two percent agree with the statement while $47 \%$ disagree, with $11 \%$ expressing no opinion. The older women disagree most strongly; of women with dependents, only $22 \%$ agree; of those with no dependents, $29 \%$ agree. Approximately $51 \%$ of the younger women and $60 \%$ of the single young male officers agree with the charge. The comparison of those who will definitely stay (22\%) and those definitely leaving (62\%) is quite dramatic. It is evident that those leaving are much more likely to agree that the more rank ANC officers attain the more they are concerned with promotion instead of patient care. Figure 3-11 provịdes statistical details.

Only 15\% of the Corps agree with the statement that the Army's promotion system is the best way to meet the need for competent officers in higher grades. Seventy percent disagree with that statement, while 
How Ar wy Mursos Foel Abeut Stajing o Leaving

Relatod te Whother They Agree That the More Radic ANC Officers Obtain the Mare They Are Concernod with Premotion instead of Patient Gare

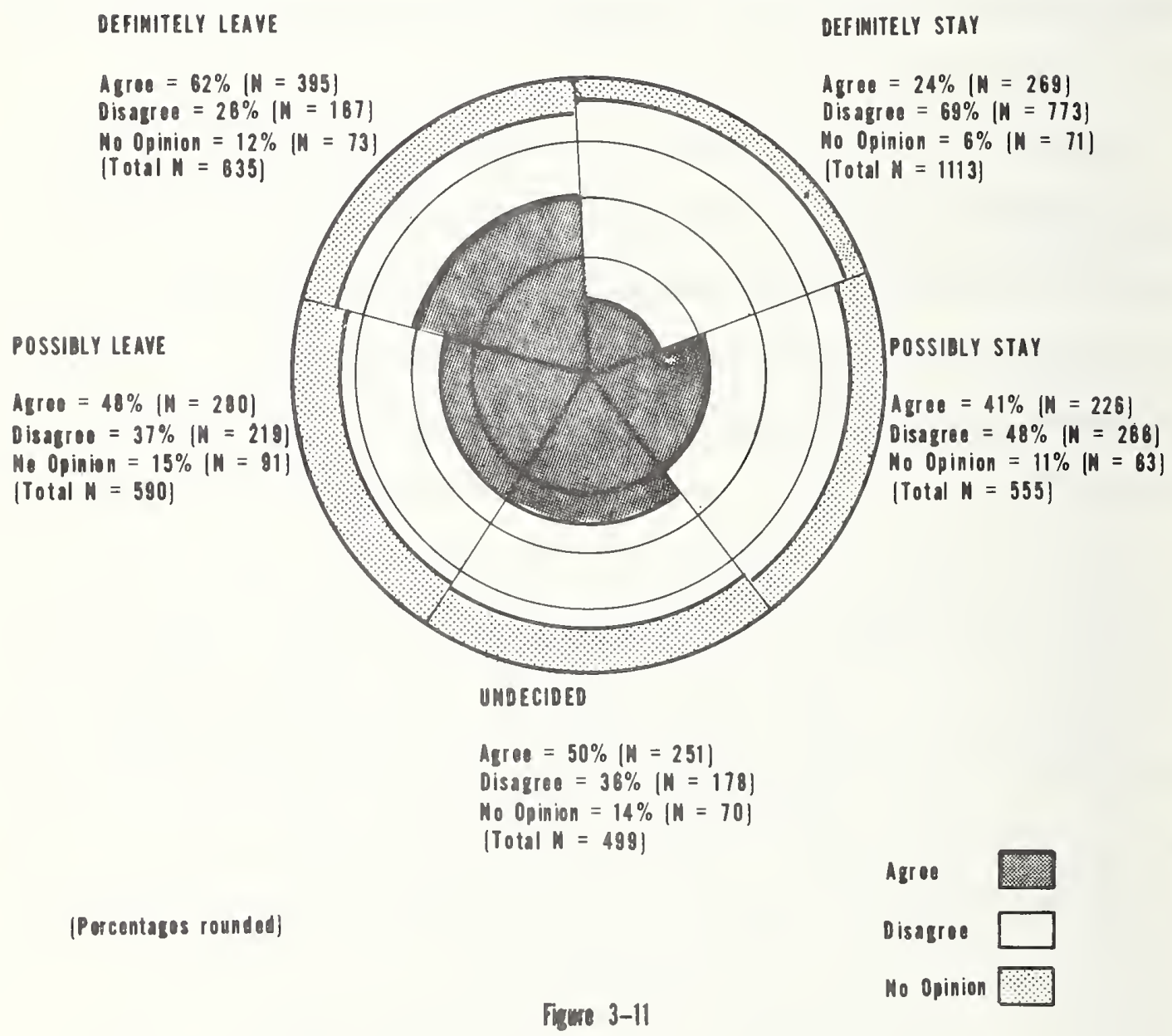


$14 \%$ expressed no opinion. With the single exception of the older women with dependents, there is no more than a $10 \%$ spread between the response patterns of the younger and older nurses, whether they are married or single. Slight differences do emerge among various age groups, with younger offices less inclined than older officers to agree that the current promotion system is the best way to get competent officers in higher grades. The RA's view of the present promotion system is more positive than is that of the reserves. Only 7\% of those definitely leaving support the present promotion system.

Thirty percent of the Corps feel that the present promotion system is fair, compared to $54 \%$ who disagree with that statement; $16 \%$ expressed no opinion. Among the various groups, the older reserve officer is most likely to disagree with the assertion that the present promotion system is fair.

Not withstanding the heavy overlap in three groups, the data concerning how respondents felt about an Army career in relation to the promotion system indicate a high level of correlation between the generally critical views of the system shared among those leaving, the younger groups, and reserves as a group. This correlation is frequentlv reflected in previous comments in this section of the report.

13) Pay, Allowances, and Benefits

An examination of the specific items in the set of attitudinal questions that are concerned with pay, allowances, and benefits, reveals no new information other than that contained in direct response to the relevant personnel policy proposals discussed in Section 3.2, with which they are integrated. 
14) Attitude of Family and Friends

Twenty-eight percent of Army nurses say that friends and family may influence them to leave the service, while $65 \%$ of their associates disagree with that statement. The young male officer (40\%) appears to be most susceptible to this pressure. Older men with no dependents and the older women with dependents are least susceptible, responding in agreement with this statement only about $10 \%$ of the time. Thirty-seven percent of young reserves say that friends and family may influence them to leave, and just over half of those who will definitely leave the service agree with this statement compared to only $10 \%$ of those who will definitely stay.

The families of $91 \%$ of the nurses approve of their being Army nurses. The only group among whom more than $10 \%$ disagree are those who say they will definitely leave the Army. Even in this case, only $14 \%$ say their families do not approve of their serving in the ANC.

Support from friends is a little weaker than from families, but still a clear cut majority for the Corps as a whole and for each subgroup. Three quarters of the Corps say their friends approve of their being an Army nurse and only $14 \%$ disagree with the statement. A mere one-fifth of young reserves and only $29 \%$ of those who way they will definitely leave say their friends do not approve.

Fifty-five percent of the respondents say that civilian attitudes critical of the Army are unjustified. However, $30 \%$ disagree, and $15 \%$ expressed no opinion. Only young reserves are approximately evenly split on the question with $41 \%$ an agreement and $40 \%$ disagreeing. However, 73\% of those definitely staying feel that critical civilian attitudes are unjustified while only $30 \%$ of those definitely leaving agree with them. 
15) Inequities in Allowances and Benefits

The differences in allowances and benefits based on sex, marital status and dependents concern the second major theme of importance to retention of younger nurses. Benefit differences between men and women officers are a source of dissatisfaction with $67 \%$ of the Corps. One fifth expressed no opinion, and $13 \%$ disagree. Almost $80 \%$ of the older women express dissatisfaction with such inequities, but only $32 \%$ of the older men do. Younger married males agree with the older men, but single young men appear to be a little more concerned about the inequities. The level of dissatisfaction is higher among those definitely leaving, among reserves, and among those directly affected - the women. This data is displayed in Figure 3-12.

In reaction to the statement that differences in male and female benefits are a fair reflection of the differences in family responsibility, $62 \%$ of the Corps disagree, $17 \%$ agree, and $21 \%$ expressed no opinion. The greatest contrast is between the younger females with dependents (79\% disagree) and the young men with dependents (34\% disagree). Generally speaking, male nurses show much less concern than females. There is only a slight difference, approximately a $10 \%$ spread, between those definitely staying and definitely leaving the service.

In responding to the statement that married Army nurses who have children are not able to handle all duty and station assignments in either peace time or mobilization, $48 \%$ of the nurses agree, $35 \%$ disagree, and $17 \%$ give no opinion. Sixty-three percent of the older nurses with no dependents agree with this statement, while only $48 \%$ of the older women with dependents agree. The lowest leve1 of agreement is among the older men 
Army Murses Foolings atout Staying or Loxing

Roiatod to Agreoment with Dissatisiaction over Dependancy and Denefit Bifterences

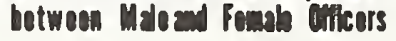

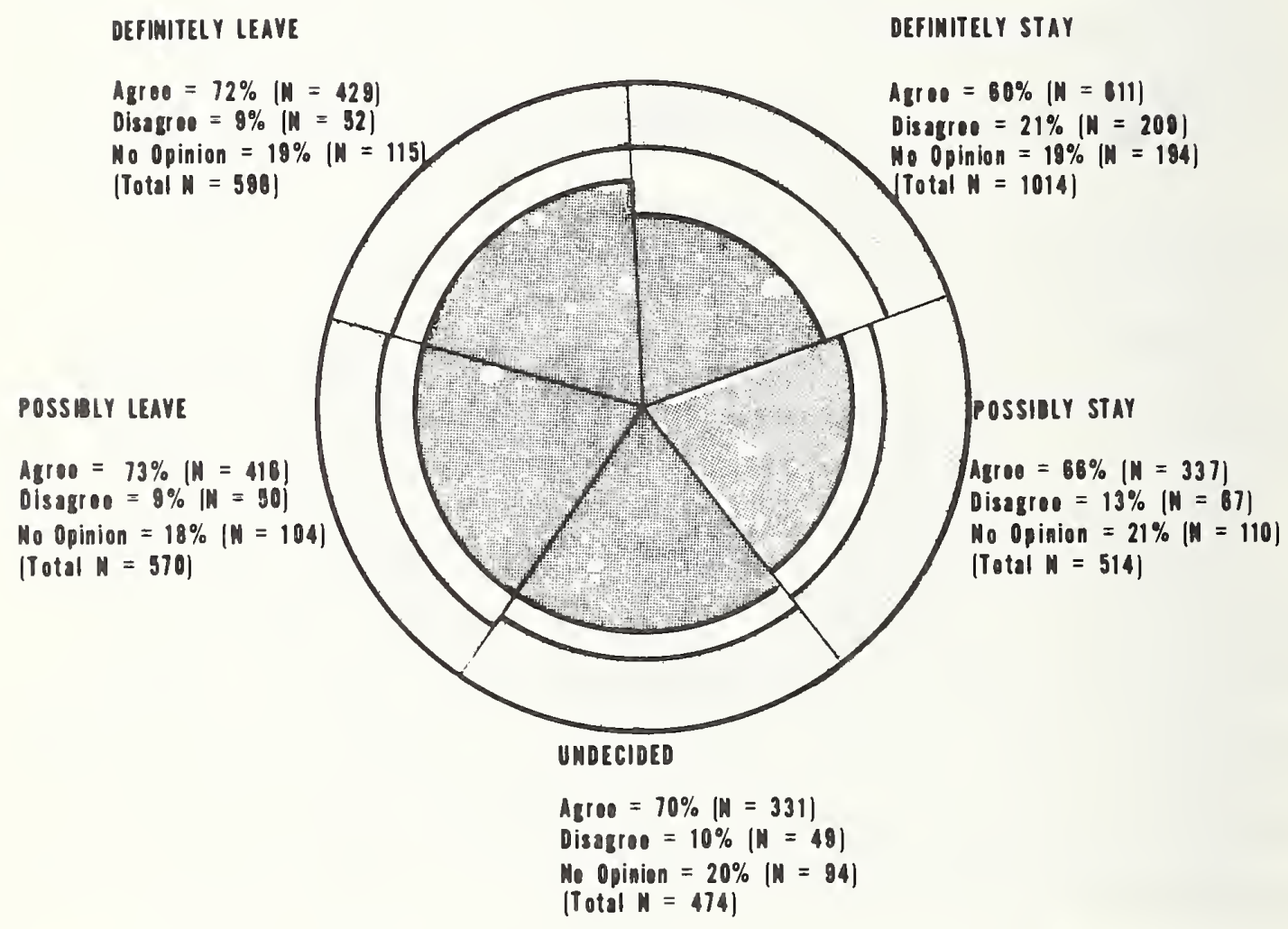

[Porcentages roundod]

Agreo

Disagree

Figure 3-12

We Opinion

in 
with dependents - 36\%. The young reserves are also less inclined to agree with this statement, by only a small margin, than are the young or older RA or older reserve officers. Those leaving are only slightly less likely to agree that married nurses are limited by their dependents than are those staying.

Sixty-eight percent of the respondents disagree with the statement that the difference in benefits paid to married vs. single officers is fair. On 1y $11 \%$ agree, and $16 \%$ expressed no opinion.

16) Service to Country

Service to country, and the form that that service takes, along with the international role of the U.S., can be used as an indicator of military professionalism, distinguishing between the military and health care professional realms. Three out of four nurses say that serving in the Army Nurse Corps is important to them as a way of serving their country. Fourteen percent disagree, and $12 \%$ expressed no opinion. The range runs from $64 \%$ among young reserves to $81 \%$ and $82 \%$ among older reservists and Regular Army officers, down to 59\% for young women with dependents. The strongest agreement with this statement is registered by the older women with dependents $(88 \%)$. Among those definitely leaving the service, only $\underline{45 \%}$ agree that serving in the ANC is a way to serve their country; but $38 \%$ of those definitely staying agree.

In response to a statement that Army nursing service means less than civilian nursing would in fulfilling their duty to society, $76 \%$ of the nurses disagree. On1y $12 \%$ agree, and $12 \%$ expressed no opinion. Interestingly, single young male officers are most likely to agree with this statement (but only $20 \%$ do so). The groups which is definitely leaving the service is 
the only one in which the figure rises markedly. In this group $34 \%$, still a minority, agree that Army nursing means less to them than civilian nursing as a means of fulfilling their duty to society; this compares to the $46 \%$ from the same group who disagree.

17) U.S. International Role

In reaction to the statement that it is important for the U.S. as a great power to remain committed to the defense of the free world, $64 \%$ of the nurses agree, $24 \%$ disagree, and $13 \%$ expressed no opinion. Younger women with dependents have the lowest level of agreement at $53 \%$. Single older women and young RA officers register the strongest support (76\%); $70 \%$ of the older RA's and the older reserves agree. However, the younger reserves agree only at $55 \%$. The group which includes those who definitely intend to leave is the only one having less than $50 \%$ who agree that the U.S. should remain committed to the defense of the free world; $46 \%$ of these agree with this statement, $38 \%$ disagree, and $16 \%$ give no opinion.

In reaction to the statement that they do not like the United States to be involved in other countries, only $21 \%$ agree while $63 \%$ disagree and 16\% expressed no opinion. Essentially the same pattern occurs on this question as in the previous one. There is a slight shift in the relationship between the responses of younger and older officers in each of the reserve and Regular Army categories. That is, the older officers were less inclined to be critical of U.S. military involvement in other countries than the younger officers, although the younger officers were less inclined to have reservations about U.S. commitment to the free world. It is possible that there was a slight difference of interpretation as to whether "defense of the free world" includes military involvement of the United States in the affairs of other countries. 


\subsection{Current Assignment}

In response to the question asking whether the current duty station is the nurse's choice or the result of the needs of the Army, only a slight variation occurs among MOS's. Senior (3430) and specialist nurses limited in number (such as 3431) and those more likely to be needed at one type hospital than another (3446) are more likely to say that their assignments are a result of the needs of the Army. The preponderance of nurses in most MOS's say their present job is their choice. General duty and medical-surgical nurses are least likely to say so, but all groups agree at the $50 \%$ leve1 or higher (up to $88 \%$ ), that their current job is their first choice. The differences among MOS's disappear in response to the question asking whether the nurse was given an opportumity to express job preference.

\subsection{Assignment Preference}

A bare majority of officers ( $52 \%$ ) say the geographic location of their present duty assignment is their first choice. Eleven percent say second choice, and $38 \%$ say third or less. However, most MOS groups are more evenly divided between first and third choices. Medical-surgical nurses received first choice by $60 \%$, to $10 \%$ for second and $30 \%$ for third or less. Because they are the largest single group they tend to bias overall figures. They also avoid the greater difficulty of assigning first choice to nurses with specialties held by fewer officers.

Responses reflect this pattern of geographic assignment preferences: West Coast, East Coast, Midwest, Germany, Southeast, and Hawaii in that order, followed by other areas in lesser number. 
The more certain the nurses are that they are staying in the Army, the more professional experience tends to become important as an assignment factor. On the other hand, the more certain officers are that they . are leaving, the more important family and geographic area are as assignment factors.

\subsection{Summary of ANC Officer Worldwide Questionnaire}

The Army Nurse Corps officers registered their attitudes, opinions, and professional judgments on a wide range of topics covering Army nursing and service life. A number of important themes emerge from their responses.

- Professionalism in nursing was a major theme, manifested not only in the high value ANC officers place on the high professional standards of their own performance, the quality of care for their patients, continuing education and advanced clinical preparation, and the expanded role of the Army Nurse, but also reflected in their strong desire for more equal professional status, their concern that rank and authority in the military system often override the most competent professional judgment, and, in each instance where some aspect of professionalism was juxtaposed to military, organizational, or personal demands, strongly supporting professionalism.

- Inequities based on sex and marital status were issues of great importance to the majority of the Corps. Principal among specific issues were liberalized maternity regulations, equal status for spouses of both female and male officers in matters of dependent allowances, accompanied tours, survivor's benefits, and housing allowances.

- Pay, allowances, and benefits are also important. Except where they touch on professional status and recognition, however, they are not associated with the primary issues on which career decisions will normally be made, so long as Army nursing is generally competitive with the civilian sector in terms of overall economic security.

- Female ANC officers regard inequities in pay, allowances, and benefits that are based on sex, marital status, and dependents as major disadvantages. These issues have undoubtedly affected retention rates for younger nurses. 
- Staying or Leaving. Over two-thirds of the younger nurses (20-24 year age group) indicated a high expectation of leaving the service on completion of their obligation. The highest retention rate by an overwhelming margin is among RN's who enter the service through direct appointment from civilian status. Diploma nurses from the Army Student Nurse Program have the next highest retention rate. Army student nurse degree programs reflect the higher mobility of baccalaureate nurses, who have lower retention rates after the initial service obligation has been met.

- A low proportion of nurses who obtain their nursing education through Army financial support programs are likely to serve more than the required obligation. The higher the professional qualifications, orientation, and professional mobility nurses achieve, the more likely it is that they will choose to leave the service.

- Both junior and senior officers tend to agree that there is a generation or communication gap. Younger nurses tend to feel that older nurses rely too much on rank and authority rather than up to date professional knowledge, that the more rank they attain the more they are concerned with promotion rather than patient care, and that they have not kept up to date professionally. Older nurses tend to feel that younger nurses are not willing to adapt to the requirements of service in the military or to the need of the hospital as an organization to insure adequate staffing on all shifts.

- Administration and Facilities. Over half of those who expressed an opinion feel that Army hospital administration is generally competent, but not particularly responsive to patients' needs. About the same proportion tend to agree that the Army medical facilities and equipment are often obsolete. At the same time, most nurses agree that the Nurse Corps enjoys a good reputation and that the quality of patient care is generally good.

- An overall view of the responses suggests that the strongest potential appeals to retain those nurses with the highest professional interests and qualifications, who say that they are probably going to leave the service, are in challenging professional opportunities on the one hand, and in eliminating major inequities that affect women on the other. These respondents rated as "major advantages" of an Army nursing career advanced clinical preparation, expanded role opportunities, more liberal maternity regulations, comparable status for their spouses in terms of allowances and benefits, and recognition of their actual dependents, whether or not they are married. Those officers who have elected to stay or believe they will remain say that pay and allowances were a major factor. However, those who say they will 
either definitely or probably leave do not rate this as a crucial factor, which probably indicates that military pay, allowances, and benefits are already competitive and not a major issue.

The broader context within which these issues form a general pattern is a complex set of relationships, often conflicting, involving nursing professionalism and status vis-a-vis military traditions, Army bureaucracy, AMEDD organization, the other health professions, and changing perceptions of the role and status of the nurse. The inescapable clash of certain aspects of each is exacerbated by the aspirations of the professionally oriented nurse struggling for full professional status.

The conflict of nursing, as an auxiliary profession to the military, rests in part on the difference between the use of controlled violence and the preservation of life as principal functions, in part on differing sets of skills, and in part on the inherent conflict between individual professional judgment and hierarchical administrative authority in a bureaucratic institutional setting.

As we noted early in this section, the MEDDAC environment contains elements of both the military and health professions. The conflict between them is a complex issue that surfaces most directly in the matter of professional competence versus rank and authority. While the military are seeking to build high professional standaràs in nursing, the military system of command and authority, and organizational problems common to all bureaucracies, form obstacles that highly professional nurses find difficult to accept.

At the same time, the Corps has a body of ANC officers dedicated to bringing the highest standards of nursing to the Army. Achieving this 
professionalism is important in two areas of general importance to the future of the Corps: 1) Retention of nurses with a highly professional nursing orientation is assumed to be advantageous to the delivery of the best possible health care for the Army; and 2) professionalism in the operational context in which nurses practice in the Army, along with organizational capability, should enhance the effectiveness of those who will provide the Army Nurse Corps with leadership in the future. 

4.0 THE MEDDAC - THE OPERATING ENVIRONMENT OF THE ANC

This portion of the study had several general objectives: quantitative characterization of the nursing environment; identification and quantification of relationships among staffing, workload, quality of care (QOC), and other possible relevant variables; comparison of hospitals under different commands; and (in conjunction with the ANC Force Structure Mode1, to be described in later sections) comparison of projected strengths with actual and planned strengths. Detailed descriptions of these aims follow.

The nursing environment was characterized by obtaining, tabulating, and checking data on many facets of the MEDDAC: number of nurses by MOS, component, grade, etc.; number of doctors; facilities number of operating rooms, number of beds, etc.); proportion of "Intensive Care" cases, and other variables. The survey instruments used to obtain the data are described in Section 4.0.1, the resulting data base is described in Section 4.0.2, and analyses of the data are to be found in Sections 4.3, $4.4,4.5$ and 4.6.

Identification and quantification of relationships between variables may have been pursued in any or all of several different ways: correlation, regression, factor analysis, subjective judgment, scaling techniques, discriminant analysis, and possibly others. A combination of correlation and regression was chosen, as it appeared to offer most promise within applicable time constraints. This approach is described in more detail in Section 4.3, with examples in Section 4.4; an overall view is found in Section 4.1. (In order to have a coherent data base to work with, these analyses were done on a reduced data set corresponding to only the larger hospitals.) 
Comparisons between hospitals in different commands, different areas, etc., are indicated in two ways: by direct comparison of tabulated data, as is found in Section 4.5; or by applying the techniques of the preceding paragraph to smaller sets of hospitals corresponding to the different areas, commands, etc., and then by comparing the relationships found for the different sets. The latter procedure was not actually used because of the variability among MEDDAC and the spottiness of the data.

It was desired to compare the September 1972 MOS and total staff requirements with annual 5-year projections of a11 ANC MOS's. Comparison of the MEDDAC requirements with the annual simulation projections of the ANC Force Structure Model are described in Section 5.3. This comparison involves each year's reduction in professional military strengths resulting from the Deputy Chief of Staff for Personne1 (DCSPER) budgetary constraints, and from statutory separations described in Section 5.0 and in Part III. The comparisons are of interest because of the OTSG view that the 1972 data is somewhat typical of a partially mobilized or "limited war" scenario. The NBS survey of MEDDAC activities is described as a "snapshot," possibly useful for planning, even though the continental United States (CONUS) and overseas MEDDAC requirements do in fact change slowly with time.

\subsubsection{Original Survey Instruments}

In the planning stage of this study, NBS was asked by the OTSG to assist in gathering and analyzing both specific and nonspecific MEDDAC data regarding personnel, facilities, wards, and clinics. The original data gathering planning by OTSG was in terms of "MEDDAC Survey" instruments (herein and hereafter referred to simply as "Instruments") which had been 
developed by the OTSG work committees. The original Instruments consisted of the following four sections:

(Section A) Activity Identification

(Section B) Personnel Identification Data

(Section C) Task Detail and Duty Identification

(Section D) Distribution and Utilization Data

The large amount of data requested by OTSG included staff-workload information, memberships in nursing societies, other organizational affiliations (including union memberships), and military grade distributions by racial and marital status groups. The original four sections of the Instrment did not include data on either the numbers or types (categories) of patients (e.g., the intensely ill and/or minimal care patients) and very little data on care indicators. It was, therefore, apparent to the NBS study team that the OTSG's anticipated broad needs for a wide range of nursing-personnel data might result in a complex and obfuscating data base larger than the more immediate requirements of this study. Therefore, plans were made by the NBS staff, in accordance with the more limited and specific objectives below, to revise the data requested in the Instruments.

Certain modifications to the original Instruments were made in order to obtain the desired quantitative characterizations of the MEDDAC. These modifications were made in work sessions (described in Section 2) attended by both the NBS staff and the members of the OTSG. A revised survey

form containing four new sections was developed. These sections are:

(Section A) Personne1

(Section B) Facilities and Activities

(Section C) Tasks in Your Ward or Clinic

(Section D) Non-Nursing Tasks 
4.0.2 The MEDDAC Data Base

The data obtained in Sections A, B and C of the Survey Form from 93 MEDDAC installations comprised approximately one-half million data elements; these were on punched cards, ranging from 75 to 419 cards per hospital. This data set, the primary data base, is known in the project as Set No. 1; it was abridged to provide two different working sets, as described in the next paragraphs.

It was deemed neither possible nor productive to attempt exploration of all relevant relationships among all MEDDAC: the data base was too large and too spotty. The first data reduction was elimination of certain redundant or inconsistent data elements; elements were eliminated that had too many missing entries; others were eliminated where MEDDAC were too small and/or had too many missing data entries. This series of elimination procedures left 67 hospitals and 93 variables. These data were edited, formatted, and arranged in matrix form, with each row representing a hospital and each column a variable; this was designated as Set No. 2. The first columns of this matrix may be seen in Table 4-1; the complete matrix may be found in Annex II-5.

Finally, Data Set No. 2 was further reduced by elimination of certain hospitals known to be "unusual" or small, and certain variables which could be confidently expected to play no important role in the correlation/regression analyses planned, resulting in Data Set No. 3, consisting of 47 hospitals and 67 variables. 


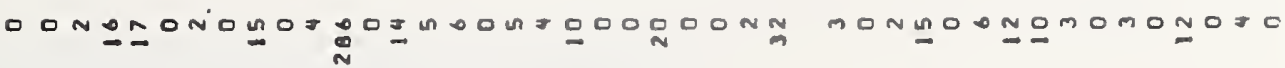

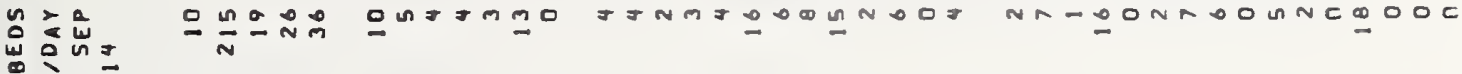

$\geqslant U$

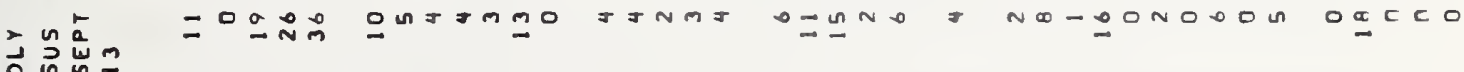
经的 $\geq$ U

n $\geq$

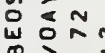

ⓤ

능

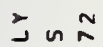

근른

$0 \sum$

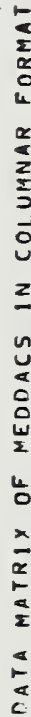

$\geqslant \stackrel{\omega}{=}$

$\dot{0} \leq \mathrm{x} 0$

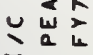

$j \leqslant n a$

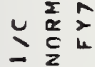

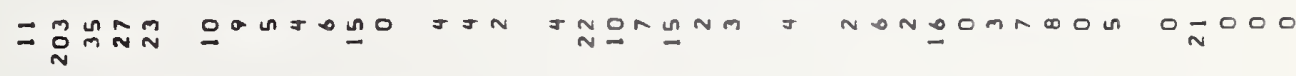

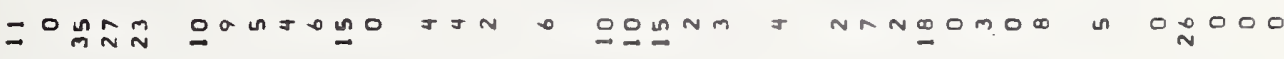

$\simeq \geqslant a$

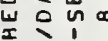
×

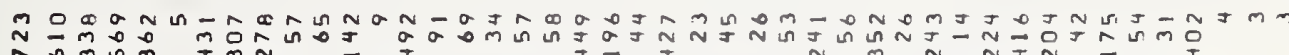

in a

\& $\begin{aligned} & 0 \\ & \text { V. }\end{aligned}$

$\geq \sum_{u}^{2}$

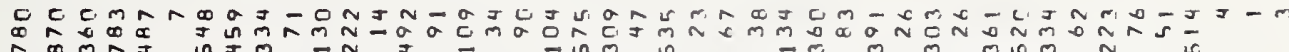

若

a

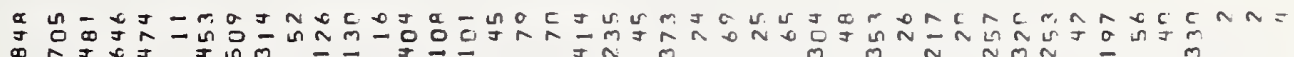

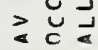

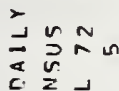

c.

$\geq$

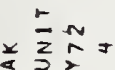

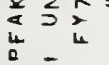

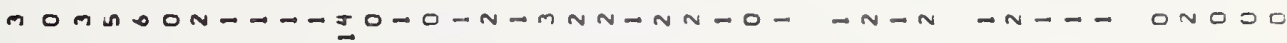

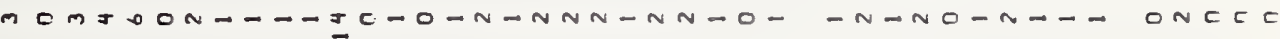

当

$\sum \bar{\varepsilon} \sim m$

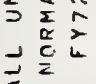

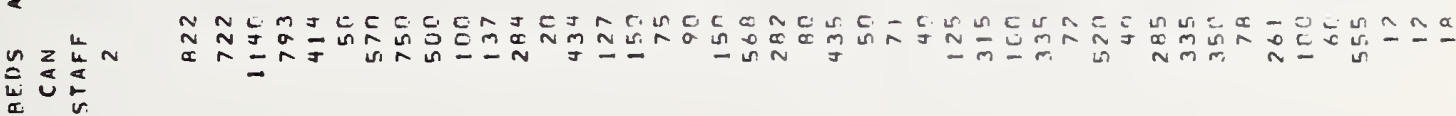

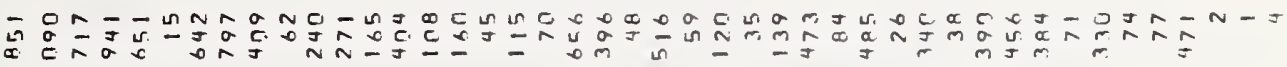

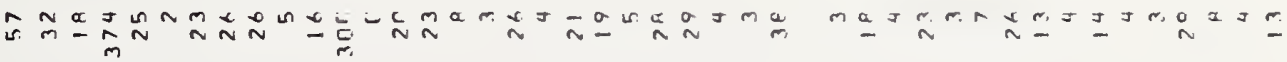

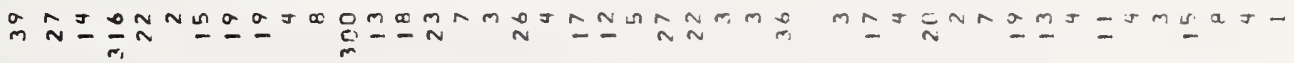

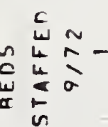

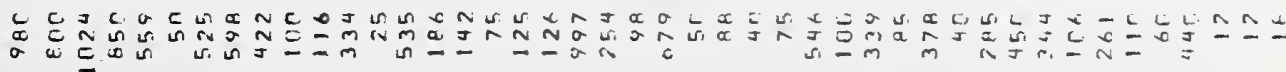

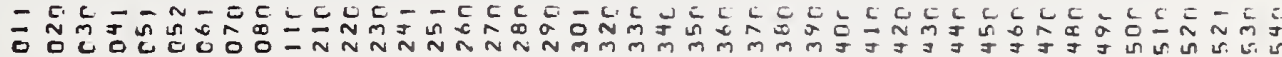




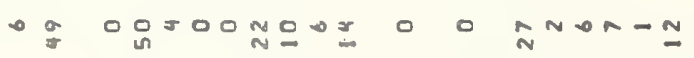

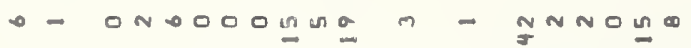

- onmoodming m o nNmogo

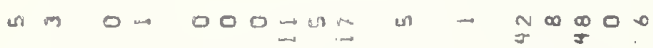

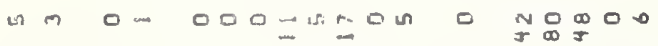

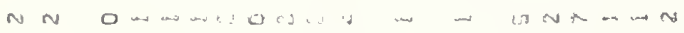

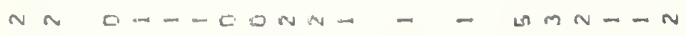

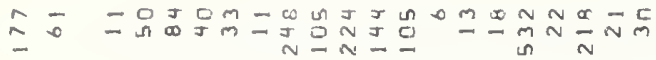

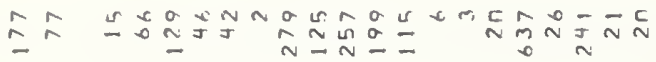

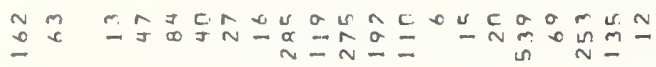

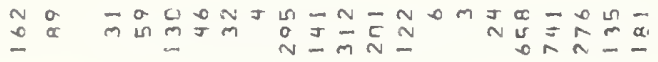

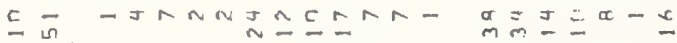

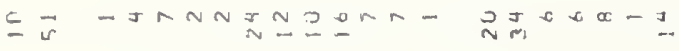

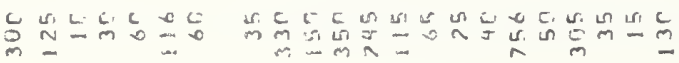

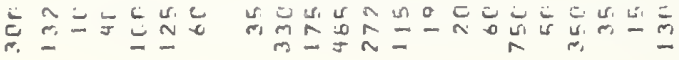

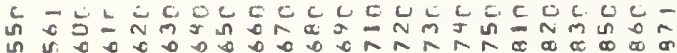




\subsection{Staff/Workload/Quality-of-Care Relationships}

This section describes in general terms the rationale of and the kinds of relationships sought.

- A large hospital, considered as a large system with many constituent parts and many interrelationships, is not an easy thing to understand. Surely (for example) the number of doctors, the number of critically ill patients, the proportion of specific workload (e.g., obstetrics), and many other factors have an effect on how many nurses (of various specialties) are needed. One is led to wonder whether a close look at the relationships between these and other variables might show common features among different hospitals, since common features in turn could conceivably result in better understanding and from thence to better (or more economical) care. It is true, of course, that nursing strength is subject to Army regulations. However, it is also true that deviations from authorizations are to be expected because of both fluctuating patient load and local situations. How do these deviations affect the indicators of the quality of patient care (QOC)? Also how do selected indicators relate to the basic but more elusive quality of patient care? In addition to QOC indicators described in the literature (discussed below) and studied by this project, how does the number of nurses per doctor, nurses per patient, or doctors per patient relate quantitatively to the quality of patient care? Must one also consider other variables in order to explain the variability in quality?

In a different vein, would it be possible to distill the insight and experience of many hospitals into (comparatively) simple formulas which 
state how many nurses would be required if the patient load were increased by some given percent, or indicate how many nurses would be needed to staff a new hospital in a given environment? What kinds of tradeoff can be made between professional nurses and other nursing personnel?

The questions posed in the preceding paragraph are meant to be suggestive, not exhaustive. It was not possible to follow up all conceivable relations, of course. Correlation analysis was used to identify sets of variables that might be related in useful ways; then these sets, and other sets that were of interest even before the correlation analysis, were treated by regression analysis techniques. The simple correlation coefficients of the variables are in correlation tables used in selecting candidate variables and appear in Annex II-4; their use is discussed in Section 4.4. The variables chosen a priori included obvious measures of workload such as number of bed occupied days, number of doctors, proportion of patients in "intensive care," and the ratio of the numbers of professional to nonprofessional staff, as well as others.

The general aim of staff/workload/patient care analysis and regression analysis was to fit mathematical relationships between the variables (staff, workload, etc.) and to subsequently interpret the results. These fitted relationships were later used in obtaining the calculated number of ANC officers and the number of Department of the Army civilian (DAC) registered nurses in each hospital.

Quality of patient care is a very important concept. However, it is not a simple concept. A number of "indicators" of QOC have been proposed in the past, but nothing definitive has yet been accomplished. Therefore, several potential indicators were investigated in this study 
with the aim of getting an overall measure that would somehow look at more than one factor. It is reasonable to suppose that at an understaffed, overworked hospital, the QOC indicators might be lower while with plenty of staff the QOC indicators might be higher. Can this be quantified and demonstrated? It was noted early in the study that the QOC indicators proposed by other researchers were not particularly sensitive to small perturbations of the staff-to-patient ratios. Some possible explanations for this apparent insensitivity are discussed in Section 4.6 of this report.

\subsection{MEDDAC Relationships and the Army Nurse Corps} Force Structure Mode1

Utilization of ANCFSM permits study of the effects of Title 10 (Statutory Law on Armed Service) and the consequences of application of selected regulations and management policies including contract officer incentive (COIN) pay. The objectives mentioned above are considered necessary and useful in future OTSG projections relating to preferred simulation configurations of the force structure. The assembly and analysis of medical department activities data represented a major portion of the technical work associated with this study. As mentioned above, this portion of the report specifically relates to nursing workloads, staff composition, quality of patient care, and related variables of the operating environments of the ANC.

The data obtained with the Instruments make it possible to derive current MEDDAC needs and then to compare needs with available ANC staff in future configurations of the force structure projected by the model. This comparison has been made in this study for the nine MOS categories and is presented in Section 4.5. Responses obtained in the attitudinal 
survey, the Instruments data, and parameters related to applied management policies are all inputs to ANCFSM and in practice are best considered simultaneously.

\section{4:3 The MEDDAC Regression Mode1}

This section presents a brief overview of the principal statistical tool, referred to in this study. as the MEDDAC Regression Model (MRM), for developing the more important relationships between staff and workload variables. As indicated above, analysis of the large amount of data collected required advanced statistical methods such as correlation analysis, multiple regression theory, hypothesis testing, etc. An exposition of the mathematical and statistical methods is presented in Annex II-3 which also contains a detailed list of the major relationships established among the various staff and workload variables in the MEDDAC data bank.

One of the first problems faced in the analysis of the data matrix was the identification and isolation of the more important variables for fitting equations used to calculate the MEDDAC staff variables. The results of a correlation analysis indicated that besides obvious variables relating to beds and staff which would be expected to be included, the variable, number of Operating Rooms, was highly correlated $(\mathfrak{k}>.80$ in each case) with the number of M.D.'s, number of ANC officers, Total MCCU, and Total Bed Occupied Days. Accordingly, the number of Operating Rooms was included in addition to those variables previously mentioned.

The rationale just described applied mainly to the selection of the independent variables, the variables appearing on the right-hand side 
of the regression equation. Early attenpts to use the variable, number of ANC officers, as a dependent variable were not successful. Accordingly, it was decided to use the staff variable, Total Professional Nurses, conșisting of ANC Nurses plus DAC Registered Nurses (DAC-RN). When this was attempted the results were dramatically improved, and it then proved possible to obtain extremely good fits.

The regression calculations themselves were carmied out with the aid of an NBS statistical package system (OMNITAB) using the on-site Univac 1108 computer. The reader is referred to Annex II-3 for discussion of the detailed procedures and methodology.

In order to quantitatively relate the MEDDAC requirements with future staff projections and future staff availability it was necessary to determine which fitted equations were potentially useful in computing nursing staff from available statistical data. The collected quantitative data of the variables of each MEDDAC fell into four categories: (1) Staff variables (S), (2) workload variables (W), (3) quality of care variables (QC), and (4) derived and other variables (OV). The numbers and types of each of these variables are shown in Annex. II-5; "other variables" include turnover rates of types of nursing staff and Dining Room Rations. Examples of "derived" variables are ratios of military to civilian nursing staffs, of physicians to nurses, and of professional to nonprofessional staffs. One independent variable of special interest is known as the "Medical Care Composite Unit (MCCU)." This workload unit includes the following statistical data: Beds, admissions, births, and clinic visits. Closely related variables such as Total Bed Occupied Days (BOD), Average 
Daily Patient Census, Beds Staffed, Average Beds Occupied/Day, and similar statistics, covering various time intervals and categories of patients, have also been included in the NBS data bases.

\subsection{Examples of Results}

\subsubsection{Several Variables}

An example of the results produced by the MEDDAC Regression Mode1 is the prediction of the professional nursing staff, using the three variables, Bed Occupied Days, Visits, and Births. The fitted equation obtained takes the form

$$
y=8.927+.7707 \times 10^{-3} x_{17}+.4238 \times 10^{-4} x_{15}+.6493 \times 10^{-2} x_{14}
$$

where the variables are as follows:

$$
\begin{aligned}
& y=\text { Number of (ANC }+ \text { DAC-RN) nurses } \\
& x_{17}=\text { Number of Bed Occupied Days (BOD) FY } 72 \\
& x_{15}=\text { Total Visits FY } 72 \\
& x_{14}=\text { Total Births FY } 72 .
\end{aligned}
$$

This equation means that if values of the indicated variables are substituted on the right-hand side, the equation will give an estimate of the number of professional nurses, $y=(A N C+D A C-R N)$, in a MEDDAC.

An impression of how well the above relationship fits can be obtained from Figure 4-1 which plots the actual ("Observed") values of y against the calculated ("Fitted") estimates obtained by substituting the values of the variables for each MEDDAC in the above equation. Most of the values are seen to lie close to a straight line. They would all actually lie on a line if the fit were perfect, i.e., if each calculated estimate were equal to the actual number of (ANC $+\mathrm{DAC}-\mathrm{RN})$ nurses. In the present case, 


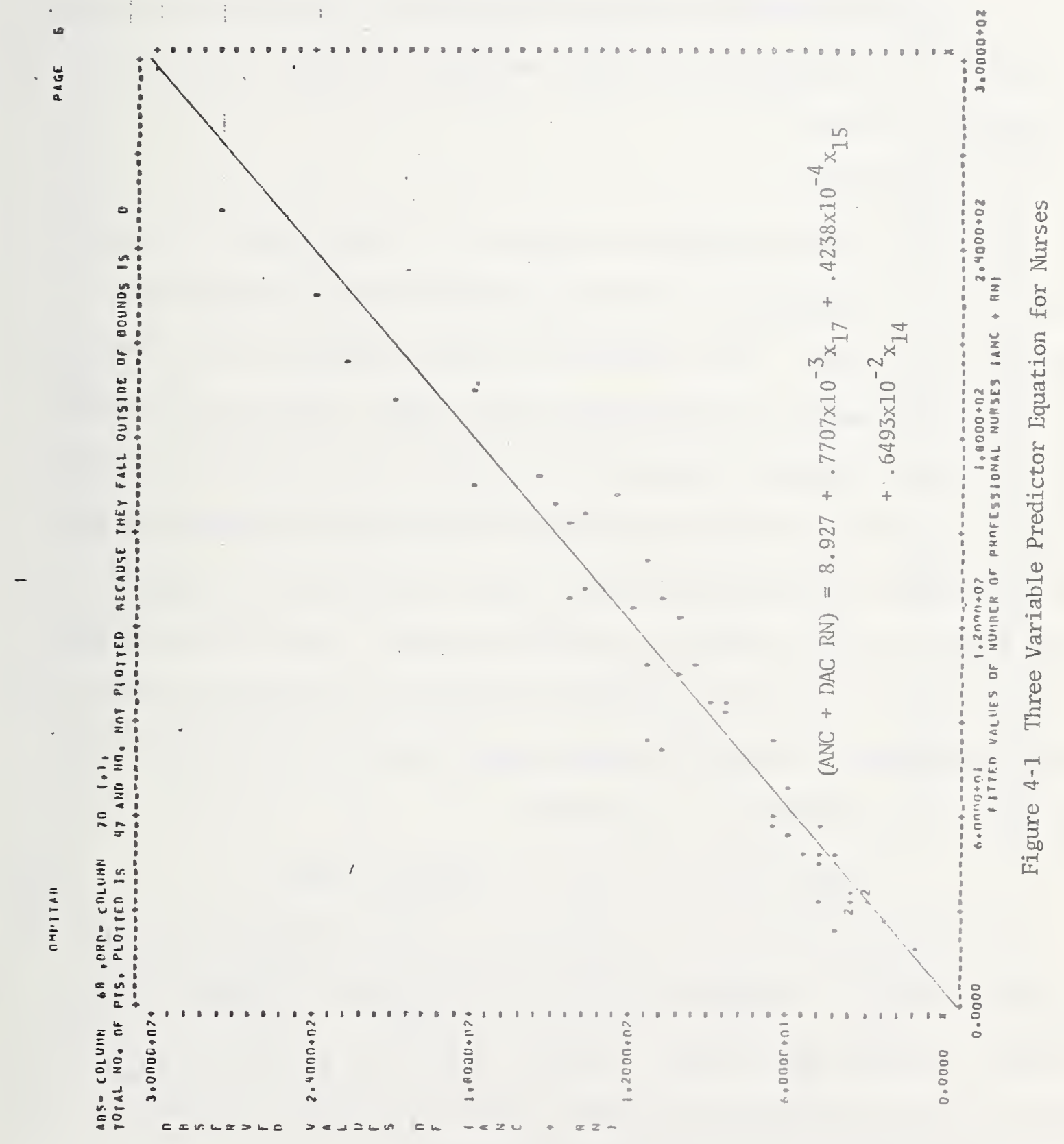


the fit is remarkably good, being calculated as .957 on a scale from 0 to 1 (and denoted by the symbol $\mathrm{R}^{2}$ in the Figure). A detailed exposition of this measure of fit is given in Annex II-3.

When the number of explanatory variables was increased from three to ten, the goodness of fit increased slightly to .986. This shows that it need not be necessary to have many variables in order to obtain a reasonably good fit.

\subsubsection{One Variable}

It also seemed worthwhile to look at the other end of the scale, where only one independent variable was fitted to the same dependent variable $y$ as above. This indicates how good a variable is as a predictor of the actual number of professional nurses (ANC + DAC-RN) in the MEDDAC. Of the various variables tried one at a time, it was instructive to make four fits to see how closely each of the three that are combined in the three-variable fitted equation above, and, in addition, the remaining variable in the MCCU definition, namely Admissions, can fit the observed staff variable $y$ when used separately. These are also shown in Annex II-3, and one of these is 11lustrated here, namely that for Bed Occupied Days (BOD). The relationship is as follows:

$$
(\mathrm{ANC}+\mathrm{DAC}-\mathrm{RN})=20.721+.9248 \times 10^{-3}(\mathrm{BOD}) .
$$

The plot of actual vs. computed $y$ is shown in Figure 4-2, where the goodness of fit is calculated as .939. For the other variables, Visits, Births, and Admissions, these fits were $.718, .231$, and .597 , respectively. Thus, of all one-variable indicators, Bed Occupied Days is by far the most accurate predictor of total staff requirements. 


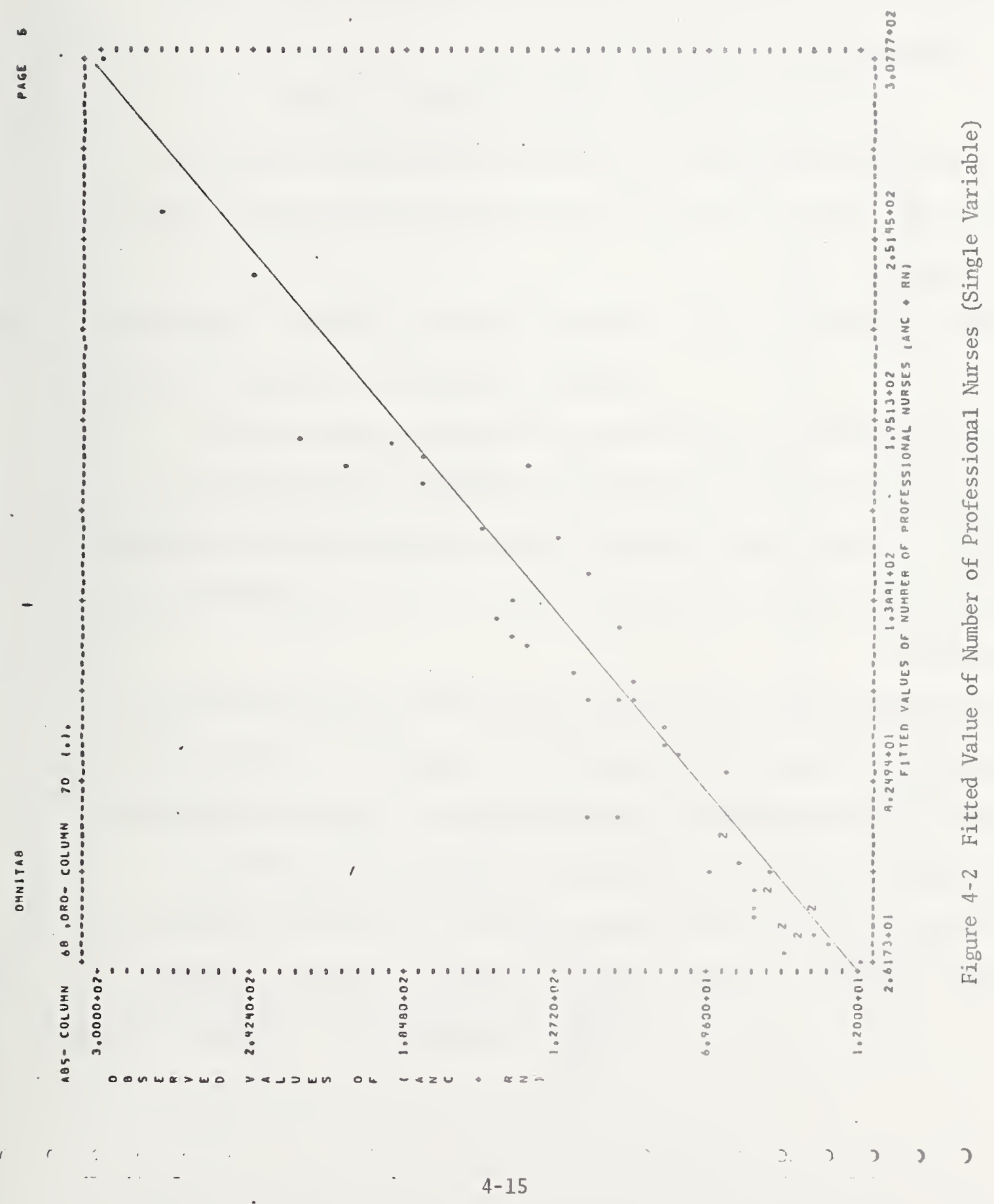




\subsubsection{The MCCU Variable}

The standard definition of the MCCU variable is given by MCCU $=$ Bed Occupied Days +10 (Admissions) +10 (Births) +0.3 (Visits),

where all quantities relate to the same time interval (yearly tota1).

A one-variable fit gives

$$
(\mathrm{ANC}+\mathrm{DAC}-\mathrm{RN})=.2035+.3219 \times 10^{-3}(\mathrm{MCCU})
$$

The corresponding plot is Figure 4-3 with goodness of fit .884. If we now substitute in (4) the expression for the MCCU given in Equation (3), we obtain

$$
\begin{aligned}
(\mathrm{ANC}+\mathrm{DAC}-\mathrm{RN})=.2035 & +.3219 \times 10^{-3}(\mathrm{BOD})+3.219 \times 10^{-3} \text { (Admissions) } \\
+ & 3.219 \times 10^{-3} \text { (Births) }+.09657 \times 10^{-3} \text { (Visits) }
\end{aligned}
$$

This may be regarded as equivalent to fitting the staff variable $(\mathrm{ANC}+\mathrm{DAC}-\mathrm{RN})$ to the four independent variables, Bed Occupied Days, Admissions, Births, Visits, subject to the restraint that the coefficients of these variables be in the ratio $1: 10: 10: 0.3$, as indicated in Equation (4).

The question of interest then is how good a fit can be obtained with the same variables if the restraint is removed, i.e., what will be the ratios of the coefficients corresponding to a better fit than that which is obtained by use of the current definition of the MCCU?

The result of the unrestrained fitting is (plotted in Figure 4-4):

$$
\begin{aligned}
(\mathrm{ANC}+\mathrm{DAC}-\mathrm{RN})=12.138+ & .8464 \times 10^{-3}(\mathrm{BOD})+.7389 \times 10^{-4} \text { (Visits) } \\
- & .2776 \times 10^{-2} \text { (Admissions) }+.8903 \times 10^{-2} \text { (Births) }
\end{aligned}
$$




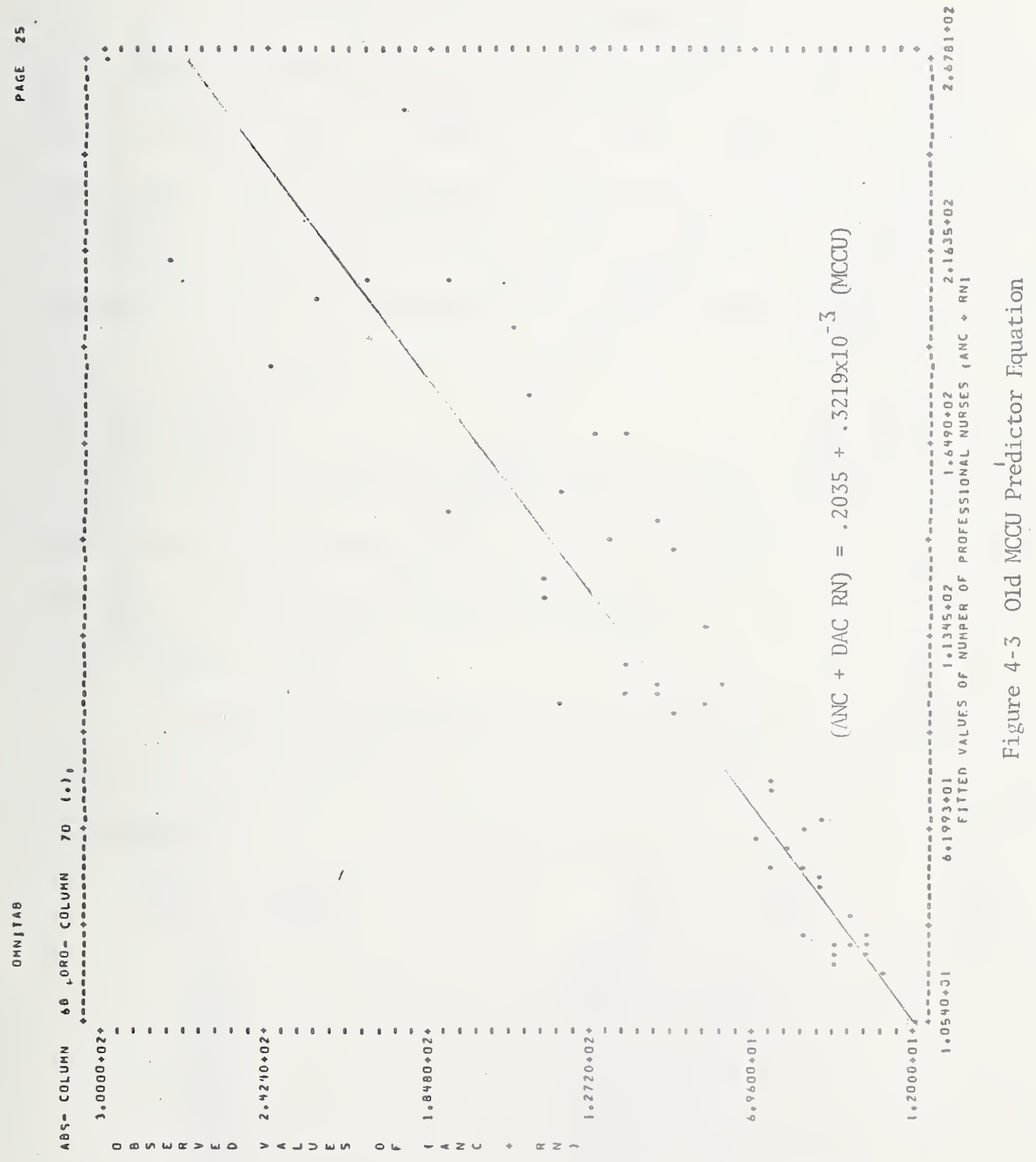

4-17 


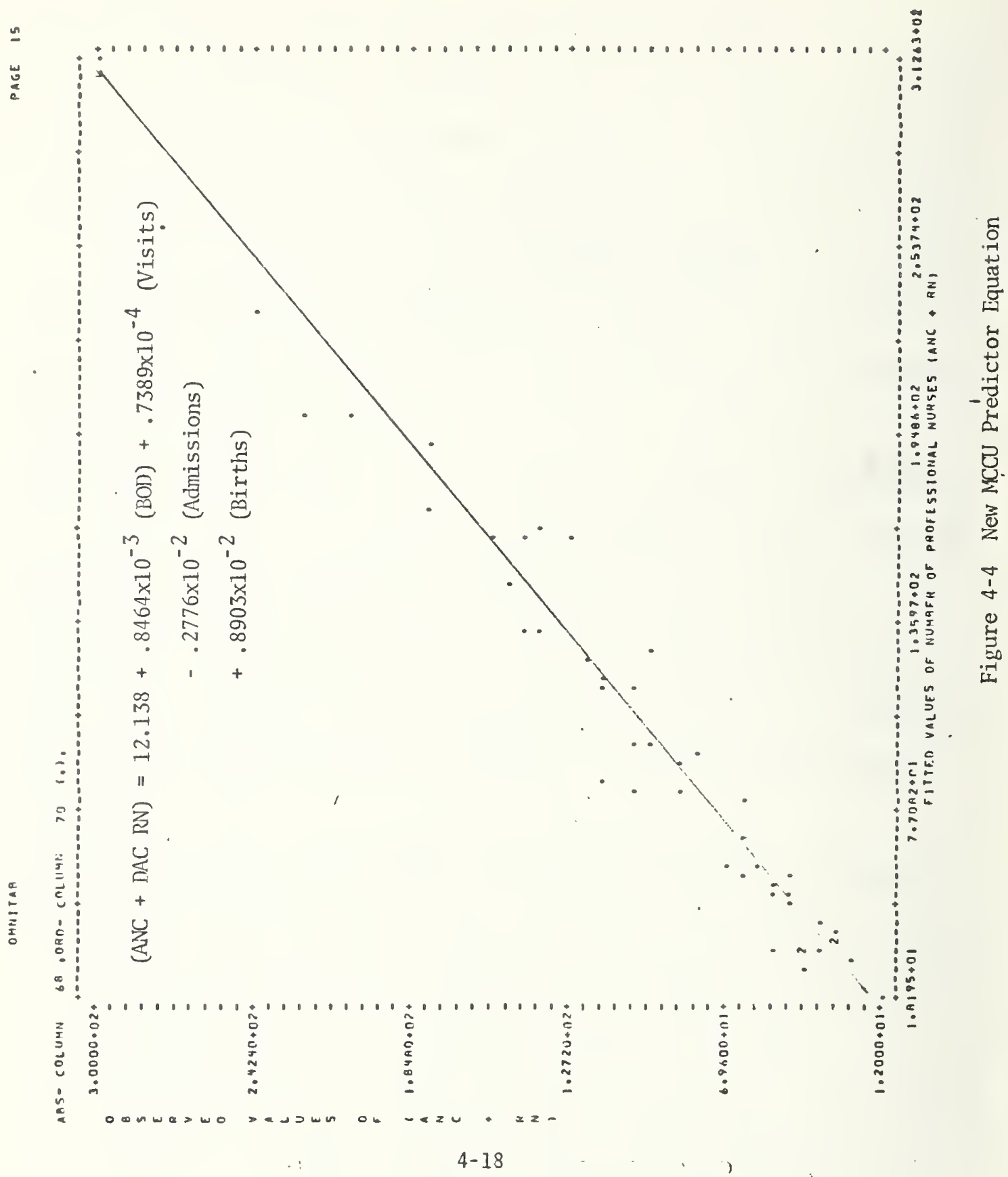


with goodness of fit .968. Equation (6) may also be written as

$$
\begin{aligned}
(\text { ANC }+ \text { DAC-RN })=12.138 & +.8464 \times 10^{-3}[\text { Bed Occupied Days } \\
& -3.28 \text { (Admissions) }+10.51 \text { (Births) } \\
+ & 0.087 \text { (Visits) }] .
\end{aligned}
$$

The bracketed expression gives a linear combination of the same variables as in the MCCU, which, if treated in the same manner as the currently defined MCCU, gives a superior fit to the staff variable (ANC + DAC-RN). A discussion of the occurrence of a negative sign in a regression is given in Annex II-3 but its interpretation in an MCCU-type combination would require further work.

\subsection{Data Analysis}

This section analyzes the data matrix Table 4-1 from two points of view: relationships between values for the individual hospitals, and aggregates for geographical groups of hospitals.

\subsubsection{Analysis of MOS Data}

The nursing requirements of medical department activities are in large part specified in terms of the number of nurses required in nine MOS categories:

\begin{tabular}{l} 
MDS Category \\
\hline 3449 \\
3448 \\
3430 \\
3431 \\
3437 \\
3442 \\
3443 \\
3445 \\
3446
\end{tabular}

Nurse Title

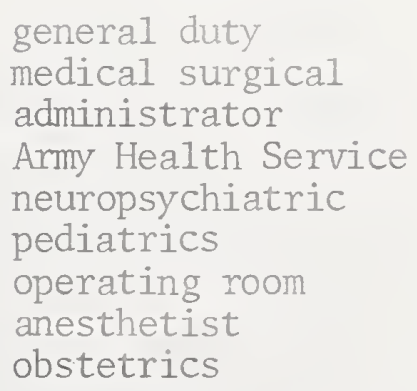

Using the NBS survey, data were collected from hospitals on the numbers and types of duty MOS's currently required in each of the hospitals. 
The requirements are specified in terms of Army Nurse Corps MOS's and duty positions occupied by DAC RN's. The two have been combined to establish the total requirements of FY 1972.

It was of interest to the study to examine the hispital needs in specific military occupational specialties (listed above), to compare these needs with the primary MOS's reported by the nurses in the 1972 survey, and to consider projection into the future using the NBS Army Nurse Corps Simulation Model. Such information for each of the nine military occupational specialties currently on duty, and presumably representing needs of the hospitals, is depictea in Table 4-2 and in Figure 4-5 for MOS 3442. Charts for all nine MOS's appear in Annex II-9. In Figure 4-5, the first of the six bars represents the number of duty MOS's reported by the hospital. These are presumed to be the requirements. The second bar represents 21 nurse officers not in hospitals but at other stations such as training, research, etc. These officers have the specified primary MOS's and, therefore, could satisfy MEDDAC requirements, but are currently assigned elsewhere. Presumably these other assignments are essential tasks requiring the specified MOS's. The third bar represents 171 Department of the Army civilian (DAC) nurses whose job description is identical with the officers duty MOS. The fourth bar then displays the total nurse requirements of 378 for FY 72 (snapshot) as the sum of the first three bars. How many of the MOS 3442 nurse requirements are available during FY 72 from the ANC Force Structure? How many would be expected to be available in 1977? These are questions that may be answered by making reasonable assumptions concerning transfer, recruitment, and attrition as is done in the NBS simulation model. 


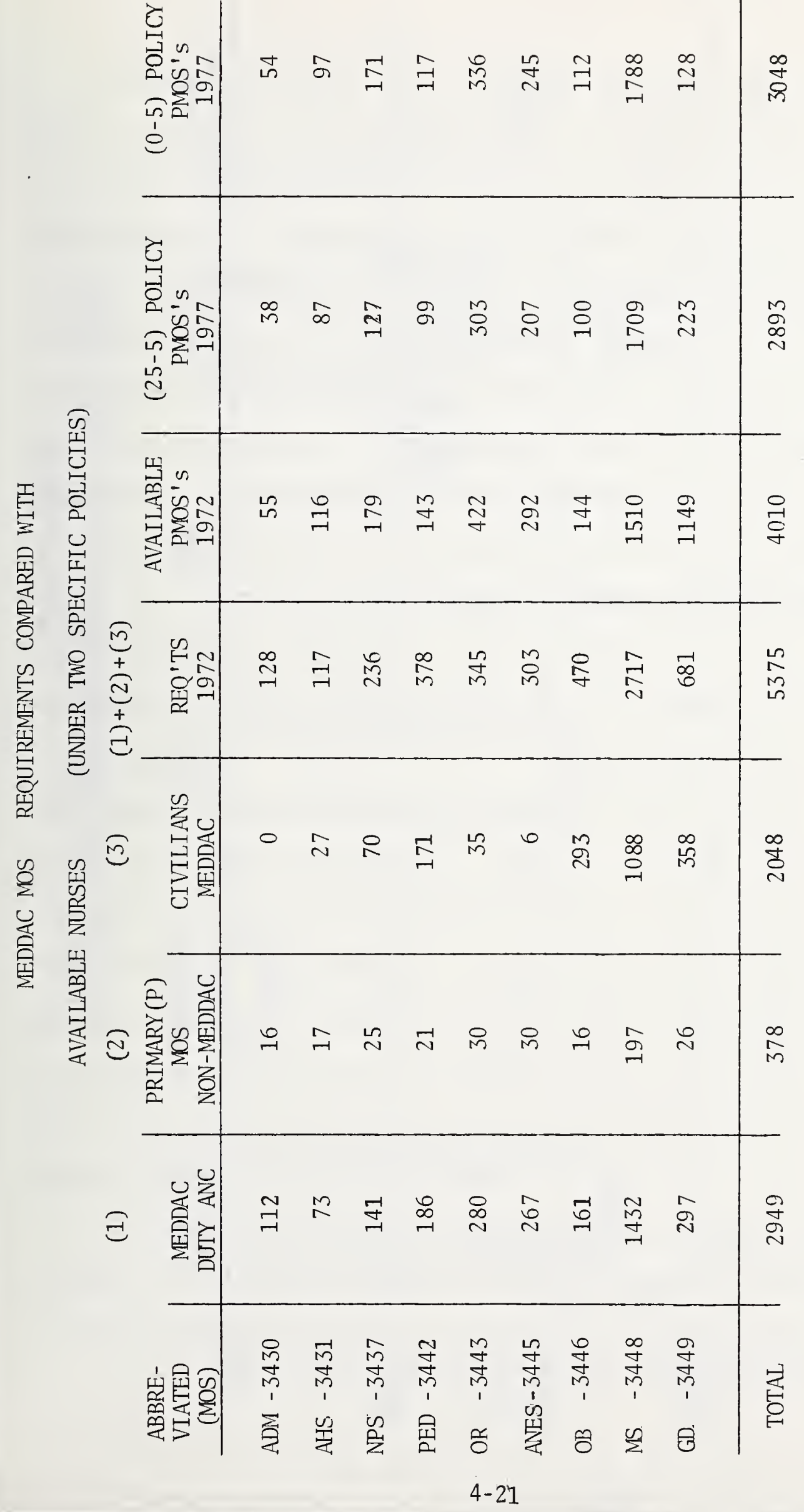


The model referred to in Section 5 was operated under two specified policies: policy 25-5, a 25\% decrease in strength (to 1281 officers) over a 5-year period and policy 0-5, no decrease over the same period. This value was used in estimating the number of MDS's available to the MEDDAC from the force structure. The number of MOS 3442 officers available under this specific policy, not requiring special recruitment or training, is 99 as shown in Table 4-2 and in the fifth bar of Figure 4-5. Obviously, this number of officers is insufficient to meet the requirements if they would remain at the current level (378, fourth bar).

The data resulting from simulation are depicted and summarized in Figure 4-6. As shown in this figure there should be considerable concern for the apparent shortage in the following MOS areas: 3446 (obstetrics), 3443 (operating room), 3445 (anesthetist), 3442 (pediatrics), and 3437 (neuropsychiatry). Consider Table 4-2: 161 obstetric military nurses, supplemented by 293 civilian nurses (and 16 on duty elsewhere), lead to a total requirement of 470 nurses. However, currently there are only 144 available. Obviously, the 144 would decrease by a minimu of 10 to 30 percent over the next five years. Unless specific plans are made to increase the number of obstetric military nurses to meet the requirements for the future, the only way in which the Army will be able to operate these hospitals successfully, assuming the current 1oad, will be to hire additional civilian registered nurses.

An examination of MOS 3446 (obstetrics) and MOS 3442 (pediatrics) in Figure 4-6 indicates the need for looking ahead and training nurses for the requirements of these two specialties. Approximately 470 nurses 


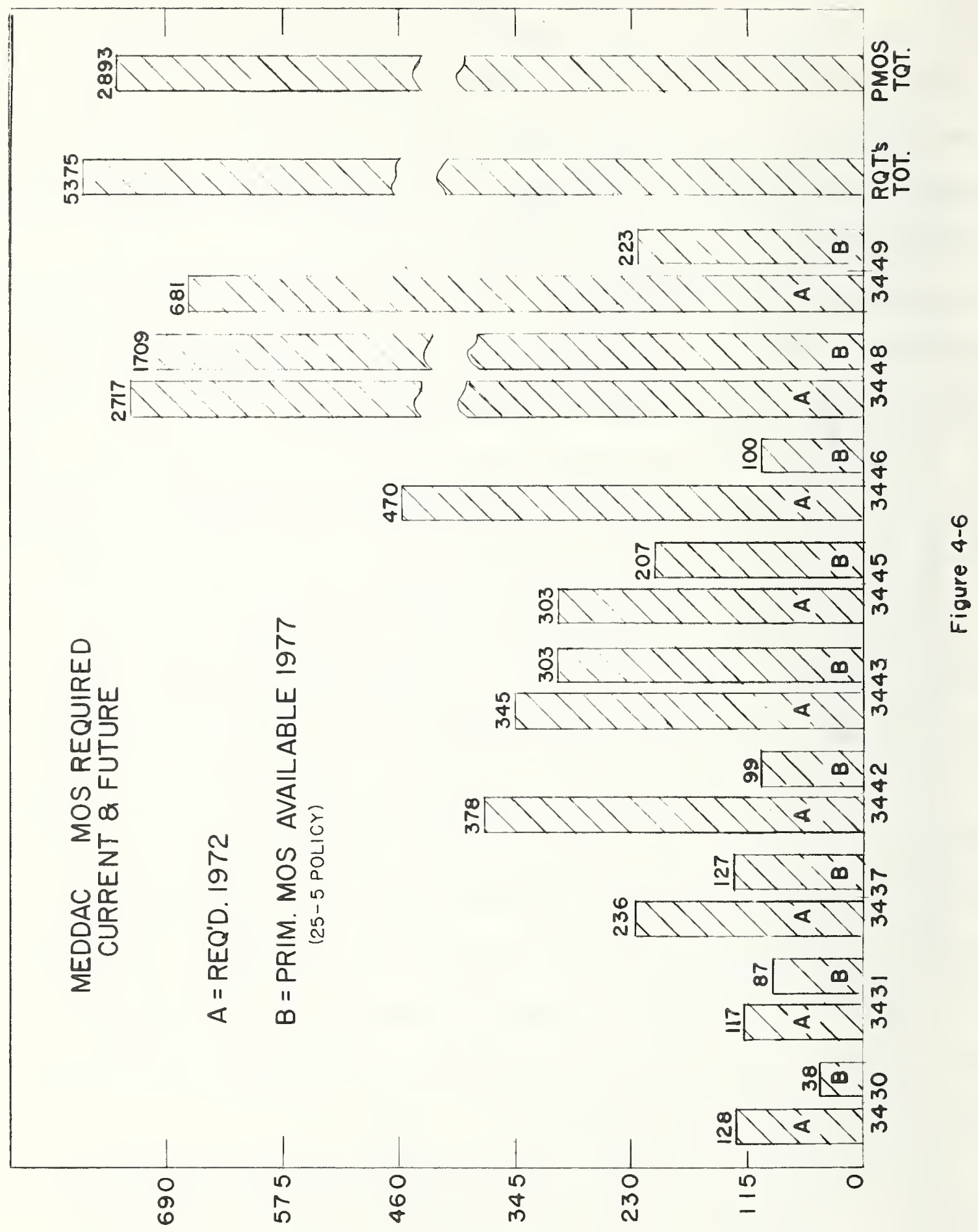


are presently on duty having assignments comparable to MOS 3446, but only 161 are in the Army Nurse Corps. Looking at ANCFSM's projection, and replacing only certain nurses lost through attrition, it becomes evident that a reduction of approximately 30 percent of obstetric military nurses will diminish the number 161 to some number closer to 115. The discrepancy between the needed number (approximately 167), and 115 indicates the advisability for planning and future training. Figure 4-6 summarizes two of the bar charts for each of the MOS's. For example, the number of nurses in MOS 3430, is represented by the first two bars of this figure, and the number in MOS 3431 is indicated by a second pair. In all cases, for each of the pairs, there would be shortages (under 25-5 policy), and in some cases, rather severe shortages (see MOS 3437, the neuropsychiatric nurse, MOS 3442 , the pediatrics nurse, and MOS 3430, the administrator nurse). The shortages (e.g., MOS 3446) can easily be visualized from Figure 4-6. Some question may be raised with regard to the validity of both the requirements and the future estimated numbers. It is clear that if one trains enough nurses in each of these specialties there will be no shortages.

The survey data, the models, and the questionnaire results are intended to be used in a combined (iterative-conjoint) fashion. The simulation model outputs contain annual MOS configurations of the simulation policies which are compared with the actual hospital requirements. The simulation policies should be examined for compatibility and acceptability using the survey data as a guide. This is an example of what is referred to as a conjoint use of the various management tools mentioned in this report. The bar charts in Figures 4-5 and 4-6, the summary 
Table 4-2, and the computer output Table 4-3, are intended to be compared with specific policies used as inputs to the ANCFSM simulation.

The operation of the model, under reasonable policies and programs, will reveal future shortages. This is an example of how the output of the Force Structure Model (assuming it to be valid) can be compared with the output of the data base on hospitals for detection of shortages and excess. It should be pointed out here that regression fitted equations for each of the MOS's can be generated by the techniques used to generate the regression equations of Section 4.4 based on the variables of the data matrix (Table 4-1).

\subsubsection{Graphical Relationships}

This subsection deals with the important staff variable, total professional nurses (Army Nurse Corps nurses plus civilian registered nurses), plotted against three other variables, in which the correlation coefficient is greater than 0.80 in each case. Some additional figures with highly correlated variables may be found in Annex II-10.

It is of interest to plot the dependent variable "number of professional nurses" as a function of the more important independent variables. See Figures 4-7, 4-8, and 4-9. In these three graphs, the average number of nurses is plotted against: the number of beds with which the hospital is equipped, the average number of beds occupied, and the number of M.D.'s respectively. As mentioned earlier, the number of beds staffed and BOD are two important variables in the determination and calculation of nursing requirements. 
䛒

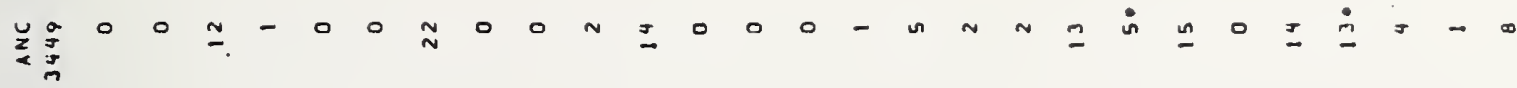

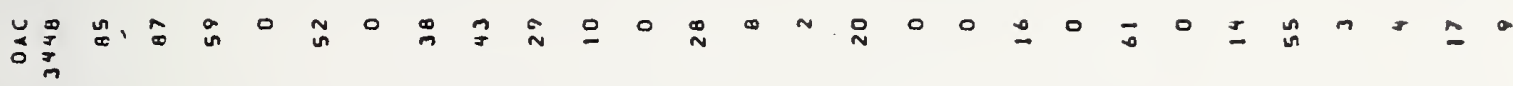
茛节品

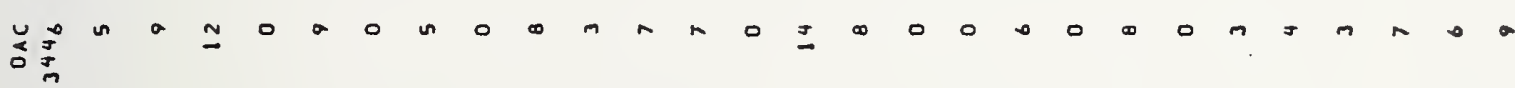

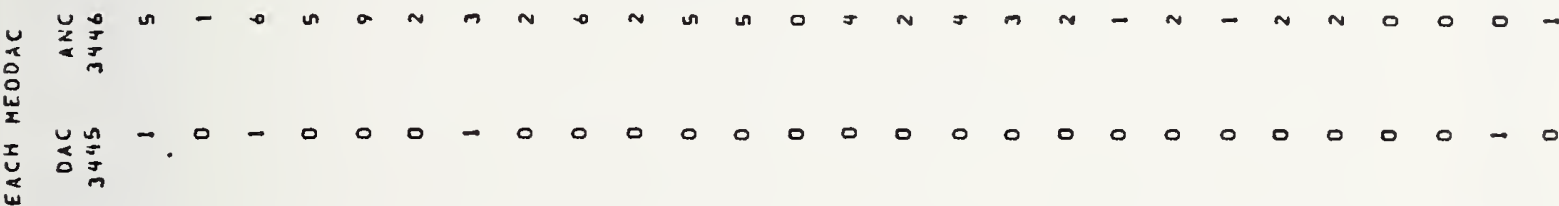

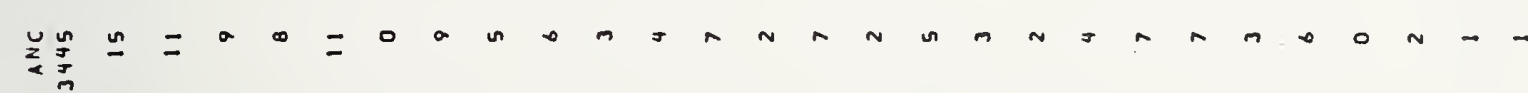

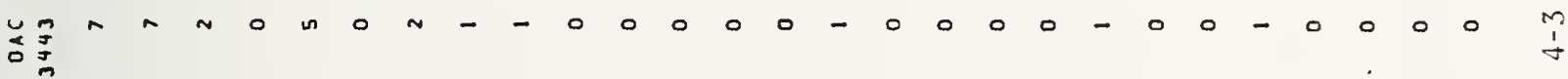

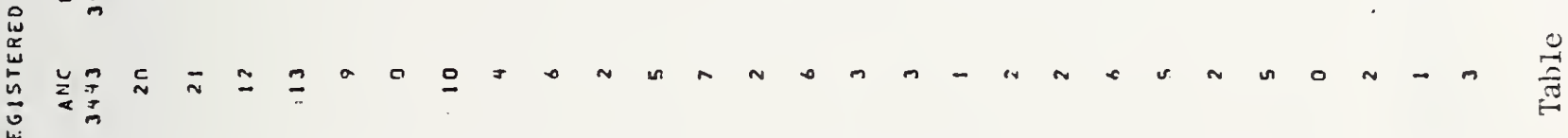

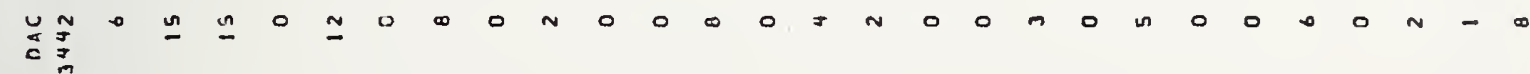
公

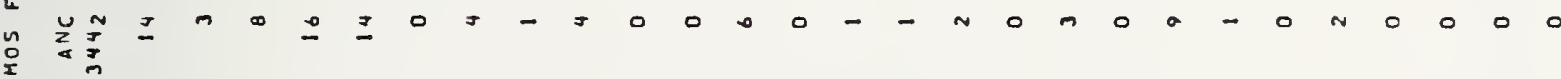

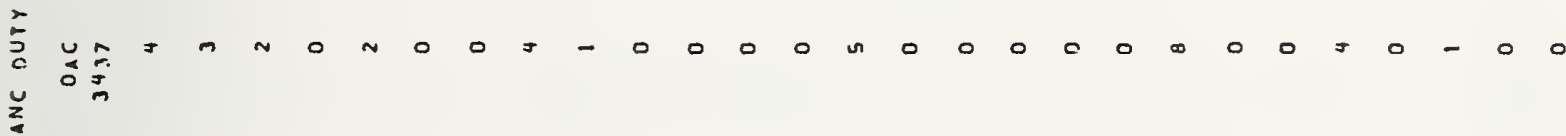

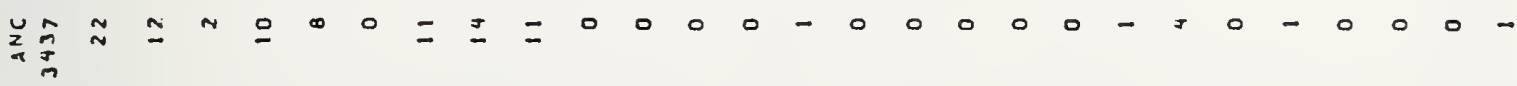

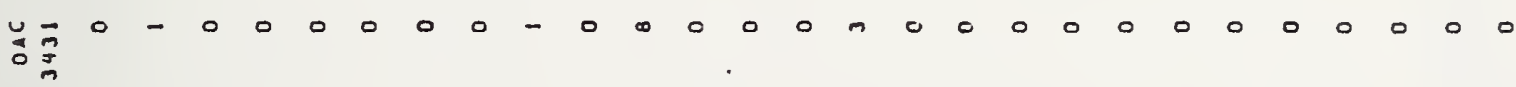

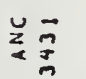

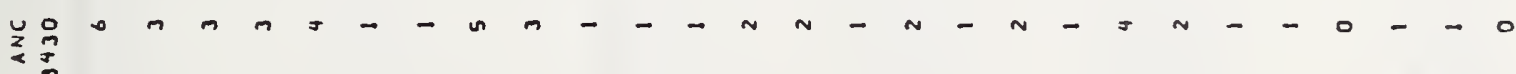

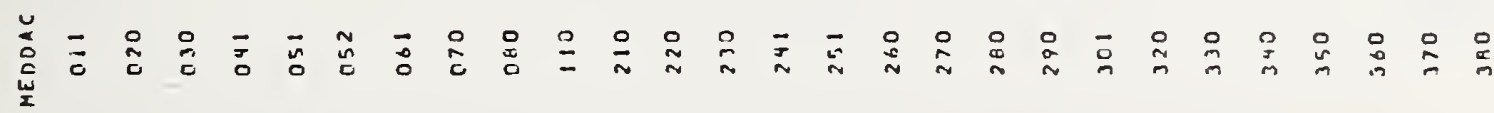
4-27 


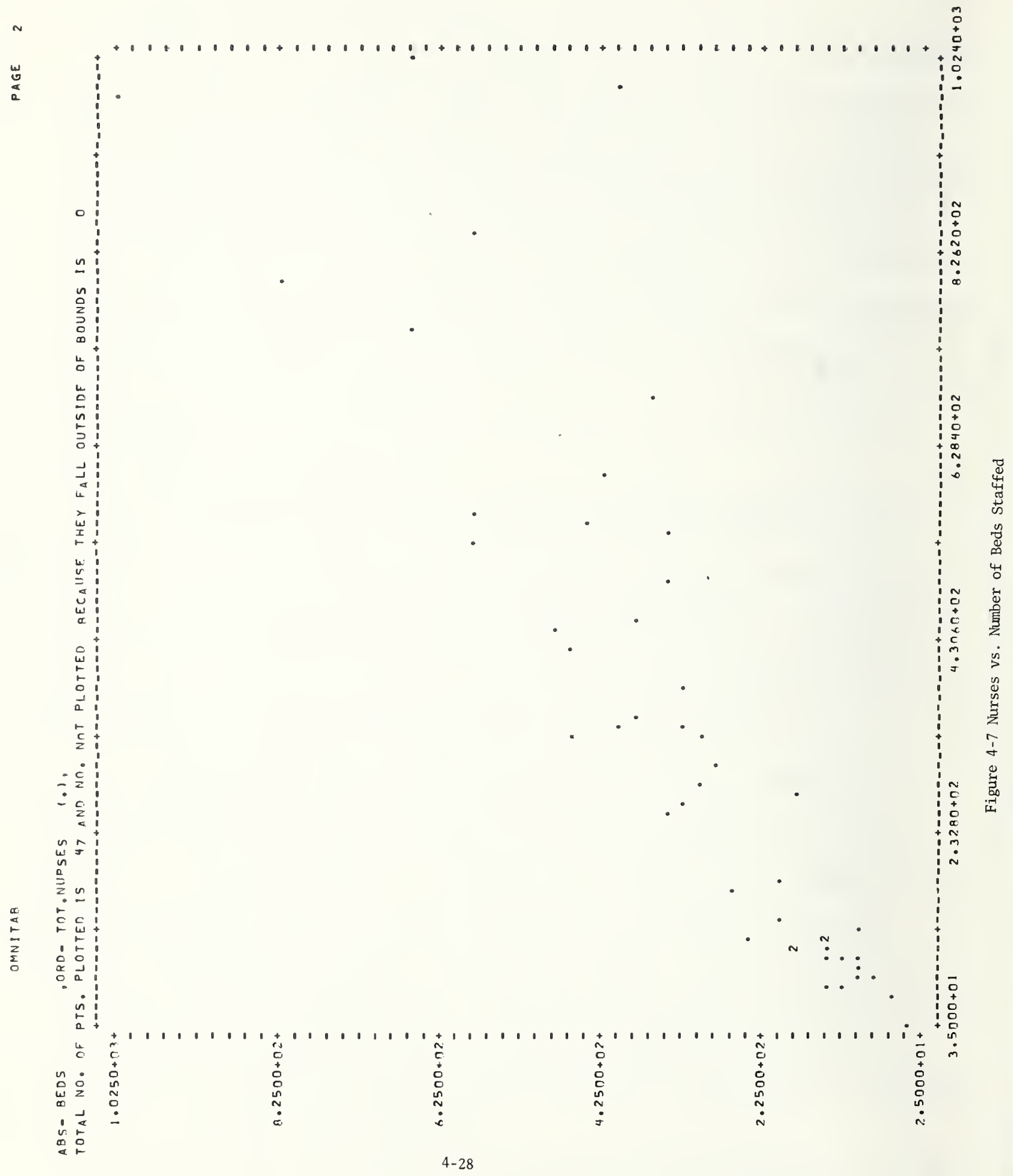




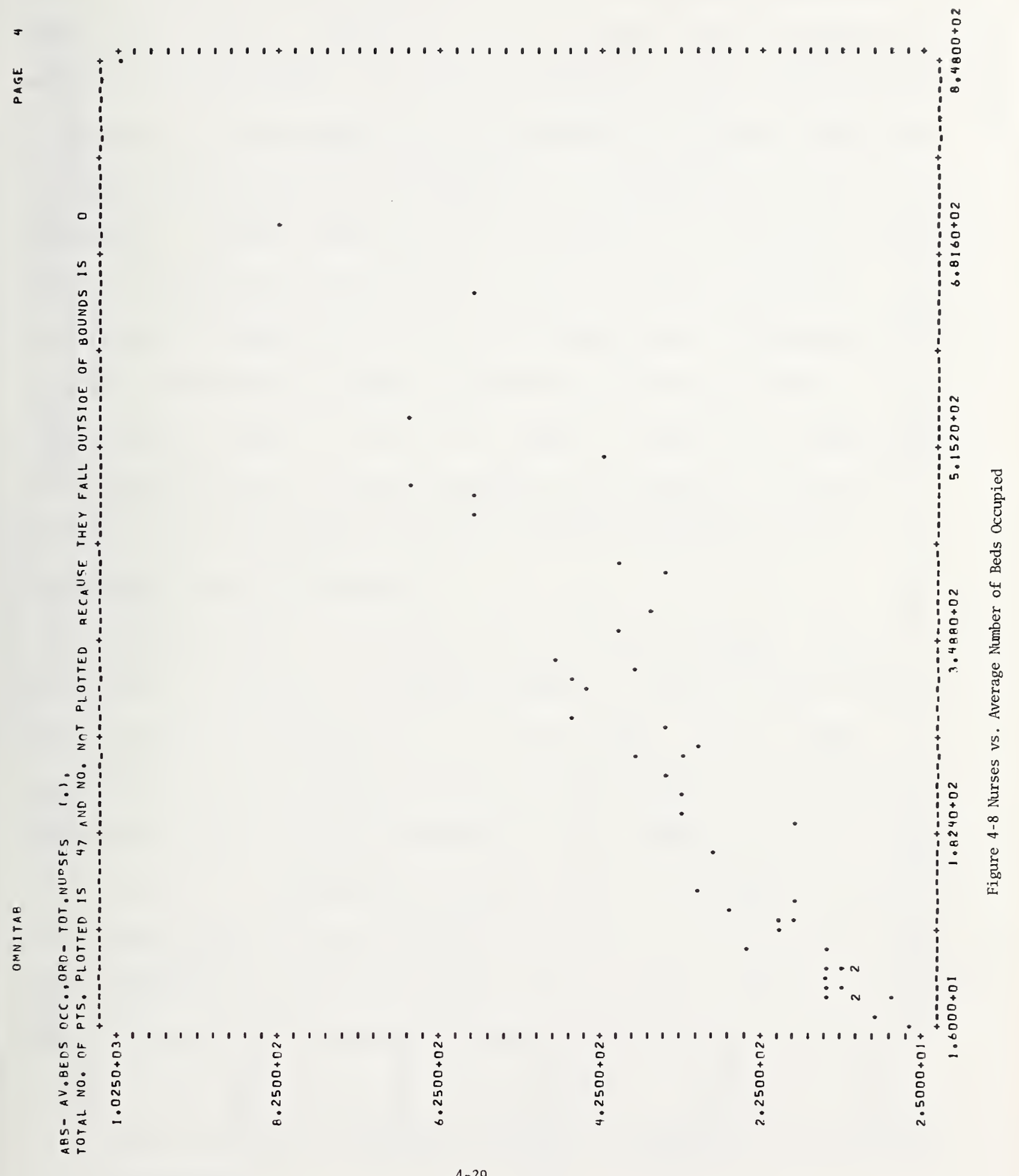




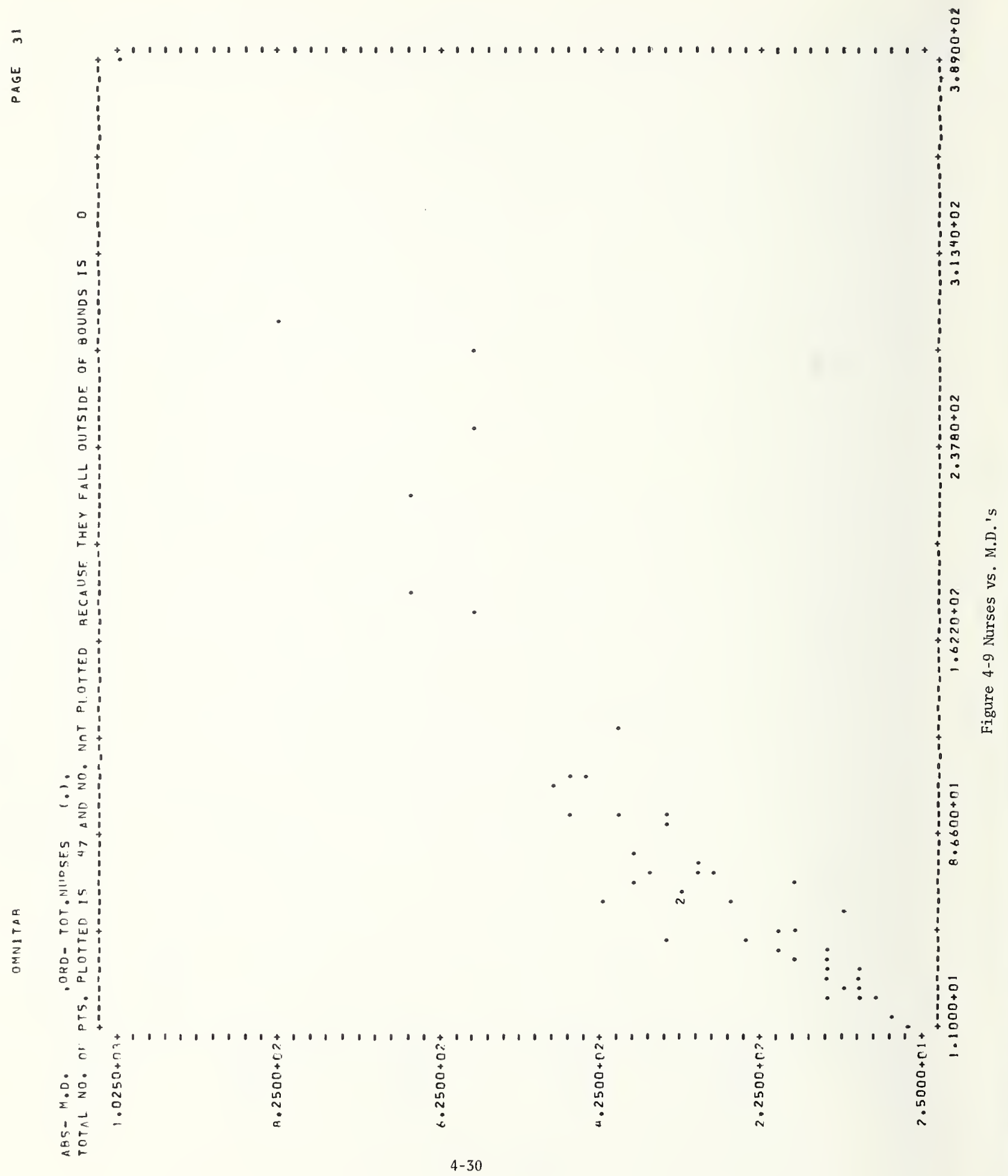


This basic factor in determining the required number of both civilian registered nurse and the ANC officers is somewhat modified by other factors such as: the number of M.D.'s on the staff, the amount of on the job training (OJT), the number of outpatient visits, and the number of intensely ill, as compared with the minimally ill patient. These four factors seem to be relatively secondary in the determination of the nurse requirements. Stated another way, once the numbers of staffed and occupied beds are determined, the other factors, i.e., the number of doctors, etc., are highly correlated with the number of occupied beds. Consequently, one can make a reasonably acceptable approximation of the total number of nurses required simply by counting the number of staffed and occupied beds. Once having made this basic determination, it is possible to revise the estimate of nurse requirements upward or downward depending upon the importance of the other factors.

The importance of the number of M.D.'s in the hospital in determining number of nurses is of special interest. It must be understood that a doctor's specialization, e.g., brain surgery, plastic surgery, psychiatry, etc., is significant. His particular speciality will have an important effect upon the requirements of the number of nurses. Figure 4-9 is a plot of the professional nursing staff vs. the number of M.D.'s. The extremely high correlation between the M.D.'s on the one hand and the professional nursing staff on the other hand is evident from the correlation matrix. One way of interpreting the high correlation is to say that the workload of the nursing staff is in part related to the number of M.D.'s and becomes an important independent variable in computing the nursing staff requirements. 
An additional set of figures appears in Annex II-10. The reader will note the high correlation between the staff and selected variables included in the regression-fitted relationships previously described. 4.5.3 Geographical Distribution

This analysis considers the original data matrix (Table 4-1) variables aggregated over broad geographical sectors, i.e., total and average values of the variables related to hospitals in the Continental United States (CONUS), Europe, All Other overseas locations, and the global aggregates. All of these values are presented in Table 4-4, which is the first page of Annex II-11 that a1so indicates the category to which each variable belongs.

In the data base (see Annex II-11), one observes that 5,600 professional nurses (2963 ANC + 2637 civilian registered nurses) serving in 63 hospitals or MEDDAC throughout the world, carried on a wide range of activities expressed in terms of the numerical values of the variables. For example, these 5,600 nurses: handled approximately one-half million admissions in FY 72; were involved in delivery of 54,000 births; handled over 20 million visits; reported over 4 million total bed-occupied days; and were involved in the delivery of service represented by over 15 million medical care composite units (MCCU) .

The geographical distribution of the enormous workload of these hospitals may be observed by comparing the columns for the Total CONUS 


\begin{tabular}{|c|c|c|c|c|c|c|c|c|c|c|c|c|}
\hline 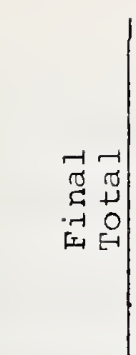 & 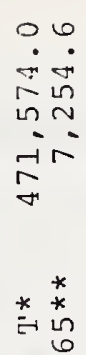 & \begin{tabular}{ll|}
0 & $\infty$ \\
$\dot{-}$ & $\dot{1}$ \\
$m$ & $m$ \\
- & $\infty$ \\
$\dot{n}$ &
\end{tabular} & 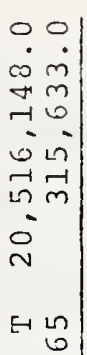 & 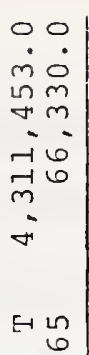 & 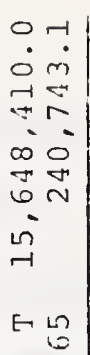 & $\begin{array}{ll}0 & n \\
\dot{\sigma} & m \\
\sim & \end{array}$ & $\left|\begin{array}{cc}0 & 0 \\
\dot{\infty} & \dot{1} \\
\infty & \dot{v} \\
-1\end{array}\right|$ & $\begin{array}{ll}0 & 0 \\
0 & 0 \\
0 & 0 \\
N & N \\
n \\
r\end{array}$ & $\left|\begin{array}{ll}0 & 7 \\
\sim & \ddots \\
\tilde{N} & 0\end{array}\right|$ & 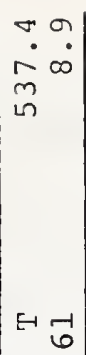 & 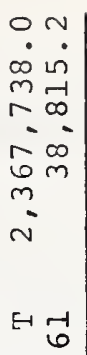 & \\
\hline 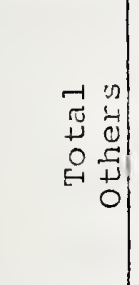 & 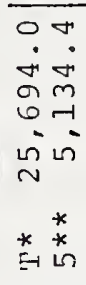 & 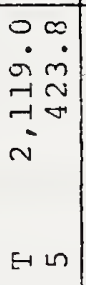 & 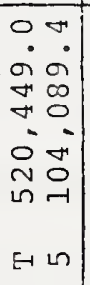 & 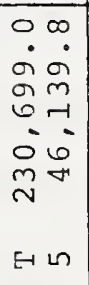 & 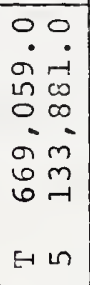 & $\begin{array}{ll}0 & 0 \\
\dot{n} & \dot{m}\end{array}$ & $\begin{array}{cc}0 & \infty \\
\nabla & 0\end{array} \mid$ & $\begin{array}{ll}0 & m \\
0 & 0 \\
i n & 4 \\
\infty & n \\
n & -1\end{array}$ & $\mid \begin{array}{ll}0 & n \\
\dot{N} & 0 \\
0 & n\end{array}$ & $\mid \begin{array}{ll}r & 9 \\
\dot{\sigma} & 0\end{array}$ & 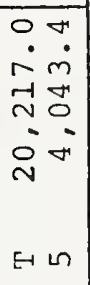 & \\
\hline 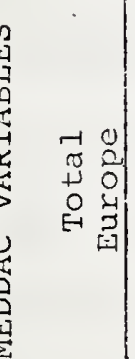 & 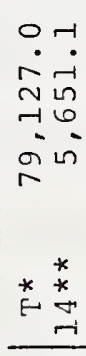 & $\begin{array}{cc}0 & m \\
0 & 0 \\
\infty & 0 \\
\vec{v} & 0 \\
\vdots & 0 \\
- & -1 \\
-1 & -1\end{array}$ & 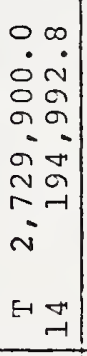 & 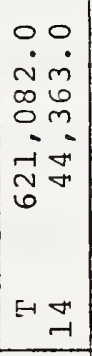 & 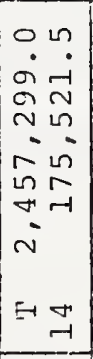 & $\begin{array}{cc}0 & N \\
\dot{\infty} & \dot{N} \\
m\end{array}$ & $\left|\begin{array}{cc}0 & 0 \\
\dot{0} & - \\
0 & \\
-1 & \end{array}\right|$ & $\mid \begin{array}{ll}0 & 0 \\
\dot{0} & 0 \\
\vec{r} & m \\
\sigma & -1 \\
-i\end{array}$ & $\left|\begin{array}{ll}0 & m \\
0 & -1\end{array}\right|$ & $\begin{array}{ll}\nabla & \infty \\
\infty & 0 \\
\infty & 0\end{array}$ & 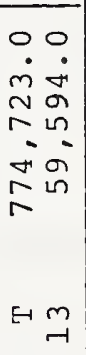 & $\begin{array}{l}7 \\
1 \\
7 \\
\square \\
\square\end{array}$ \\
\hline 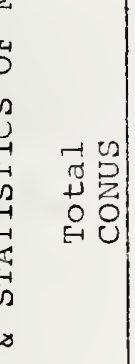 & 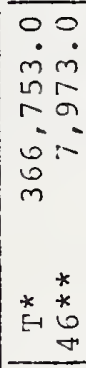 & $\begin{array}{ll}0 & m \\
\dot{\nabla} & \dot{7} \\
b & -1 \\
m & \infty \\
i & \end{array}$ & 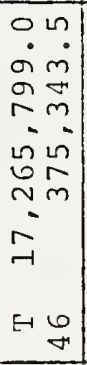 & 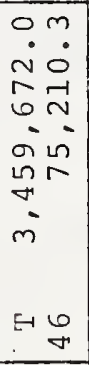 & 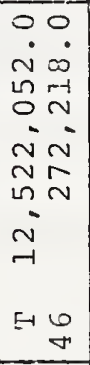 & $\begin{array}{ll} & \infty \\
\dot{m} & \dot{m} \\
r & \end{array}$ & 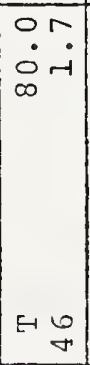 & $\begin{array}{ll}0 & m \\
\dot{m} & \vec{N} \\
0 & \tilde{r} \\
\vec{v} & \tilde{v} \\
\vec{v} \\
\vec{r}\end{array}$ & $\begin{array}{cc}0 & 0 \\
\dot{0} & \dot{n} \\
0 & -1 \\
i & -1\end{array}$ & $\begin{array}{l}m m \\
\dot{\sigma} \\
\sigma \\
m\end{array}$ & 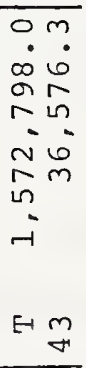 & 舃 \\
\hline 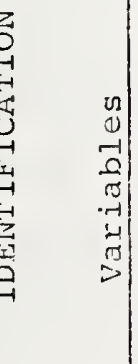 & 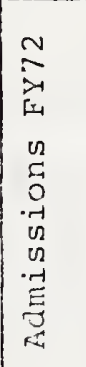 & 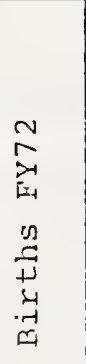 & $\begin{array}{c}N \\
2 \\
2-1 \\
=-1 \\
02 \\
+5 \\
-1 \\
0 \\
-1 \\
>-1\end{array}$ & 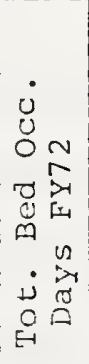 & $\begin{array}{l}N \\
2 \\
01 \\
w \\
0 \\
0 \\
y \\
z\end{array}$ & 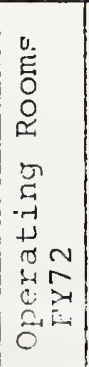 & 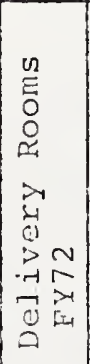 & 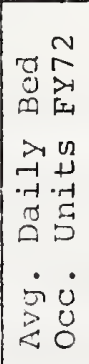 & 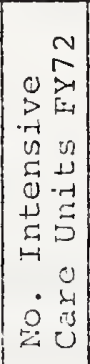 & 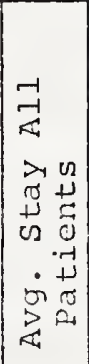 & 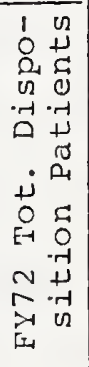 & 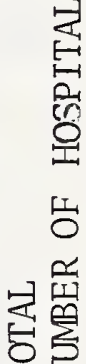 \\
\hline $\begin{array}{l}\dot{0} \\
\tilde{u}\end{array}$ & 3 & 3 & 3 & 13 & 3 & 3 & 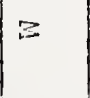 & 3 & 3 & $a$ & 0 & $* *$ \\
\hline
\end{tabular}


with that of the rest of the world. Very roughly, it appears as if almost 80 percent of the total workload (MCCU FY 72) was carried on in the Continental United States, somewhat under 20 percent of it was carried on in Europe, and the remaining 4 percent was carried on in other parts of the world, including Alaska, Korea, and Southeast Asia.

It is the quantitative expression of these numbers which constitutes the current nursing workloads. One can express these workloads in terms of the average number of nurses required in hospitals of various sizes, the number of MOS's required per hospital, and so on. The workload ultimately must be expressed in terms of the number of professional nurses necessary to do the job. Since the total nursing force consists of both civilian and military nurses, there will be tradeoffs in assignments whereby civilian nurses will sometimes be doing military jobs and military nurses will, on occasion, be required to assume some of the more traditional civilian nursing jobs.

\subsection{Quality of Care}

One of the roles of the U. S. Army nurses resides in their contribution to the quality of patient care, and therefore a study of the Army Nurse Corps should examine the extent to which the quality of patient care is affected by the number of nursing staff.

The difficulty with this statement is that the quality of patient care is an extremely complex subject, involving a substantial number of 
variables, in which the role of the nursing staff cannot be fully determined, except under the most controlled conditions.

Even the measurement of quality of patient care poses its problems; how, for example, can the numerous indicators of patient care (e.g., hospital infection rate, complaint rate, average length of stay, etc.) be combined into one single composite index for each hospital? With such an index it would be possible to compare any two hospitals, rank-order a list of hospitals, or determine whether overall quality of patient care was improving or deteriorating at a given hospital.

The purpose of this section is: (1) to develop a first-cut methodology for the construction of such a composite index for the overall quality of care, and (2) to apply this index to the MEDDAC data base and note the results obtained.

4.6.1 Theory

In previous studies quality of care has been represented by a vector of several variables or indicators, often including hospital infection rate, care complaint rate, average stay for special surgeries, etc. The total number of such variables comprising the quality of care vector is ordinarily large (nine in this study), and should supply the user with substantial information about the quality of care at any given hospital.

This approach, however, has two principal shortcomings: a) direct comparisons of the overall quality of care between hospitals cannot be made-from which it follows that the list (or any sublist) of hospitals 
cannot be rank-ordered by quality of care, from highest to lowest, and b) the contribution of each component contains other effects which tend to obscure the true indicator of quality of care.

The solution to this problem resides in the establishment of a single index which will represent overall composite quality of care. The composite indicator will permit comparisons between (and rank ordering among) the various hospitals in the survey and can be used to determine changes in overall quality of care at a given hospital through time. To show how this is done suppose that $v_{1}, v_{2}, \ldots v_{n}$ stand for the $n$ variables comprising quality of care. The quality of care index is a scalar, related to these $v^{\prime} s$, which in its most general form is given by the function:

$$
\mathrm{QOC}=\mathrm{f}\left(\mathrm{v}_{1}, \mathrm{v}_{2}, \ldots, \mathrm{v}_{\mathrm{n}}\right) \cdot
$$

One of the simplest candidates for (8) is the unweighted, additive composite given by:

$$
\mathrm{QOC}=\mathrm{v}_{1}+\mathrm{v}_{2}+\ldots+\mathrm{v}_{\mathrm{n}} \text {. }
$$

Before (9) can be applied, however, several important steps must be carried out. The first of these is normalization, in which each variable is adjusted so as to be on a per patient basis; that is, total infections or total complaints must be first divided by admissions to arrive at a per patient rate. The next step is to introduce standardized (dimensionless) variables, of the form:

$$
\mathrm{v}_{1}=\left(\mathrm{v}_{1}-\overline{\mathrm{v}}_{1}\right) / \sigma_{1},
$$

where $\bar{v}_{1}$ is the mean for the set of hospitals under consideration and $\sigma_{1}$ the standard deviation of the first variable, $v_{1}$. The reason for using standardized variables, instead of original variables, is to insure that 
no one variable dominates or overpowers the others (or is, conversely, "lost" if small in magnitude), due to its particular choice of dimensions. The third and equally important step is to select the form of the original variable $v_{1}$ for use in (10) for which increasing $v_{1}$ (or $v_{1}$ ) implies increasing quality of care. That is, all individual quality of care variables utilized must be compatible in direction as well as dimension. To illustrate, the variable "unusual occurrences" should not be directly combined with "hospital infection rate." Instead, unusual occurrences/ admissions should be combined with the normalized hospital infection rate.

The quality of care index, QOC, in (9) can be regarded, in effect, as a score in an examination where the questions have equal weight. Should the user feel that certain components must count more heavily than others, then the differentially weighted composite:

$$
\mathrm{QOC}=\mathrm{a}_{1} \mathrm{~V}_{1}+\mathrm{a}_{2} \mathrm{~V}_{2}+\ldots+\mathrm{a}_{\mathrm{n}} \mathrm{V}_{\mathrm{n}}
$$

can be used. As is readily apparent, (11) reduces to (9) when all the $a_{i}$ 's are unity. One final caveat that must be made is that the set of individual indicators $V_{i}, i=1,2, \ldots, n$ should be as statistically independent (see 6.3.2, page 6-8) as possible. That is, if the indicators in a certain subset were highly correlated with each other, their combined effect might be to dominate the composite index, reducing its sensitivity to variations in the remaining indicators. If high statistical dependence is known or suspected among certain indicators they should be combined into subgroups with the resulting subcomposites used to form the final composite index. For example, if it were the case that $V_{1}, V_{3}$, and $V_{7}$ were highly correlated, one could replace them with the variable $V_{1}$, formed as indicated below. 
In general, one tries to introduce groupings of the form:

$$
V_{j}^{\prime}=\frac{1}{n_{j}} \sum_{i=1}^{n_{j}} V_{k_{i}}, \quad \text { (where } \Sigma n_{j}=n \text { ) }
$$

such that the sets $\left\{\mathrm{V}_{\mathrm{k}_{i}}\right\}$ have the highest arrangeable internal correlations, with the resulting subcomposites $V_{j}^{\prime}$ having the lowest arrangerhbe extemal correlations among themselves.

In sumnary, therefore, what the composite quality of care index (9) or (11) loses in its ability to detail the spectrum of quality of care at a given hospital, it makes up for by permitting comparison between, and rank ordering of, any group or subset of hospitals.

\subsubsection{Application}

Let us now put theory into practice Figures 4-10 through 4-18 present the normalized form of the following nine quality-of-care indicators (ordinate) plotted against hospital size (abscissa) and selected for inclusion in the composite index:

\section{Unnormalized Normalized}

(1) Hospital infection rate

(2) Average stay, all procedures

(3) Average stay, general surgery

(4) Average stay, appendectomy

(5) Average stay, hernia

(6) Average stay, cholelithiasis

(7) Care complaints, medical

(8) Unusual occurrences

(9) Nursing attitude

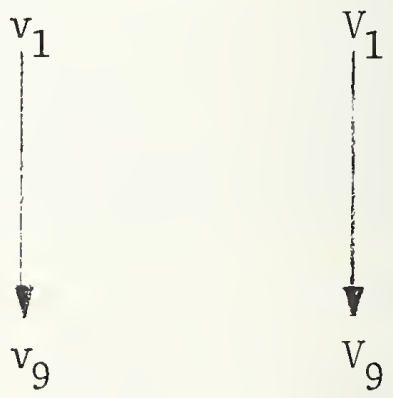

The last indicator, nursing attitude, is a variable expressing the fraction of the nursing staff that believes its hospitals to be below average in overall patient care; in this sense it is normalized on a per patient basis. Notice that increases in the magnitude of any of these indicators 
imply uniformly decreasing amounts of quality of care, and the set of indicators therefore satisfies the necessary axiom of direction, as called for in the definition of composites.

Let us now regard the figures themselves. The $x$ axis (abscissa) in all figures is the hospital size (in beds); the $y$ axis (ordinate) is the value of the normalized quality of care indicator $\left(V_{i}\right)$ - the number of standard deviations from the mean assumed by the original unnormalized variable $\left(v_{i}\right)$. For convenience the $y$ axis has been labeled "Score" in Figures 4-10 through 4-18.

In Figure 4-19, where the total composite quality of care indicator is presented (based on Equation (9)) we see what the individual indicators could not really tell us: That overall quality of care is enhanced with decreasing hospital size. Virtually all hospitals of from 10 to 100 beds have better than average quality of patient care, and almost all moderate to large hospitals (from 150 to 1000 beds) are seen to have below average quality of patient care. This could be a profound result, but must be verified by substantial additional research. This caveat is made because what we have labeled as "quality of care" is certainly net synonymous with true quality of care, but is merely a score on an exam whose results would hopefully correlate well with the abstract and rather subjective concept we are trying to measure. With this warning in mind we present Table 4-5 containing the rank-ordered quality of care index starting with the largest positive value (i.e., "worst") and going to the largest negative value (i.e., "best") for the 62 U. S. Army hospitals, worldwide. 


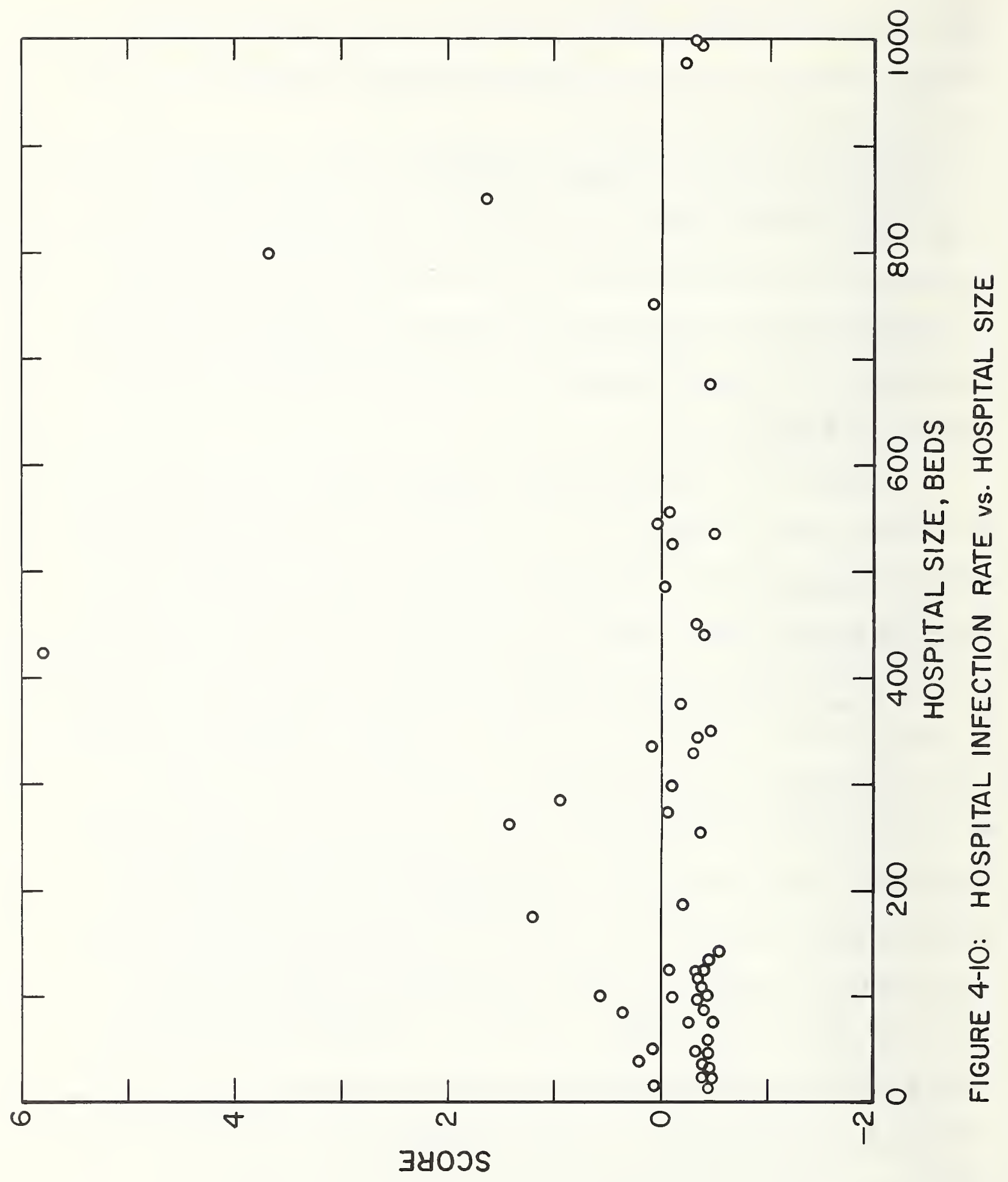




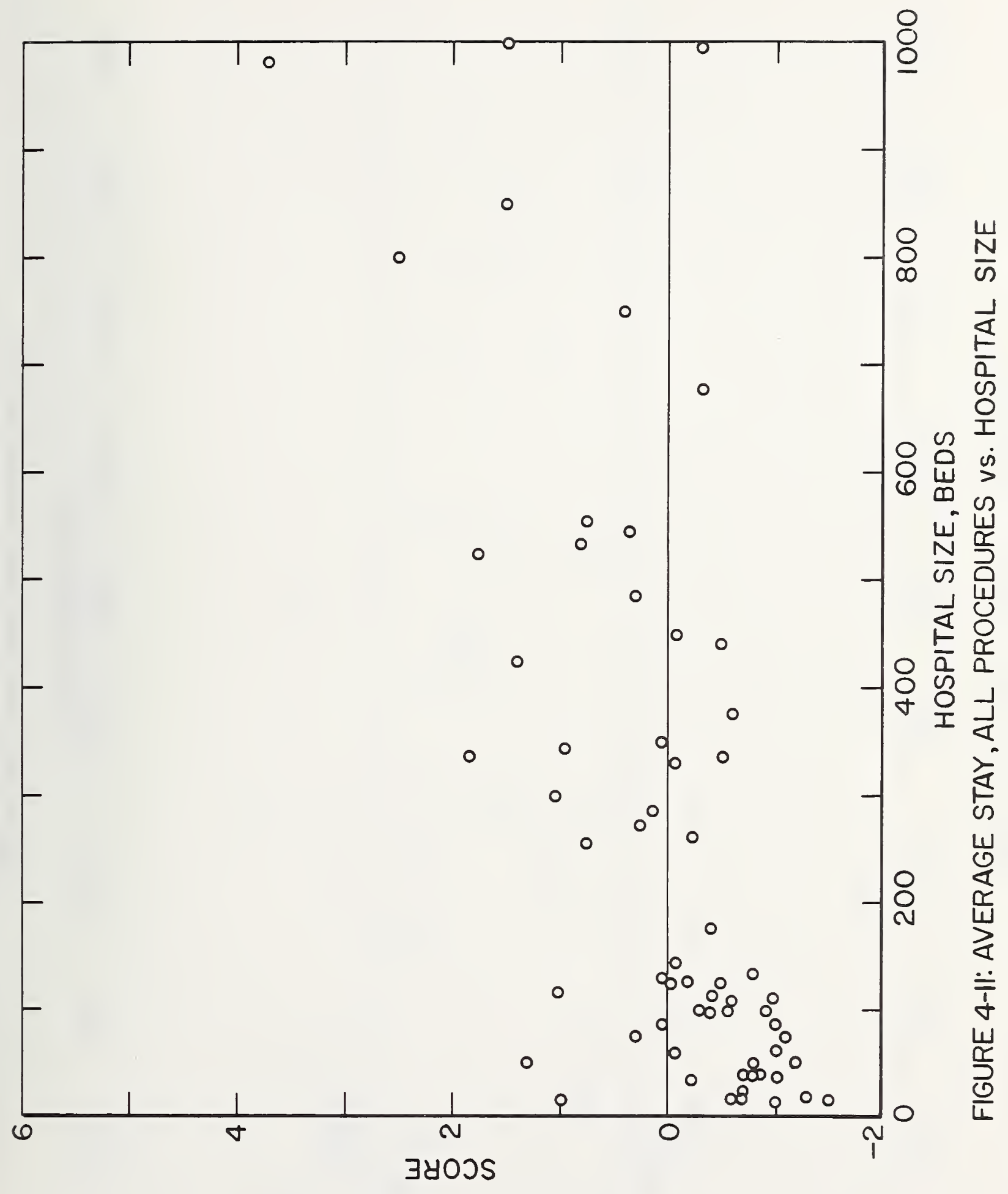

4-41 


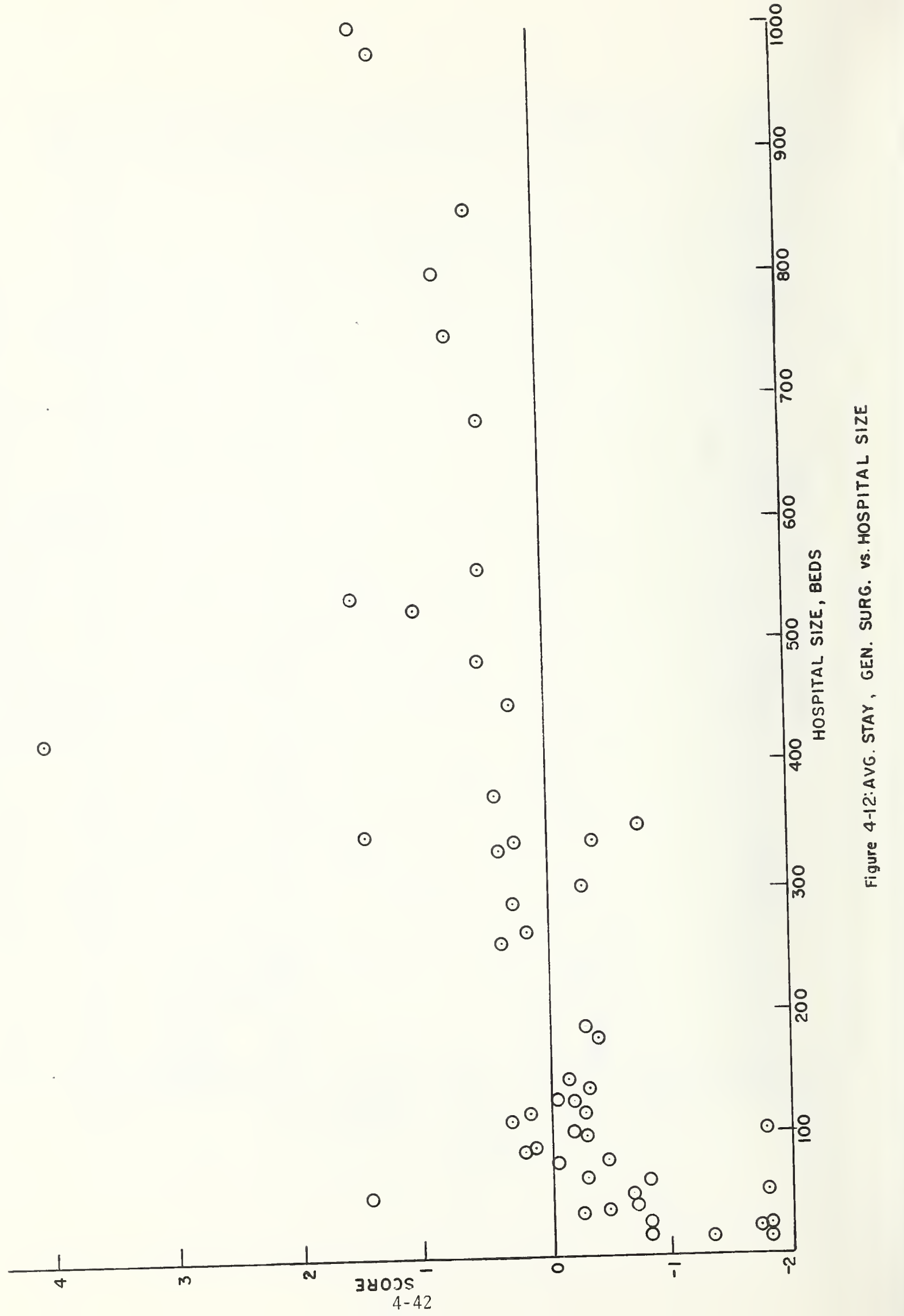


$\odot$

$\odot$
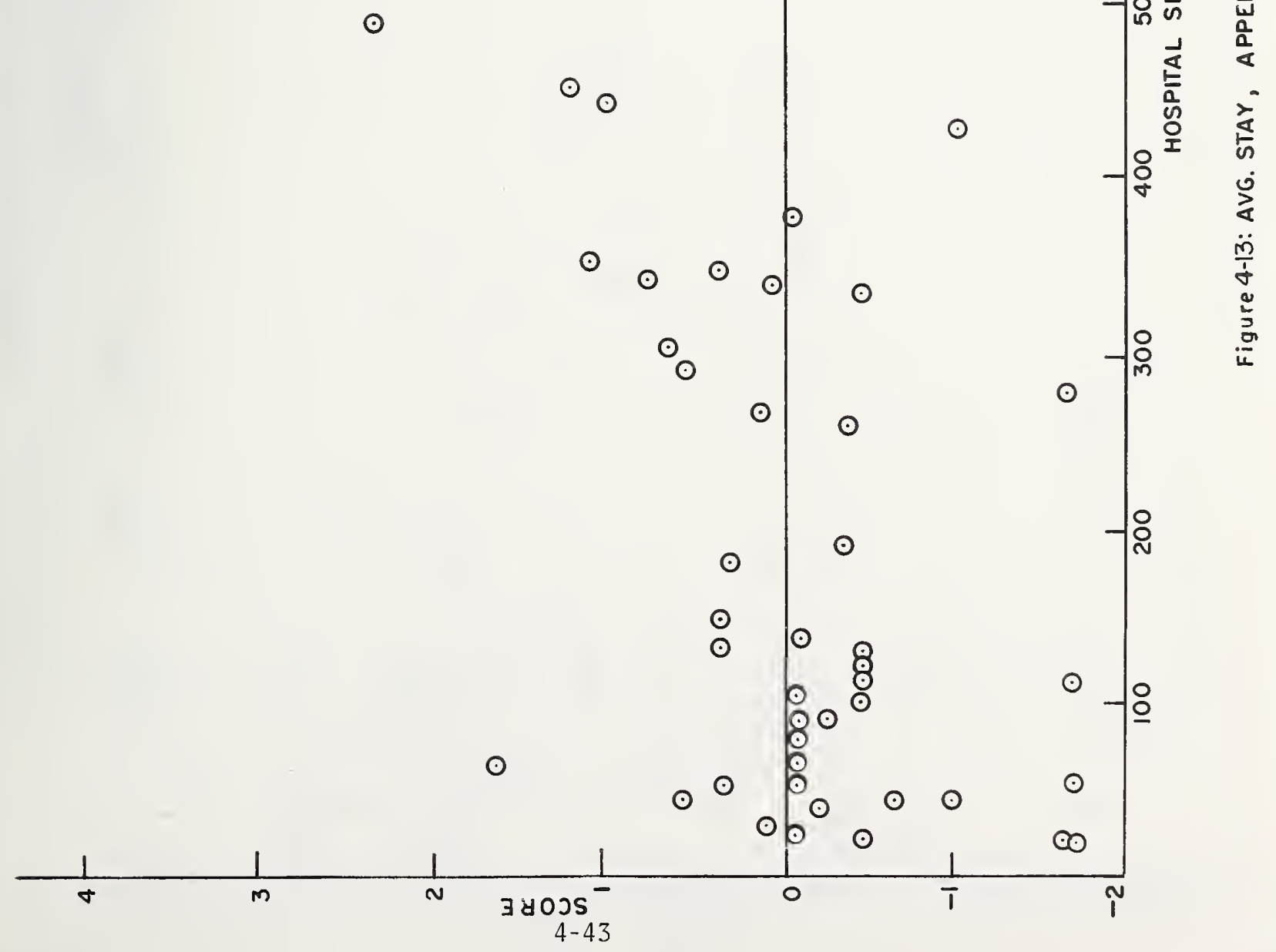


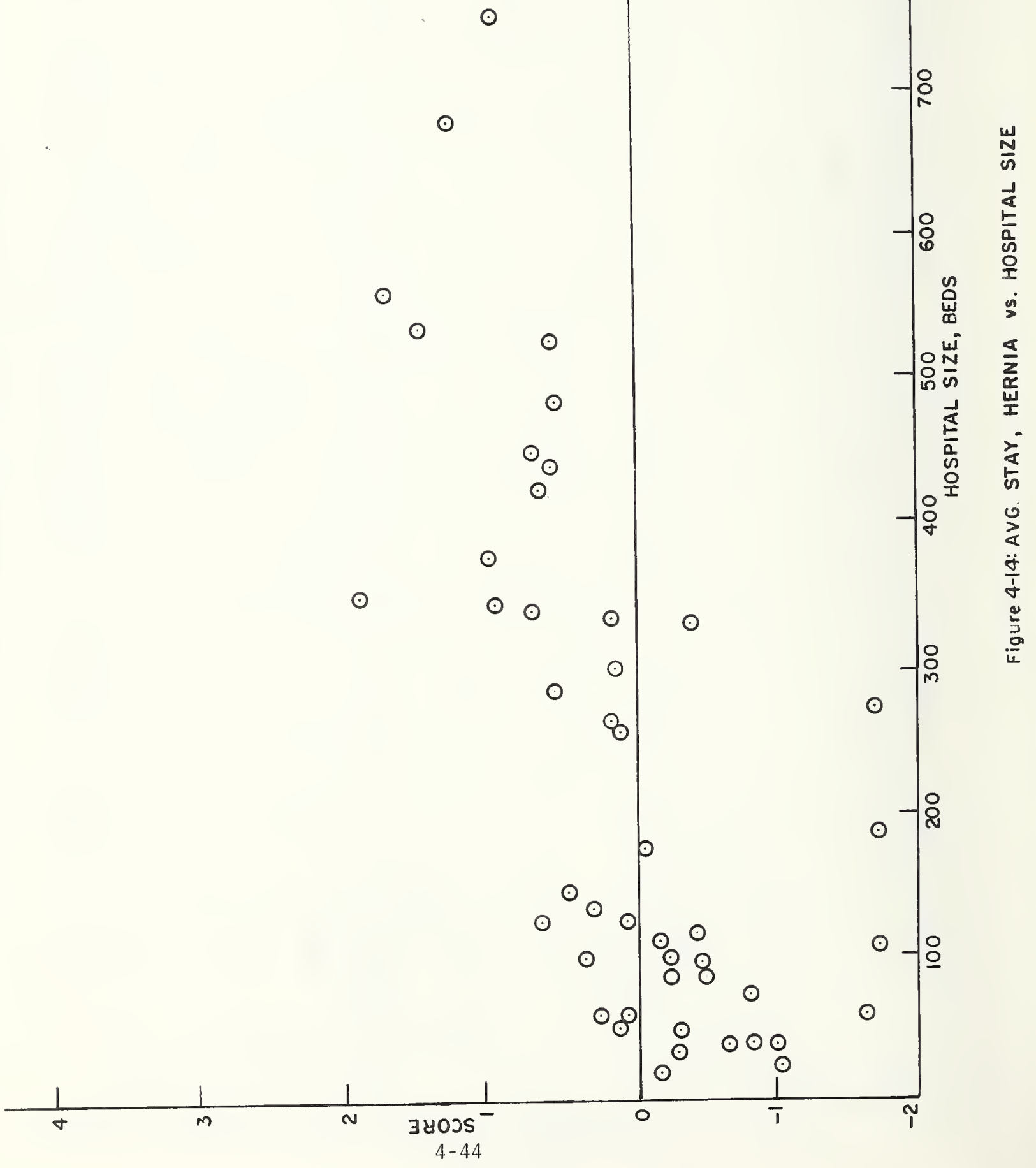




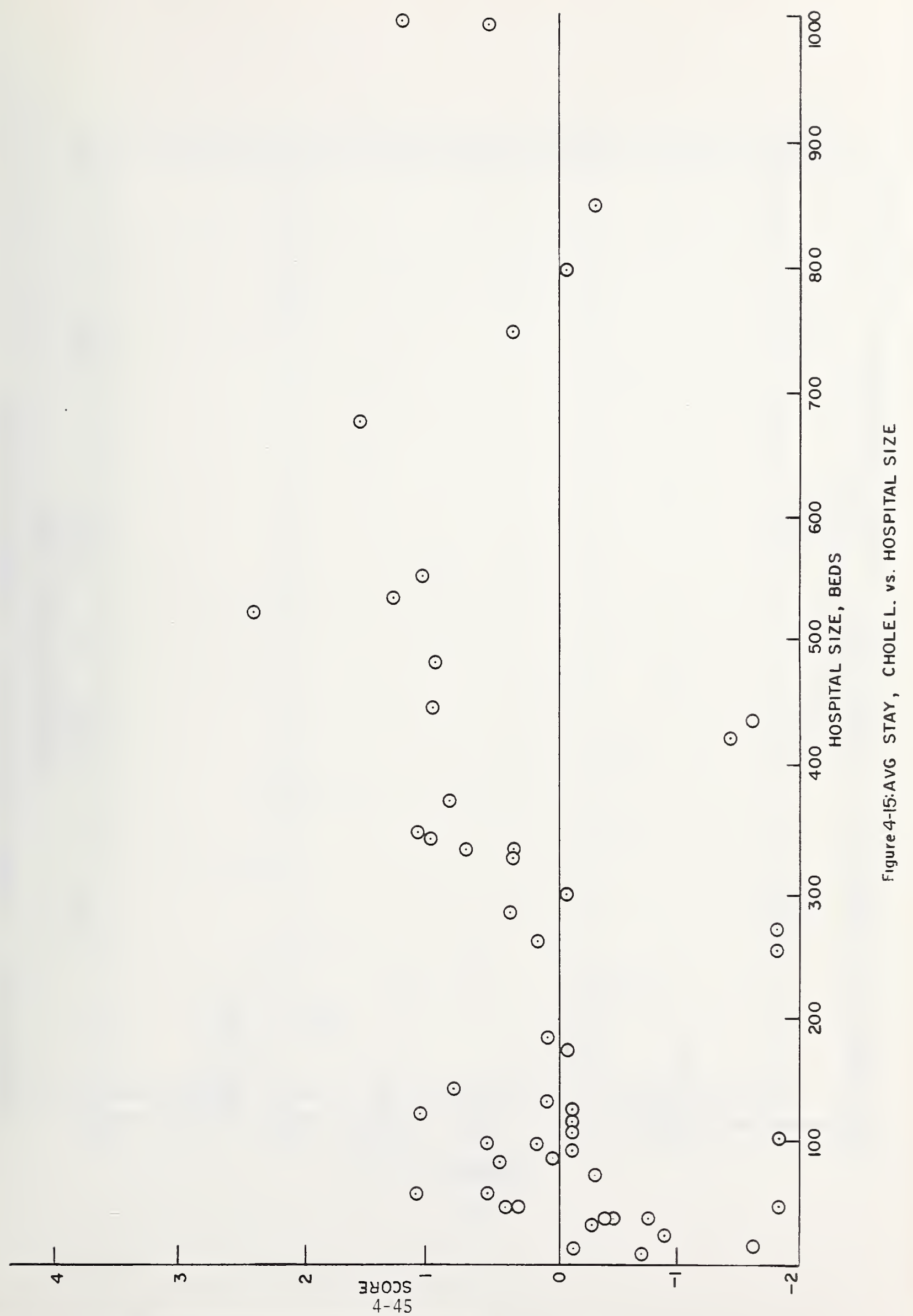




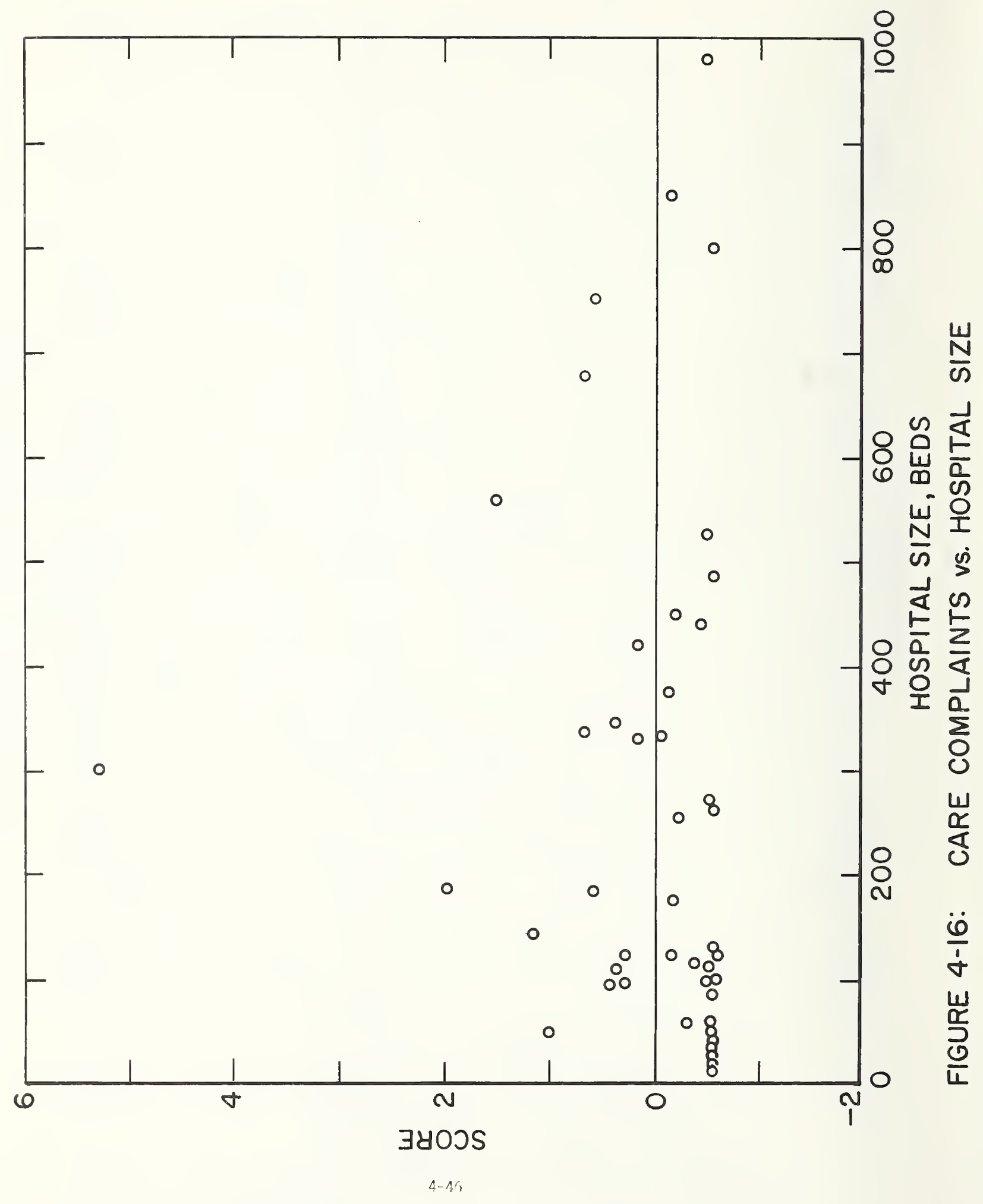




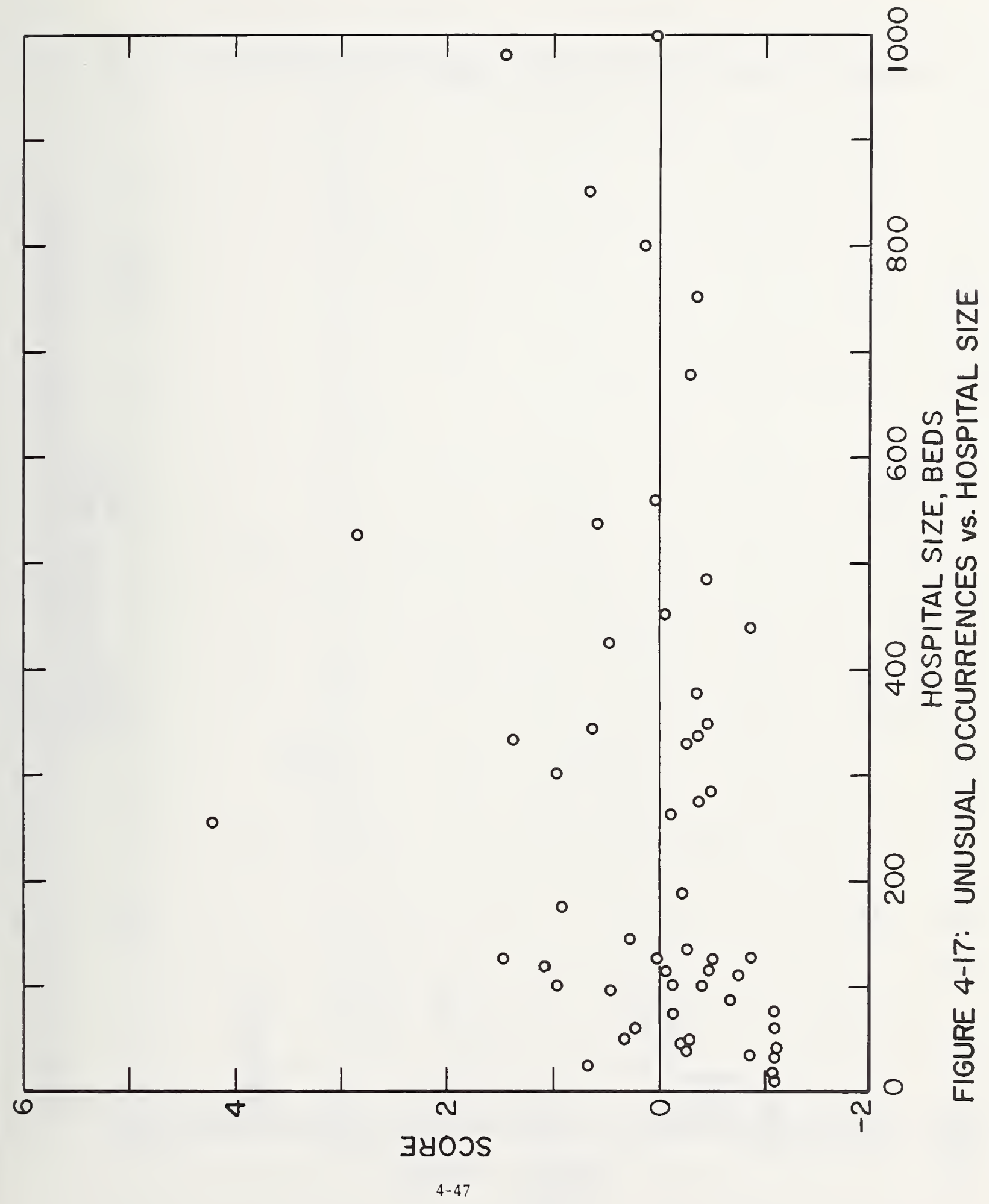




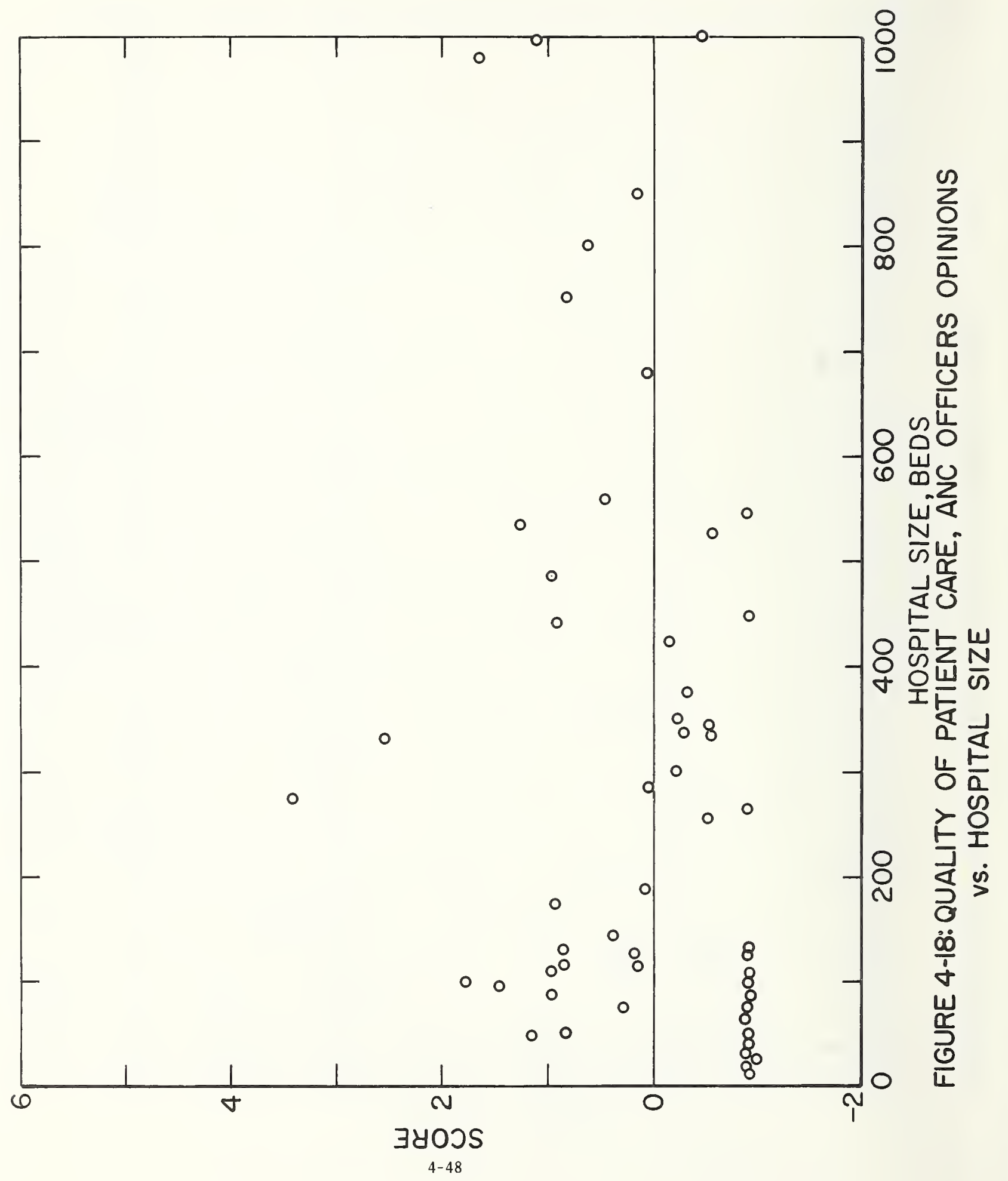




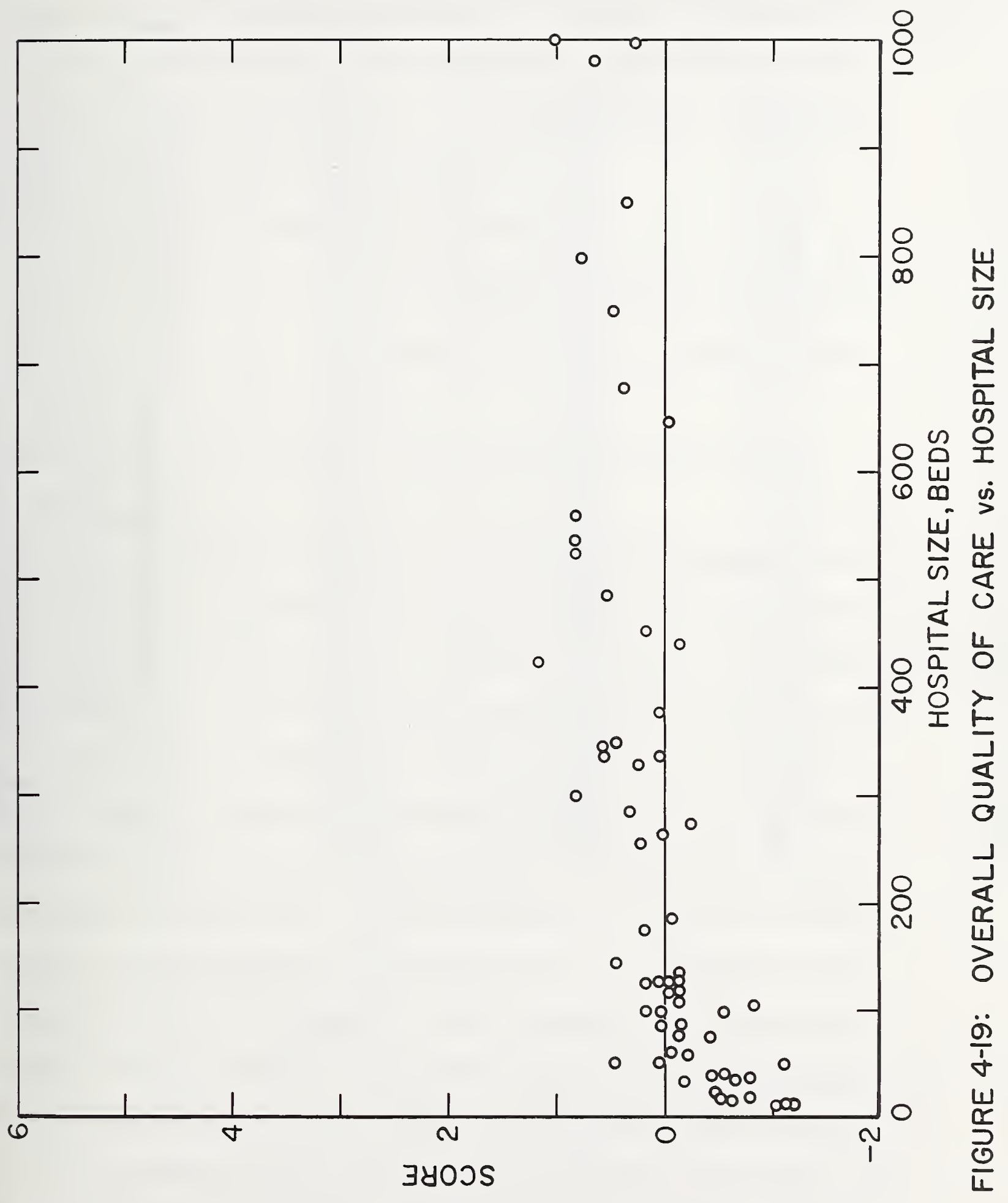


Rank-Ordered Composite Quality of Care

\begin{tabular}{|c|c|c|c|c|c|}
\hline Hospital \# & Beds & Q.O.C. & Hospital \# & Beds & Q.O.C. \\
\hline 800 & 422 & 1.1165 & 350 & 50 & .0140 \\
\hline 030 & 1024 & 1.0684 & 490 & 261 & .0138 \\
\hline 061 & 525 & .8186 & 390 & 546 & -.0587 \\
\hline 550 & 300 & .8178 & 640 & 60 & -.0628 \\
\hline 051 & 559 & .8152 & 251 & 186 & -.0668 \\
\hline 241 & 535 & .8128 & 210 & 116 & -.0877 \\
\hline 020 & 800 & .7835 & 871 & 130 & -.0939 \\
\hline 011 & 980 & .6374 & 290 & 126 & -.1309 \\
\hline 410 & 339 & .5855 & 500 & 110 & -.1320 \\
\hline 470 & 344 & .5422 & 561 & 132 & -.1419 \\
\hline 690 & 485 & .5147 & 520 & 440 & -.1438 \\
\hline 810 & 750 & .4815 & 720 & 115 & -.1476 \\
\hline 820 & 50 & .4653 & 270 & 75 & -.1569 \\
\hline 830 & 350 & .4383 & 360 & 88 & -.1806 \\
\hline 260 & 142 & .4235 & 850 & 35 & -.2031 \\
\hline 340 & 679 & .3821 & 510 & 60 & -.2235 \\
\hline 041 & 850 & .3477 & 710 & 272 & -.2632 \\
\hline 450 & 285 & .3284 & 380 & 75 & -.4095 \\
\hline 301 & 997 & .2805 & 440 & 40 & -.4297 \\
\hline 320 & 254 & .2416 & 230 & 25 & -.4934 \\
\hline 670 & 330 & .2116 & 730 & 19 & -.5237 \\
\hline 680 & 175 & .2046 & 370 & 40 & -.5387 \\
\hline 460 & 450 & .1747 & 860 & 15 & -.6283 \\
\hline 630 & 125 & .1701 & 660 & 35 & -.6350 \\
\hline 400 & 100 & .1550 & 740 & 20 & -.7983 \\
\hline 430 & 378 & .0855 & 610 & 40 & -.7993 \\
\hline 280 & 125 & .0477 & 480 & 106 & -.8328 \\
\hline 220 & 334 & .0454 & 530 & 12 & -1.0101 \\
\hline 620 & 100 & .0415 & 052 & 50 & -1.0679 \\
\hline 420 & 85 & .0360 & 521 & 12 & -1.1223 \\
\hline 330 & 98 & .0177 & 540 & 18 & -1.1498 \\
\hline
\end{tabular}

Table 4-5 
Because of the possibility that the average length of stay for the various surgical procedures may not be sufficiently statistically independent, with the same possibility for the two "complaint" rates, let us formulate an alternative quality of care index utilizing the procedure outlined earlier. If $V_{1}, i=1,2, \ldots, 9$ stands for the nine separate quality of care indicators, let

$$
\begin{aligned}
& q_{1}=v_{1} \text { (the hospital infection rate) } \\
& q_{2}=\left(v_{2}+v_{3}+v_{4}+v_{5}+v_{6}\right) / 5 \text { (a subcomposite of average length } \\
& \text { of stay) } \\
& q_{3}=\left(v_{7}+v_{8}\right) / 2 \text { (a subcomposite of the two "complaint" rates) } \\
& q_{4}=v_{9} \text { (nursing attitude) }
\end{aligned}
$$

and now define the alternative composite quality of care index as

$$
\mathrm{QOC}_{\text {alternative }}=\mathrm{q}_{1}+\mathrm{q}_{2}+\mathrm{q}_{3}+\mathrm{q}_{4}
$$

The use of (12), however, does not change the fundamental conclusion, as is succinctly illustrated in Figure 4-20. Not only does the trend remain the same, but the fitted curves in Figures 4-19 and 4-20 are virtually identical! This "stability" of fit supports and strengthens the original conclusion.

This does not complete the analysis, however, for one question that was posed in Section 1.3 was whether quality of care is correlated with the level of residual nursing staff at the individual hospitals. By residual nursing staff is meant the difference between the actual levels and the corresponding staff levels that are predicted by the "regression" fits in Section 4.4. These residuals were computed and normalized for 47 hospitals and appear in Figure 4-21. graphed against the corresponding quality of care index. As it was the smaller hospitals for which the residual nursing levels were not calculated (the original list had 67 hospitals), most points are seen to lie above the mean QOC axis (where $\mathrm{QOC}=0$ ). 


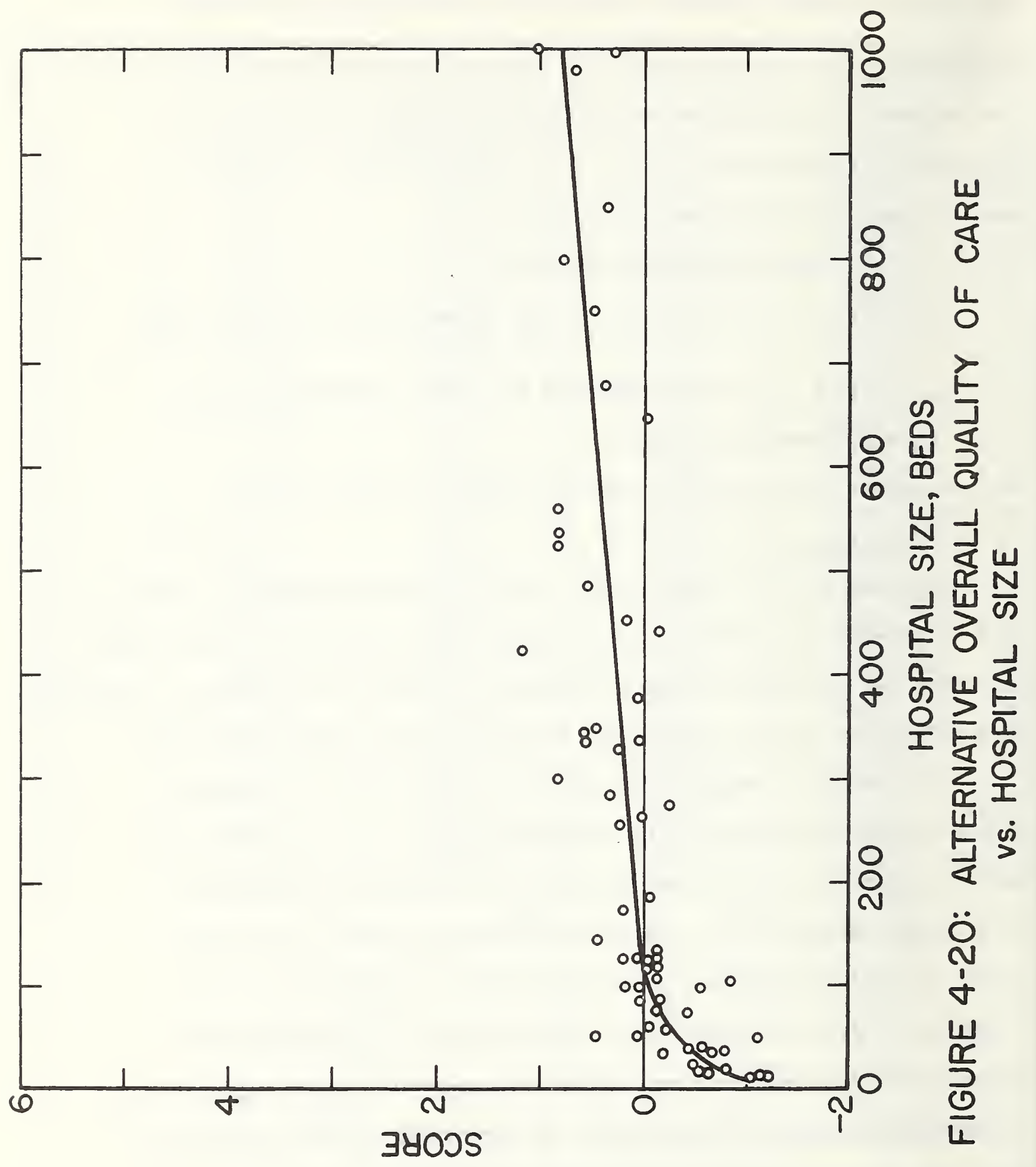




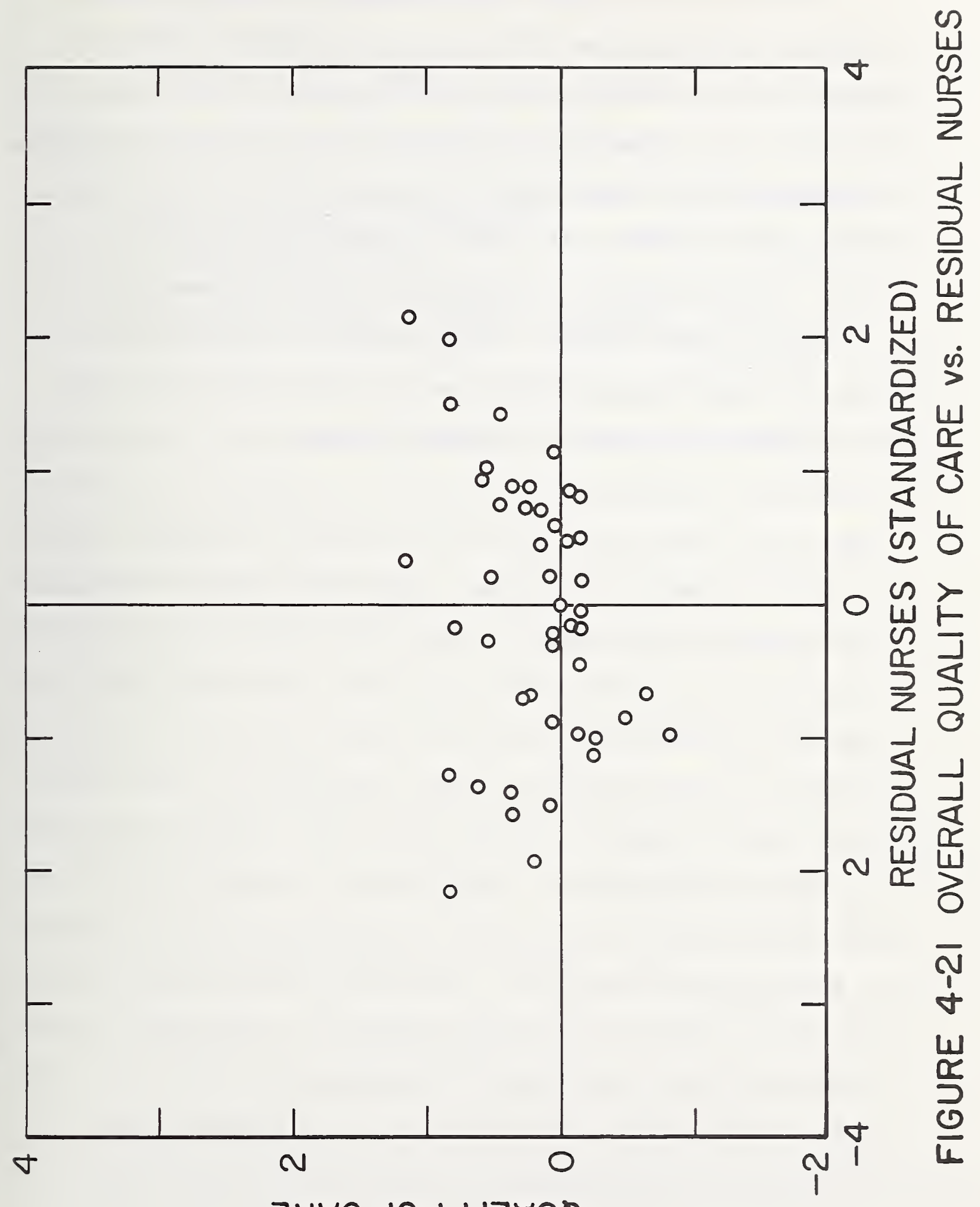

$\exists \forall \forall J ~ J 0 \wedge \perp 17 \forall \cap 0$ 
The point to note is that the average level of quality of care, as measured by the indicators of this study, for those hospitals with shortages in nursing staff (to the left of the vertical axis) is just about equal to the average level of quality of care for those hospitals with overages (to the right of the vertical axis). This implies that what this study has taken to be quality of care does not appear to correlate with the averages or shortages of nurses, as observed, in the various U. S. Army hospitals. The true extent of the effect of nursing staff quality (and quantity) upon the quality of patient care must, of course, be the subject of further research. 


\subsection{ANC Force Structure Simulation Mode1 (ANCFSM)}

The model was designed and developed by the team members to predict the characteristics of future ANC force structures and to help answer questions such as those raised in Section 2.0, namely:

1. Is there an effective way to describe quantitatively the annual changes in the ANC grade structure?

2. Is it possible to develop a model of the ANC which can generate specific configurations?

3. How many lieutenants are required for initial entry by phased year to attain and maintain a specific configuration?

4. How long will it take to achieve a specific configuration?

This aspect of the study was to provide management with a tool to aid decision-making in the areàs of recruitment, training, promotion, retention, separation, and retirement. To do this, it was necessary to comprehend the statutes, regulations, policies, and practices which govern the movement of officers within the Nurse Corps. Further, this movement of nurses had to be understood in terms of the three different promotion systems which prevail (the Regular Army or RA System, the Reserve Army or USAR System, and the Army of the United States or AUS System) and their main features regarding zones of consideration, rules of selection, pass-over differences between the components of the Army, and the regulations described in Part III which deal with separation and retirement. As mentioned in Section 2.3, the precepts and rules governing all transitions of nurses from one status to mother fall into three main groups: (1) statutes and regulations (e.g., retirement regulations); (2) annual policies made by various policy-making groups (e.g., zones of consideration for promotions); and (3) precedents set by historical experience (e.g., transfers from USAR to RA or changes in MOS). These regulations and practices are incorporated in the simulation model. 
The basic portrayal of the force structure in this work is one in which officers having closely related values of certain characteristics, e.g., dates of rank, MOS, years of service, etc., are placed, by definition, in the same cohort group. The transition rules operate on the cohort groups rather than on the individual offtcers. When these rules have been applied to all cohort groups for a particular simulated year, the resulting new cohort groups are then ready for processing for the next year. Among the changes that are provided for, and which may operate on some or all members of a cohort group, are: permanent and/or temporary promotions, transfer from the Reserve to the Regular Army, change of MDS, involuntary separation, voluntary separation (attrition), and retirement. One can think of each officer, in any particular year, as 1ocated in some particular "box" (cohort group). Departure from this box takes place after the model has essentially asked such questions as "Is this officer ready for promotion?", Is the officer one who may change his/her MDS or may transfer from the Reserve to the Regular Army?", "Is the officer one who may undergo attrition?", etc. The result of positive answers to these questions is, in effect, that the officer is removed from the current box and placed (for the next year) in the appropriate new box.

In summary, the model accepts input data concerning year-end-strengths and promotion policies, i.e., promotion points and promotion probabilities. It accepts historical or anticipated data conceming attrition and rates of transfer from Reserve to Regular Army. Finally, the model utilizes the current structure of the Corps, where officers are grouped by permanent and temporary grade, years in permanent and temporary grade, service component, 
military occupational specialty, years of active federal service, and years of active federal commissioned service. Passing from (simulated) year to year in accordance with the kinds of transitions and transition rules indicated above, the model produces, as output, a projection of the Corps structure in terms of the characteristics above, for the number of years specified. This projection can be shown in various tabular or graphical formats.

\section{I Input Data and Output Formats}

A single introduction to how the model operates can best be approached by illustrating the requisite input data and the corresponding outputs produced by the ANCFSM program. Output from the model is of two general forms, namely: (a) output which lists the input parameters, i.e., describes the scenario under which the model was executed, and. (b) output which portrays the current and projected force structures. Figure 5-1 illustrates some of the output generated by the model. Annex II-8 provides additional, more detailed outputs.

Figure 5-1A shows the promotion points, by grade and year, for five periods, 1973 to 1977 , inclusive, for permanent and temporary promotion in both the Regular Army and the U. S. Army Reserve. Promotion points define the zones of consideration for promotion by specifying the number of years of active federal commissioned service that an officer must have to be eligible for promotion. As shown in the figure, RA first lieutenants, for example, must have 4 and 5 years AFCS to be promoted to captain in 1973 and 1974 respectively, i.e., for illustrative example promotions are being delayed in future years. The figure also presents the probabilities of permanent and temporary promotion, by grade, for those in the zones of 


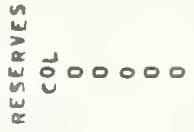

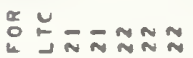

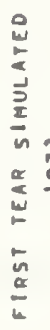

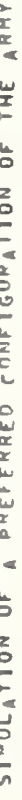

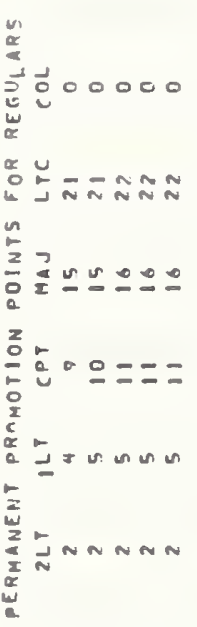

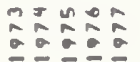

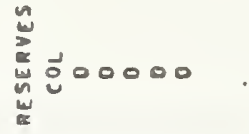

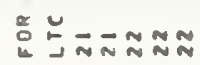

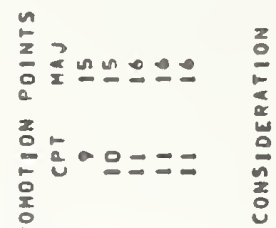

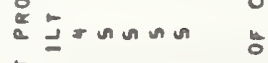

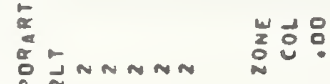

$z$

西.

궁

종:

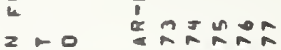

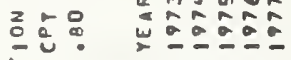

o

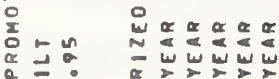

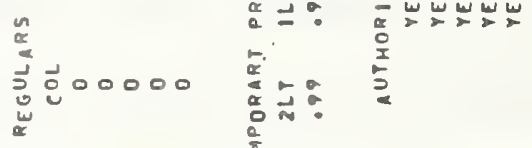

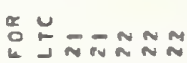

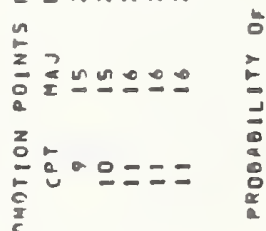

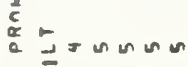

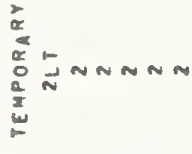

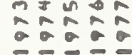


consideration. For example, virtually all (99\%) of the second lieutenants in the zone of consideration will be promoted, while only $45 \%$ of all lieutenant colonels will be. The constraint of having but one general officer is accomplished by setting the promotion probability to zero for all full colonels. Finally, the figure lists the total strength requirements, by year, for each year to be simulated. All of the data shown in Figure 5-1A are supplied by the user.

Figure 5-1B depicts the initial status of the ANC by grade and service component, and by MDS. Total salaries are tabulated for the same categories. These numbers represent input only, and because no changes have yet been simulated, all remaining columns in this figure are zero. This same general format is repeated each year of the simulation, with the changes occurring during that year tabulated in the appropriate columns.

Figure 5-1C also represents input and is a detailed breakdown of the initial profile of the Corps by grade, service component and years of Active Federal Service. This type of output is also repeated for each year of the simulation.

Figure 5-1D is the analog of Figure 5-1C for the specific category of obstetric nurse (MOS 3346). This particular breakdown for an individual MOS is not a standard model output. It is generated with very minor program changes at the request of ANC personnel. The program can, of course, be made to print these profiles for all MOS's.

Figure $5-1 E$ presents the results of actual simulation by the force structure model for the first such year requested. The 1972 authorized year-end-strength was 4124 officers, but is expected to be only 3597 at year-end 1973. Consequently, there are substantial separations (555), 


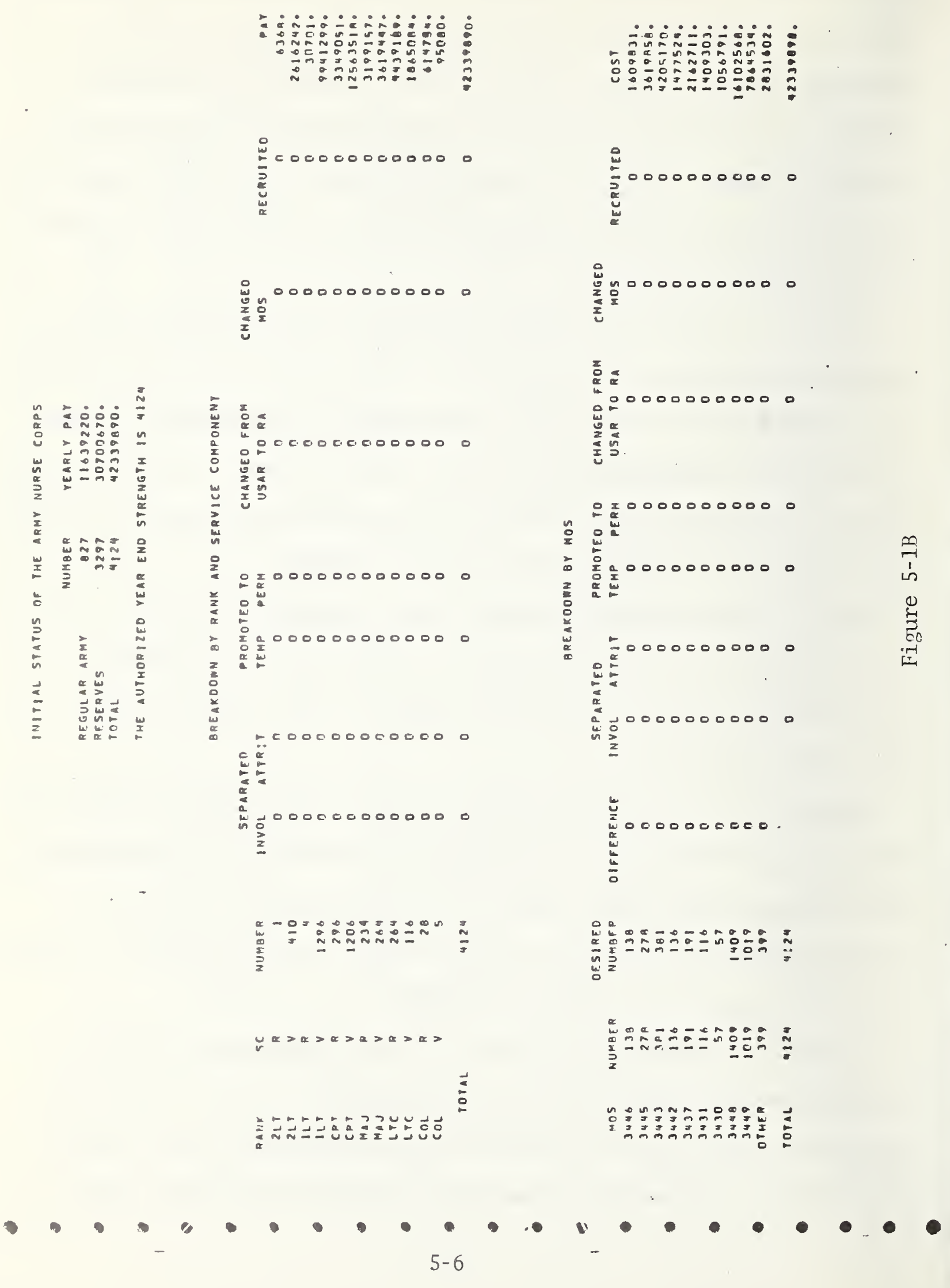




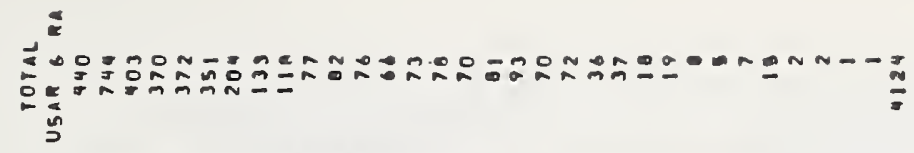

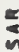

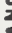

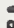

은

$\frac{2}{3}$

บ0000.00000mーN

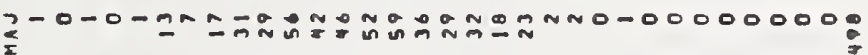

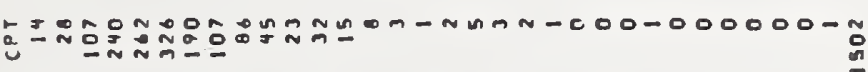

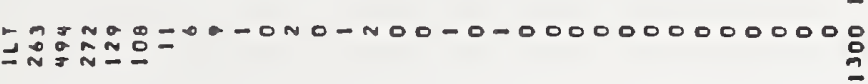
$\bar{n}: \operatorname{Non}^{2}--00000000000000000000000000=$

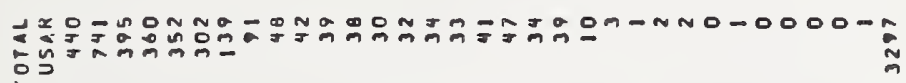
$0000000000000000-0-000-000000000$

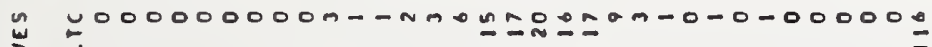

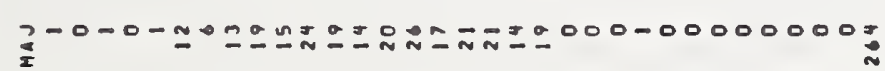

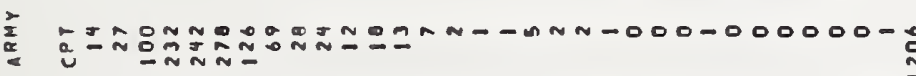

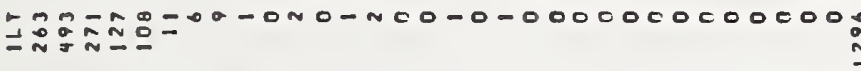
7.ำ

$$
\text { : }
$$

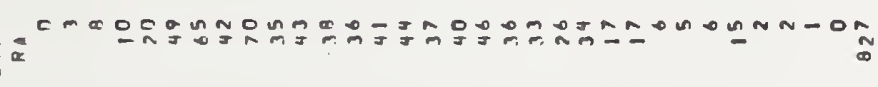
g 000000000000000000000 -n-mmann-0 z j

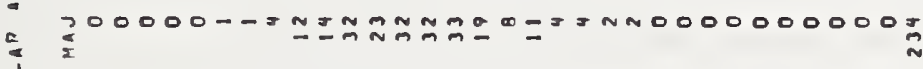
$-x^{2}$

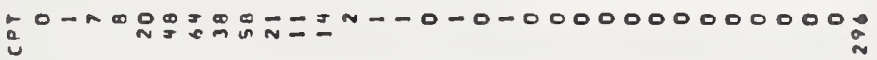
$=0-00000000000000000000000000000=$ $=0000000000000000000000000000000-$

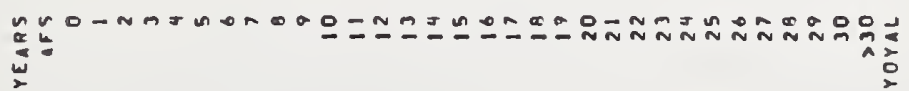
- 1 


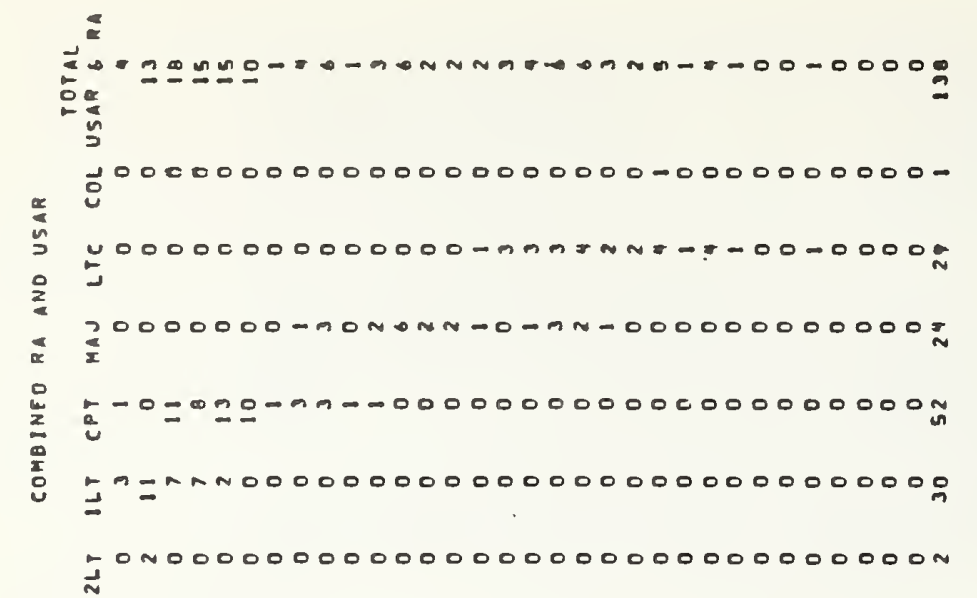

$=0 N 000000000000000000000000000000 N$

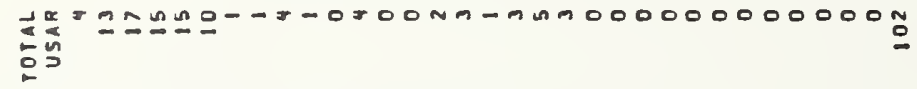
인 00000000000000000000000000000000

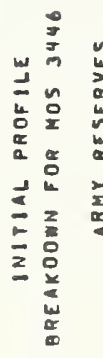

$\tilde{\omega} \sim 00000000000000-m-m n 000000000000=$ $300000000 N 00=00-00 N N-000000000000 N$

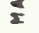

$2-00000--4-0000000000000000000000 \%$

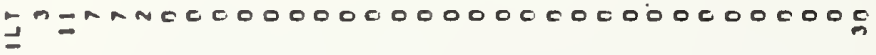

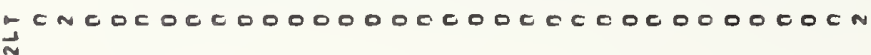

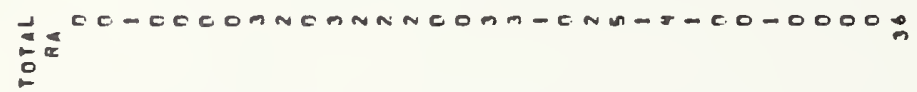

今000000000000000000000-0000000000-

I $50000000000000000 N n-0 N=-1-00-00000$ $\rightarrow$

- $30000000--0 N N N N 00-000000000000000 \ldots$

$\therefore 00-0000 n-0-000000000000000000000 \mathrm{~m}$ $\equiv 000000000000000000000000000000000$ J 000000000000000000000000000000000 


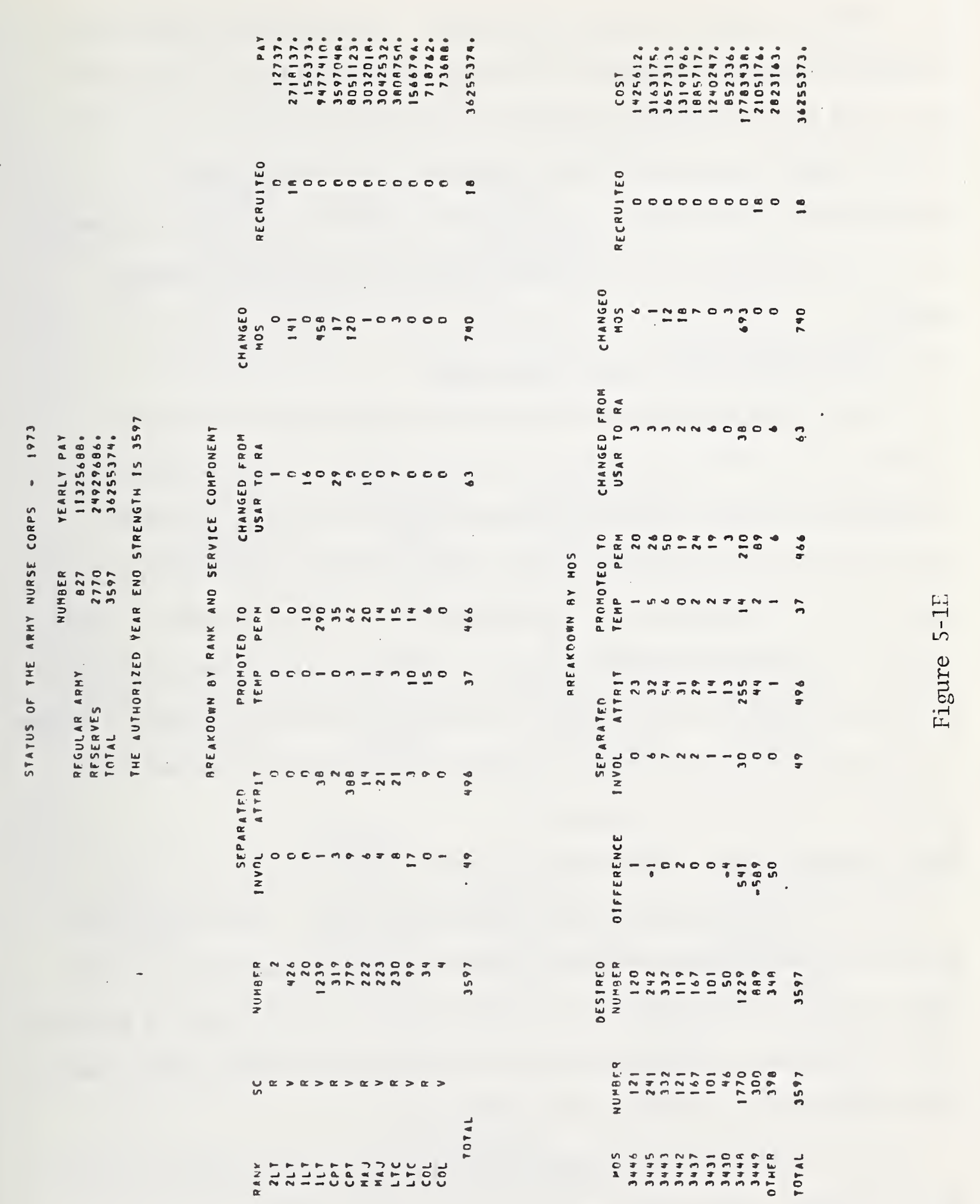


with addition of only 18 second lieutenants. It can be seen that in this simulation the great majority of attrition has taken place at the captain level, and that the nursing specialty incurring the largest loss is the medical surgical group, MOS 3448. These data are presented here to illustrate the model output. No particular significance should be attached to the actual numbers without thorough understanding of the simulated scenario.

5.2 ANCFSM Model Structure and Description

This section presents an overview, of the operation of the force structure model. The full details of its operation as well as computer generated flow charts of the program are found in Part III. The model treats each year as one unit of time. Boxes 1-3 have "initializing" functions. All changes in the force structure, as shown in boxes 4-11 of Figure 5-2 are modeled as if accurring at the same time in that year. In Box 12, the model ages the Corps by one year and returns to recompute changes in the Corps for the next year. The data processing steps are described briefly in the following paragraphs.

Mode1 Jperations (Box numbers refer to Figure 5-2.)

Box 1: Read the input data provided by the user. These data, representing the policies and practices to be simulated, include the following: number of years to be simulated, promotion points, probabilities of promotion, year-end-strengths, attrition data as described in Part III, salary schedule, and a distribution of transfers from USAR to RA.

Box 2: Read data describing the cohort groups in the current (initial) force structure. These data can be extracted from an officer Master File by a separate computer program described in Part III. 

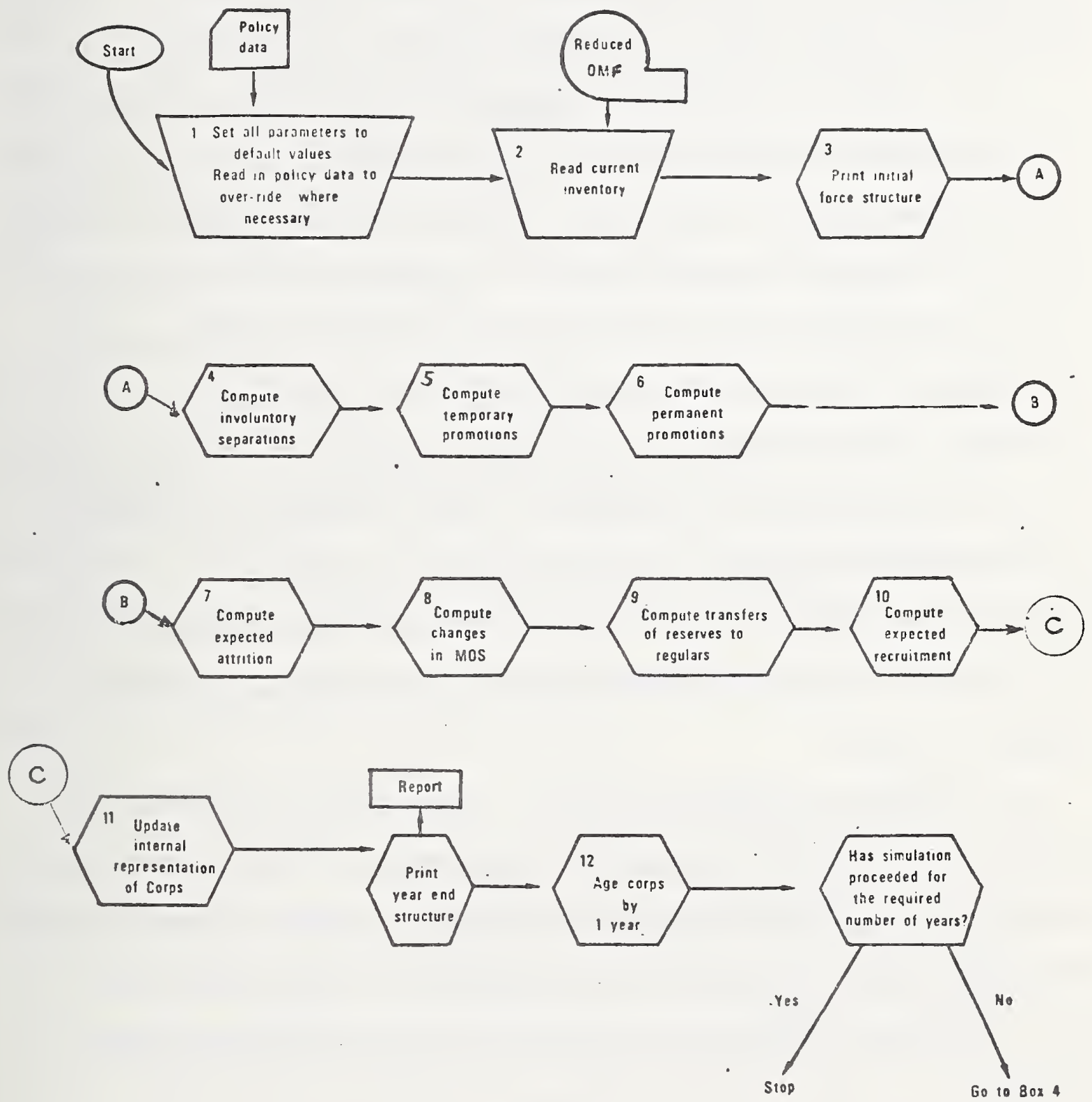

Figure 5-2

Overview of Steps in the

Simulation of ANCFSM 
Box 3: Print the input parameters of the model and display the initial force structure in tabular form and, if desired, in graphical form.

Box 4: Process involuntary separations and retirement. Officers are separated for the following reasons: a) USAR with 20 or more years AFS; b) RA colonels with 30 or more years AFS and 5 or more years in permanent grade; c) RA lieutenant colonels with 28 or more years AFCS; d) RA officers below the rank of lieutenant colonel who were passed over for promotion with 18 or more years of service and were allowed to remain until they acquired 20 years of service. Separation of these officers is based on trends found in historical data rather than on regulations requiring this action at this particular point in their careers.

Box 5: Process temporary promotions. Determine if an officer is in a zone of consideration for promotion. If so, the officer is promoted with a certain probability. Recall that both the zones of consideration and the promotion probabilities are input parameters. Officers with less than 18 years of service who are passed over are assumed to resign.

box 6: Process permanent promotions. Determine if an officer is in the zone of consideration for a permanent promotion. If so, the officer will with the specified probability be promoted. The zones and probabilities for permanent promotions are also input parameters. Officers below the rank of lieutenant colonel who are passed over for promotion are assumed to resign. 
Box 7: Determine if an officer is a candidate for attrition. Those who have recently enlisted or been promoted have not been considered candidates in most of the simulations executed thus far. (io consider these officers as candidates for attrition requires only minor program and/or data modifications.) For those officers who are candidates, attrition probabilities are calculated using the "relative attrition propensity" (RAP) relationships described in detail in Part III. Officers subject to attrition then leave the service with the probability so calculated.

Box 8: Simulate career transitions in the medical occupational specialties. A1l officers with MOS 3449 are converted to MOS 3448 after one year of AFCS. In addition, other MOS's are changed in order to maintain the distribution of officers by MOS that existed in the initial force structure as read in Box 2. The logic used in the model for changing MOS was developed after examining historical records to determine typical patterns of MOS transitions. The model can be easily modified to direct these transitions toward other target distributions.

Box 9: Simulate the transfer of nurses from USAR to RA. The number of officers to be transferred is determined by comparing the RA strength (before transfers) with the RA strength in the initial force structure as read in Box 2; the transfers are directed at maintaining that initial strength. The distribution of transferees by years of service, which can be obtained by examining historical data, is input to the model. 
Box 10: Simulate the recruitment process. Upon entering Box 10, al1 voluntary and involuntary separations have been recorded. The Corps now consists only of officers who have survived these processes. If this number is less than the authorized year-end-strength, officers are assumed to be recruited to fill the vacancies. Although the mode1 input allows for the specification of recruitment policies, definite future policies had not yet been established. Pending such establishment, the model's current version fills $20 \%$ of the vacancies by second lieutenants and $80 \%$ of the vacancies by first lieutenants. This distribution of recruits was based on past data. Al1 recruits in the mode1 are in the USAR and have MOS 3449. This recruitment policy of the present mode1 can be easily modified if desired.

Box 11: Update and consolidate the intermal computer representation of the ANC. This process reduces the computer memory requirements for the mode1.

Box 12: Advance time by one year. All cohort group attributes relating to time in service or time in grade are increased by one to reflect the passage of a year.

\subsection{Validation and Initial Results of Simulation}

The ANCFSM has been exercised numerous times during its development. In addition to the usual runs needed to debug the computer 
program, several runs were designed to validate the model logic and the associated input parameters. Validation of the simulation was approached by providing the model with force structure descriptions from past years (1970 and 1971) and exercising it to "predict" force structures up to and including 197.2. The model results were then compared with known data for this period of time.

Comparison of the predicted results with the "true" data indicated that the predicted nurse profiles (distribution of officers by rank, years of service, and service component) did not always agree with those obtained from the corresponding Officer Master Files. These discrepancies led to closer examination and comparison of the data extracted from various reports used as data sources. It was found that corresponding data from these sources (COPO-11 reports, Officer Master Files, and Separated Officer Master Files) did not agree. The discrepancies, which were discussed with ANC personnel, are apparently the result of two factors: acknowledged inaccuracies in past Officer Master Files, and uncertainty surrounding the actual dates on which these various sources were prepared. (Although the sources were dated at fiscal year ends, some may actually have been generated slightly earlier or later.) The effort required to attempt reconciliation of these past data discrepancies was judged to be beyond the scope of this study. Fortunately, similar discrepancies were not found in 1972 data and are not expected to occur in the future, since ANC efforts at improving the accuracy and completeness of these data sources are scheduled. 
It is extremely important that the validation effort be resumed when 1973 force data are available for comparison with predictions for 1973 from simulation runs started with the apparently more accurate 1972 data. A complete discussion of the validation efforts to date as well as an illustration of the data discrepancies are found in Part III.

Although it would be premature to attach great significance to model results prior to the completion of validation, it is anticipated that validity will indeed be confirmed when the 1973 data are available for comparison. For this reason, the study team went on to exercise the model several times, using the initial force structure obtained from the 1972 Officer Master File. These runs were made with a variety of settings for the input parameters, and the results have received considerable study. Figure 5-3 is a typical output from one such run in which the total number of officers in the Nurse Corps is plotted as a function of years of service. The figure shows that in the initial year (1972) there were approximately 450 officers with no experience (recent recruits), 750 officers with one year of experience, and 400 officers with two years of experience. After simulating three years, these numbers had changed to 680, 450, and 250 respectively. Such a profile can be extremely useful in identification and consideration of questions regarding costs, attrition, retention, and types of nursing experience. Scrutiny of such a curve produced under a specific policy can communicate distinct impressions, for management, of the changes that could occur over a number of years. To illustrate: it was noted that for a particular policy designated as 25-5 (a 25\% decrease in the Corps over a 5-year period) a "valley" in the profile curve was introduced in the early years. As simulation proceeded it was possible to see this 
$\frac{1}{\pi}$

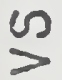

颉

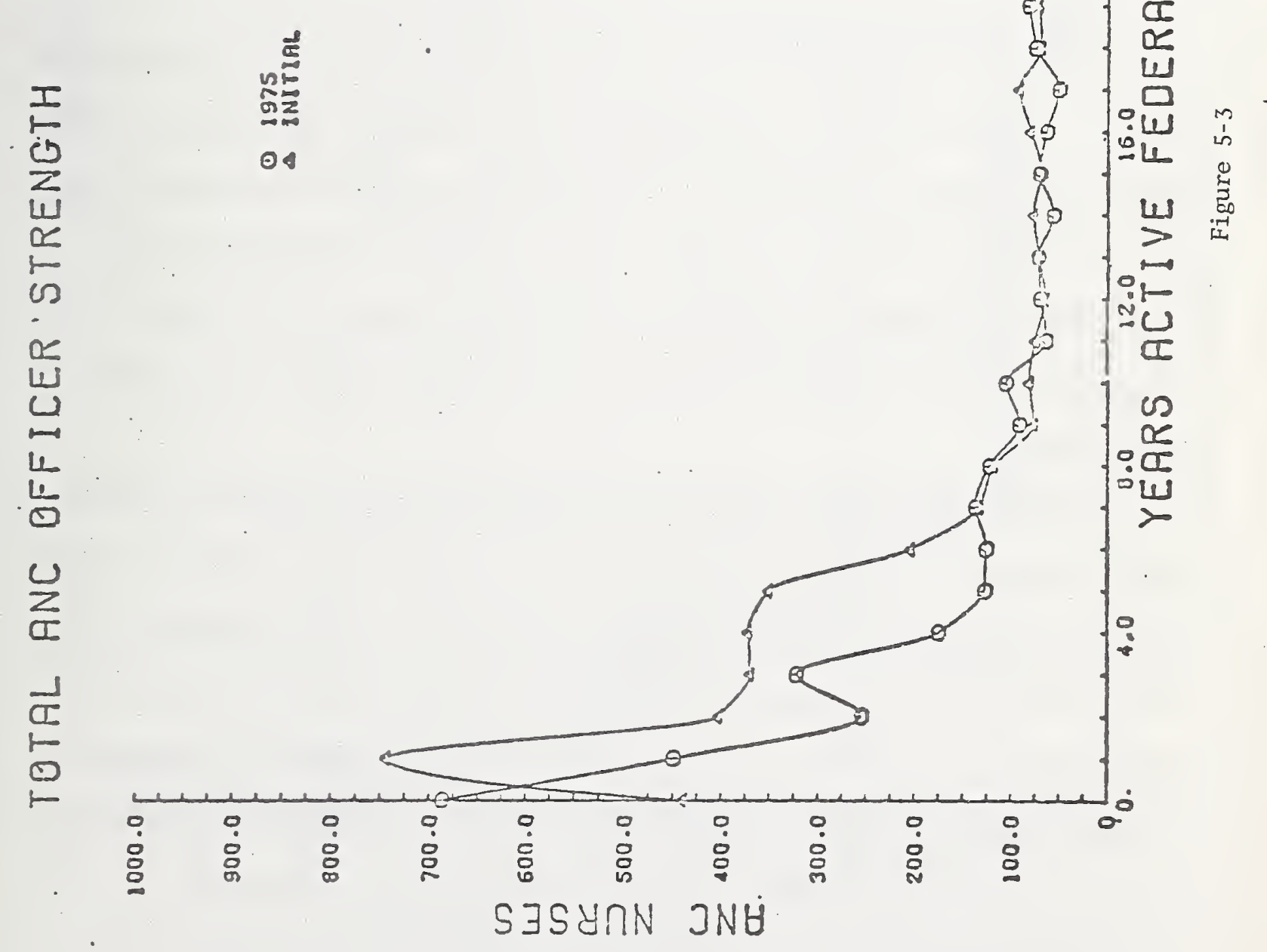


"valley" move across the horizontal axis with time. (In Figure 5-3 this valley appears in the 1975 profile curve at 2 years of service.) The movement of the "valley" directed attention to the effects of this policy in the year 1975 when the number of officers with less than seven years of service would be greatly reduced. Under the 25-5 policy the profile of officers in the higher ranks (with more than seven years service) was relatively unaffected, according to the simulation.

The worldwide questionnaire provided an additional source of data for comparison with data utilized in the simulation. In particular, the nurses were asked to give their active federal military service (rounded to the nearest year). Figure 5-4 compares the responses to this question for the 3,481 respondents with the profile obtained from the 1972 Officer Master File. Here again discrepancies were noted for officers with less than seven years of experience. It should be remembered, however, that the 1972 Officer Master File was prepared several months before the questionnaires were distributed. These discrepancies for the lessexperienced, more transient officers could be the result of this time difference.

A study of tabular and graphical outputs and the profiles, and of their changes in response to specific policy variations, enables a planner to see and visualize future ANC force structures. The simulation model is a tool for use in studying the effects of various policies upon the Nurse Corps. It cannot be overemphasized that the model can and should be modified to represent any number of policy proposals and variations. In fact, the real potential of this model will not be realized until it is exercised under the direction and guidance of ANC personnel. If, by 


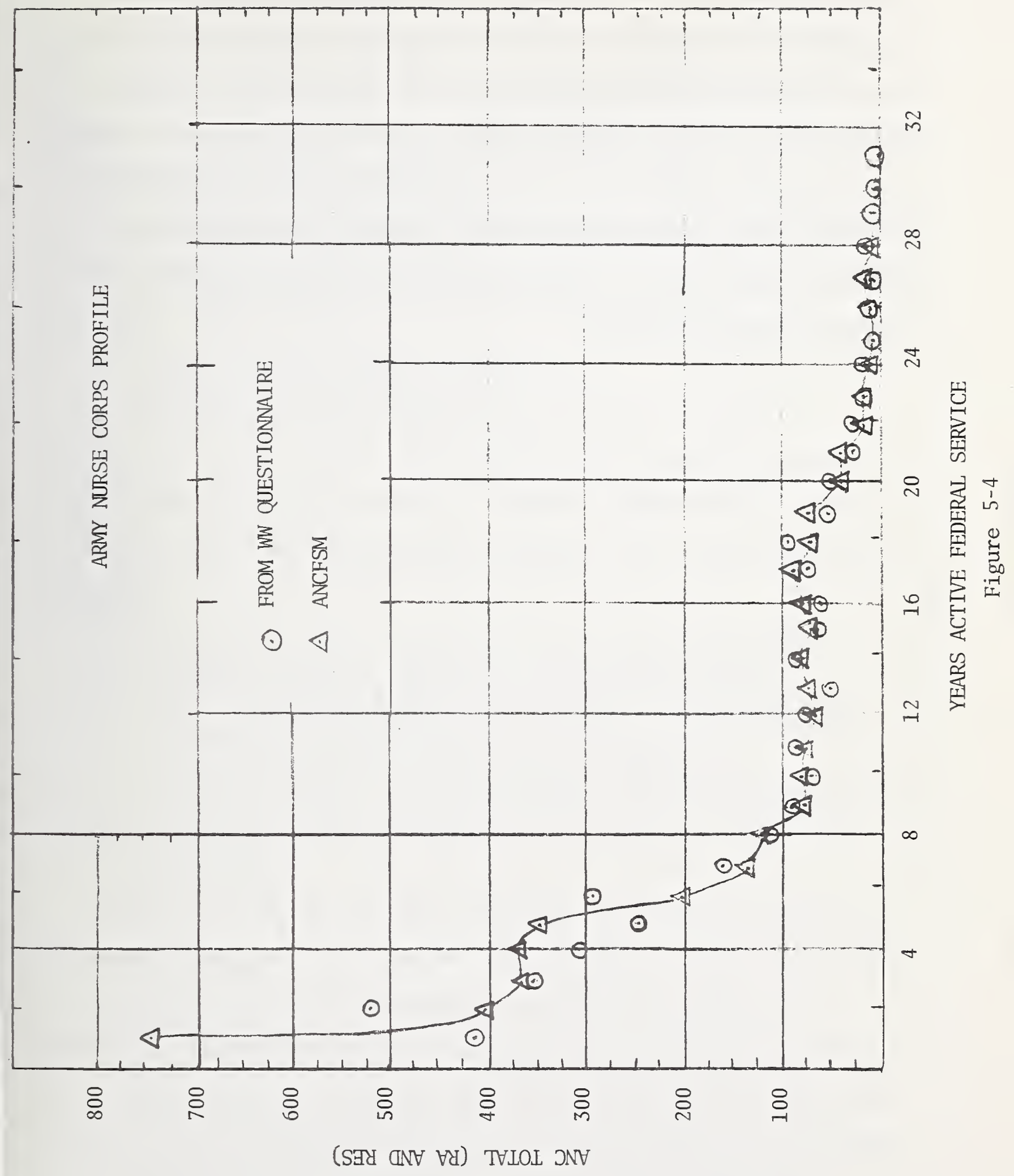


considering the needs of the MEDDAC and the changes produced by modern technology, it is possible for OTSG to formulate a preferred configuration, then use of the model under various policies will show which one best directs the initial structure to evolve toward that desired one. In this way, alternative future policies can be examined without the great cost and delay of real-life experimentation. The model is flexible, with parameters that are easy to change, and its use provides insight in a relatively inexpensive manner. 
6.0 DISCUSSION AND CONCLUSIONS

This section treats potential ANC problems and ways of minimizing these problems. It discusses the study products, projects results for possible future uses, and finally presents specific findings and conclusions.

6.1 Future Uses of Mode1s and Data

The interdisciplinary team developed techniques and tools for answering a broad range of questions of possible importance to the United States Army Nurse Corps. These include:

- A force structure simulation mode1

- Analysis of a worldwide ANC questionnaire

- Quantification of the MEDDAC.

Associated with these tools is a large valuable data base on nursing personnel that has been collected and reduced to computerized, machine processable form. This data base can be thought of as consisting of three components:

1. A data set derived from an attitudinal survey of nurses' thoughts, opinions, preferences, and dissatisfactions;

2. A data set derived from an organizational survey of the Nurse Corps, including distributions by number, nursing military occupational specialty, experience, and other U. S. Army service attributes (see Annex II-7 for survey Instruments);

3. A data set (Annex II-6) derived from a medical activities survey of the Nurse Corps, as characterized by staff and workload, quality of patient care, and other descriptors of their operating environment.

A principal objective of this project was to furnish the Office of The Surgeon General with sets of data and the means to continue a program of analysis on questions of importance. A number of possible studies and analyses emerged during the collaboration between NBS and the Office of The Surgeon General. These go beyond those planned for the NBS effort. However, they could be accomplished using the end products of this effort. Several possibilities are recommended on the following three pages. 
- For specific missions use the model for obtaining answers to the following questions:

1. Can a specific ANC configuration be developed for near future specific mission requirements?

2. What actions can be taken to correct variations from such specific configurations?

3. How many appointments as lieutenants are required for initial entry by phased year to attain and maintain a specific configuration?

4. How long will it take to achieve a specific configuration?

5. What are the described retention, separation, and promotion points required to achieve, in an orderly progression, a specific configuration?

6. What percent of the nursing corps will be leaving the service, and when?

7. What specific steps can the OTSG take (in terms of policy changes) to decrease this attrition and increase retention?

- Compare the relative attrition propensities (RAP's) of a sample of cohort groups to identify groups with relatively high and low RAP's. Establish the degree of correlation between attrition actually experienced by each group and the same groups' answers to the worldwide questionnaire item: how they feel about remaining in the service for a full career. Follow this analysis with an examination of the factors apparently most important to the career decisions of cohort groups with different attrition histories.

- The more meaningful of the personnel proposals to which the ANC officers responded in the worldwide questionnaire should be considered as subjects for future modifications and development of the force structure model (ANCFSM). Additional subroutines could be developed to simulate the effects of such proposals, and pertinent attitudinal data could be analyzed in relation to the results.

- The MEDDAC Regression Model (MRM) and the hypothesis testing techniques developed for the project permit the examination of additional 
questions pertaining to the variables already analyzed in the model, and are also amenable to the addition of new variables to obtain a better understanding of the MEDDAC environment of nursing services staff. It is possible to pose and answer such questions as:

1. What is the effect of the size of the hospital on the nurse/ workload relationships?

2. What is the effect of hospital size and hospital staff on the quality of patient care?

3. Can composite indicators be developed for determining hospital nursing staff requirements?

4. Is it possible to identify a workload quantity which correlates better with nursing requirements than the frequently employed Medical Care Composite Unit (MCCU)?

5. Is there any significant difference in staff/workload, or quality of care variables between hospital classes such as class sizes or Class I and Class II?

These are examples of questions that can probably be analyzed via the MEDDAC Regression Model and related hypothesis testing technique referenced in Section 4.3 and Annex II-3.

- Analyze in more detail the MEDDAC data on nursing staff to ascertain patterns relevant to implementation of personnel policies that pertain to such attributes and qualifications as race, sex, age, and professional training, as well as duty positions and work areas, and the use of nursing personnel in nonnursing duty positions.

- Conduct an analysis of the daily activities of ANC officers, using the activity data developed for this project's data base. The analysis should include both the activity data under general categories, as furnished by all ANC officers who completed the worldwide questionnaire, and also the more detailed data in Section C of the Survey of Nursing Personnel. 
- The foundation laid for the development of an index of professional orientation could be pursued further. Two elements of such an effort could be an in-depth analysis of the rank-ordered questions on professional and șelf-image variables summarized in Table $3-1$, the results of which could be analyzed in relation to attitudinal questions covering various dimensions of professionalism, bureaucratic functions, organizationai behavior, and individual profile characteristics.

- One important aspect of professional orientation among Army nurses is the relationships among three variable clusters: nursing skills, broader professional qualifications, and professional status. The data are available from this project to obtain a better understanding of the professional perceptions and motivations of ANC officers.

- Conduct an analysis of ANC responses to the questions: "What do you think is one of the biggest problems in the Army Nurse Corps?" and "What do you think should be done about it?"

- Finally, it is now possible to answer the following questions by interrogating the attitudinal component of the Nurse Corps data base with the computer programs of this study:

1. What attitudinal factors hamper or enhance retention and career management of nurses in the Army?

2. Can ANC officer reactions to current and contemplated policy statements and proposals be identified?

3. How do the military career expectations of ANC officers vary by grade and educational experience?

4. Can the vital factors of job satisfaction be identified and projected for educational attainments?

5. How many ANC officers are interested in entering nurse clinician specialties? How many are interested in courses that would qualify them for critical MOS's?

6. What professional values are most important to nurses, and do ANC officers associate these values with Army nursing?

7. What reason do Army nurses give for entering the ANC? For choosing to remain for a full career? 
8. What do members of the Corps feel are the ANC's biggest problems? How are these perceptions related to such factors as grade, component, MOS, sex, marital status, and dependency responsibilities?

These questions are in large part answered in Section 3 of this report. The force structure and regression models, in combination with the three sets of data, and the readily available associated statistical programs, constitute an array of techniques for examining ANC policy questions. Not only can aggregate needs and effects be projected, but the likely response of groups of individuals, with a specific attribute profile can also be made available. This array of instruments makes possible the interactive use of planning models, the professional judgments of the Corps, and the attitudinal analysis in simulating, for planning purposes, the future ANC configurations.

\subsection{The ANC Force Structure Simulation Model}

The development of the Force Structure Model revealed the possibility of testing a range of management policies relating to promotion points, recruitment, service component transfers, MOS training effects upon transfers, incentive contracts, and other grade and career factors. It was found that the MOS patterns projected by the ANC Force Structure Model are not extremely sensitive to relatively small year-end strength reductions, although these patterns are sensitive to larger year-end reductions in force. This dependence of the future MOS pattern, and other characteristics of the ANC structure, upon year-end strength policy, training plans, and other factors may now be investigated.

6.2.1 Model Projections of Future Staffs Under Current Policy

A class of findings concerning the number and distribution of nursing personnel, by specialty, that may be available in future years, has been 
projected utilizing the Army Nurse Corps Force Structure Model. These potential distributions were obtained under (i) the current year-end plans for the Army Nurse Corps, and (ii) one alternative plan. Under the current policy, a 5-year simulation projection showed, for example, that a deficit of approximately 360 obstetric nurses may be incurred unless positive steps are taken during that interval of time. A potential deficit of some 280 pediatric nurses may similarly be incurred. Assuming current policy, under the present system only 2,900 ANC nurses will be available for the projected 3,327 nurse officers potentially required in 1977 .

\subsubsection{Mode1 Variables, Corps Profile, and Policy Testing}

The simulation model exhibits certain items of interest in preliminary testing. The characteristic shape of the graph of the number of officers versus years of service (the area under the curve of Figure 5-4 represents the total Corps size) is sensitive to input parameters related to recruitment, retention (incentive) policies, and promotion policies. For the promotion policy assumed, the graph (referred to as the profile) is seen to drop quite rapidly, from a level of 600 nurses with 1-2 years of experience, to about 100 with about 7 years of experience, attenuating slowly thereafter for nurses with up to 30 years service in the Corps. This effect shows quite clearly that this specific policy results in the training of nurses who subsequently find employment outside the Corps. It is now possible to develop and test special promotion policies in which the profile curve (i) starts lower, and (ii) does not decrease quickly, but instead, decreases more slowly. Under such special policies there will be higher retention accompanied by lower recruitment and separation costs. 
6.3 The MEDDAC

The MEDDAC survey requested information on staff, workload, quality of patient care, and other variables. The issues discussed center around potential MOS shortages and the approach to the quality of patient care. 6.3.1 Hospital Requirements

Hospital requirements, as presented by tabulation of the duty MOS's enumerated in the survey, are being currently met by a mixture of military and civilian registered nurses. This mixture varies for specific MOS's, from almost $100 \%$ military nurses, to certain MOS's in which the military nurses number less than $50 \%$ of the total professional nurses. Comparison of the number of Army Nurse Corps members currently available with the specific MEDDAC tabulations indicates possible future shortages in pediatrics, obstetrics and neuropsychiatry. The data gathered from the hospitals in terms of duty MOS, when compared with the MOS projections of the model of Section 5, seemed to offer management the opportunity for projecting, planning, and training.

The findings relating to fitted equations for the number of nurses as dependent variables with other variables need comment. The success in obtaining fitted equations suggests the possibility of calculating the proportion of specific MOS staffs from appropriate MEDDAC variables. The results also suggest possible use of calculated values in a range of plans including requirements for future hospitals. The second suggestion is based on findings that it is possible to accurately compute the total number of professional nurses required by any one of the $67 \mathrm{Class} I$ and Class II hospitals. 
6.3.2 Quality of Patient Care

The quality of patient care studies in the literature must be interpreted with a great deal of caution. This "caveat", although mentioned earlier, is now discussed in greater detail in the light of findings in the report. It was found that the quality-of-care indicators of the study are not particularly sensitive to minor perturbations in the staff-to-patient ratio. That is, minor shortages or overages in nursing staff, as observed in the survey, did not correlate to any appreciable extent with the study indicators of quality of patient care. What this suggests is that the variable nursing staff is a robust (sensitive) function of workload requirements, but a weak (insensitive) function of the indicators of quality of care when such staff levels are in the vicinity of the expected levels.

However there seems to be little question of the finding that the composite quality-of-care indicator reveals somewhat better quality of patient care in the smaller hospitals as compared with the very large hospitals. It may tentatively be concluded that the quality of patient care, based on currently available data, is not correlated with current operating shortages or surpluses in professional nursing staff.

\subsection{The Worldwide Questionnaire}

The analysis of the worldwide questionnaire revealed the principal issues associated with Army nurses' decisions to leave or remain in the service.

\subsubsection{Retention-Staying or Leaving}

Over $70 \%$ of all the younger nurses (20-24 age group) indicate that they will or may leave the service on completion of their initial obligation. The highest retention rate, by an overwhelming margin, is 
among RN's who enter the service through direct appointment from civilian status. Those nurses with hospital diplomas are among the next highest group to stay in service. However, young male nurses, once they obtain an ANC commission, are more inclined to remain in the service than young female officers.

6.4.2 Minimizing the Major Dissatisfactions of ANC Officers The principal approaches that might minimize the major dissatisfactions of ANC officers and lower the attrition rate are supported by the data developed for this study. However, they are addressed in broad concept only in this report, and the analysis is limited to general categories. The officers, in addition to giving their responses to specific proposals and attitude questions, also provided their opinions on what they regarded as the biggest problems of the Army Nurse Corps, and what should be done about them.

Among the most important issues that have emerged in this study is the elimination of the traditional inequities of the military faced by the female officer. The problem is exacerbated for the predominantly female nursing profession in relation to other AMEDD, particularly the physicians of the Medical Corps. Recent and remaining inequities strike at status and self-esteem, and their removal would go far toward reducing general dissatisfactions. That is, inequities tend to cause a kind of dissatisfaction that spills over into other areas, and remedies can have a corresponding multiplier effect. One avenue that touches both selfesteem and economic pressures, for example, is professional pay.

Inequities based on marital status, dependents, and unequal burdens of responsibility are a "gut" issue of a different order; they are more 
pragmatic and do not touch so intensely on self-image. Their rectification would ease the ordinary burdens of the individual officer with heavy responsibilities to family and dependents.

A second "gut" issue of great importance is the financial squeeze faced by officers who, for reasons having to do with local housing and living costs, find the burden of supporting and housing their families particularly difficult. Adjustments to local costs and provisions for more adequate housing for military families are important to this group.

A third major issue has to do with the frustration faced by both younger and older nurses as the popular "generation gap" intersects the push for greater professionalism and professional status for nurses among the health professions on the one hand, and the traditional hierarachical system of military rank and authority on the other. The issue is joined in the question of whether nursing questions are decided on the basis of rank or of professional competence. Neither the problem nor its amelioration is simple. However, the introduction of a more professional frame of reference and a lessening of hierarchical control, particularly an extension of the range and kind of professional judgments left to the individual member of the profession in his work, might reduce this area of dissatisfaction.

6.4.3 Nursing and Army-Wide Officer Selection for Promotion

The Omnibus Act of 1967 authorized, for the first time, a general officer for the position of chief nurse, and this precedent potentially increased the number of higher ranking officers. However, two additional factors now enter into the apparently new opportunities for higher ranking female officers. These two factors are the practices of selection, 
promotion, and authorization of officers on the basis of (a) Army-wide consideration and (b) non-nursing officer qualifications criteria. ANC officers will not be selected for promotion relative to their peer group; they will be selected relative to all other officers in the zone of consideration. These two factors tend, once again, to reduce the specific selection and promotion of Army Nurse Corps officers by omitting consideration of specific nursing qualifications and requirements of good nursing practice.

These factors tend to de-emphasize the utilization of higher ranking nurses (engaged in "hands-on" nursing) in the treatment of patients as is the case with physicians in the Army Medical Corps (AMC). If the conceptual limitations on the careers of female nurse officers in the ANC are to be removed and the new opportunities of the Omnibus Act of 1967 fully realized, certain changes in the ANC configuration may have to be considered. These potential changes relate to the pyramidlike structure of special corps which may have to be broadened at the top as it is in practice for physicians in the ANC. This pyramid broadening is functionally related to six management functions previously mentioned. However, broadening of the pyramid-like structure with a subsequent evolution from the supervision/administration role concept to the "handson" assignments in quality nursing care is one which will gradually come about through appropriate use of the regulatory power of the Secretary of the Army. This study was aware of the problem and provided the data, models, and equations which may be useful in such considerations.

The above problem is related to the problem of the appropriate "mix" of ANC nurses with civilian nurses working in Army hospitals and medical 
department activities. The number and proportion of civilian nurses in the Army Nurse Corps was increased during the limited war mission in Southeast Asia. As the military step-down proceeded, there was a decrease in nursing requirements calling for a change in the "mix" of ANC officers and Department of the Army registered nurses. It is conceivable that this military-to-civilian ratio may have a significant bearing upon the objectives of this study. In particular, it may influence not only the orderly progression toward a specific configuration, but it may also exert an influence upon the promotional flow characteristics now regulated by the management policies and practices of recruitment, training, retention, promotion, separation, and retirement.

6.4.4 Professionalism: Military and Nursing

The two fields of professionalism of the ANC officers, the military and nursing, emerge from the attitudinal analysis of the worldwide questionnaire as a complex issue requiring consideration. The problem involves a conflict between professional nursing and the military bureaucracy, one based on nursing judgment and expertise, through education and experience, and the other based on rank and authority. The higher the level of professional education and orientation a nurse achieves, the more difficult it becomes to adapt to the military organization, especially when rank and authority override the nurse's professional judgment.

Professionalism is apparent in the Army nurses' responses to a variety of questions, and is important to the future of the Corps for two principal reasons: (1) retention of nurses with a highly professional nursing orientation, and (2) professionalism in the operational context in which the nurse practices, including military professionalism of a high order, for those who will provide the Corps with leadership. 
6.5 Specific Configurations via Education and Training

Education and training constitute a principal avenue for obtaining the numbers of Army nurses with the skills and experience needed by the . various medical activities. The aggregate of these numbers and types provide a given configuration of the Army Nurse Corps for a particular time frame. Other avenues, besides education and training, may also be used to achieve a particular configuration. Important among these other avenues are direct appointments to the Army Nurse Corps and the hiring of Department of the Army civilian registered nurses.

To the extent that education and training are utilized to help achieve a desired ANC configuration and appropriate civilian/military mix, the educational qualifications and interests of nembers of the Corps are of interest at three points. These include the qualifications with which they entered the Corps; current education and training in which they are participating, if any; and education and training into which they can be channeled.

Education and training programs can be guided in part by information available from this study-educational qualifications and interests from the individual officer questionnaires, needs as reported and projected by the MEDDAC, and projections of the ANC Force Structure Mode1, based on current trends or alternative personnel management policies. The major products can be used conjointly in an interactive, iterative process for determining the long-term effects of new practices and policies on the Corps' MOS profile. The procedures are as follows:

- Identify the numbers of ANC officers in each MOS by grade.

- Identify the numbers of DAC RN's in each duty MOS (that is, what the duty MOS would be if the position were held by an ANC officer). 
- Project the attrition rate for each MOS and for the programs through which those with each MOS tend to enter the Corps.

- Identify nurses currently involved in education and training programs leading toward qualification for each MOS (and, as appropriate, closely related specialties).

- Identify the number of ANC officers who indicate an interest in work related to qualification for each MOS.

- Identify Army nurses with past training in each MOS field (including but not limited to those who hold each MOS as a Secondary MOS (SMOS)).

- Project the effect of education and training programs for each MOS on ANC configuration.

- Plan for education and training programs and for direct appointment goals with outputs, and in the context of whichever policies one may wish to hold constant (such as the ratio of civilian to military nurses in a given MOS).

- Determine when goals are not achievable within the assumptions given; these may then be relaxed to examine pertinent changes (again, for example, altering the civilian/military ratio in order to obtain the needed number of nurses for a given duty MOS).

An application of the second procedure above to potential shortages in one MOS is described below. Assuming the requirement for all MEDIAC, in CONUS and overseas, is 400 pediatric nurses, we find currently there are only 150 officers in the ANC with the pediatric PMOS (3442). We further find that half of these are in the grades of major or above. The other 75 constitute the future leadership of the Corps in this MOS and they are proportionately in short supply. The remaining 250 pediatric nurses are DAC RN's.

Some ANC officers will, perforce, be assigned to duties other than "hands-on" pediatrics. Therefore, the ratio of civilian to military pediatric nurses will without planning tend to increase over time.

Further, the changes that occur, forcing the MEDDAC to rely on civilian nurses for certain types of nursing, make a reversal of the 
pattern more difficult. And, as those pediatric nurses now in the ranks become lieutenant colonels and colonels, the leadership in the MOS group becomes vanishingly small.

The process of planning, in this case, could be based on these steps:

1. Obtain the pertinent information from the data and analysis;

2. Design a training program to encourage younger nurses to go into pediatric nursing; and

3. Run the model to see what the results would be over a 5-year period in terms of building a backlog of 3442 's.

If a sufficient number of nurses have indicated an interest in pediatric nursing, the model should produce projections equal to the need, assuming that for each nurse who had said in the questionnaire she would like to enter pediatrics but now will not if given the opportunity, there is another nurse who gave some other area of nursing as her interest but will now enter a pediatric nursing course when the opportunity arises. The model would, of course, consider the grade and component of nurses moving from one MOS track to another as a result of a change in education and training while in service.

6.6 Accomplishments, Findings, and Conclusions

The basic results of the study of the Army Nurse Corps can be roughly grouped into three categories:

- The force structure model

- The worldwide questionnaire

- The MEDDAC - the operating environment of the ANC.

6.6.1 The Force Structure Mode1

The force structure model has been designed as a planning tool for evaluating the effect, with respect to time, of various regulations and policies upon the force structure of the ANC. 


\section{- Relative Attrition Propensities}

The design features and operation of the simulation model are discussed in detail in Section 5 of Part I, and in Part III. Certain findings and results are mentioned in the introduction to the report. It was found that attrition, a necessary subroutine in the model, required a special approach to minimize simulation model differences with real world fluctuations. It was determined that relative attrition propensities (RAP's) defined by a function of attrition rate are useful and in agreement with recent historical data over the period of 1968-1972.

- Annual Simulation with "Cohort Groups"

Another result of the modeling work was the representation of individual nurses by "cohort groups," i.e., groups of nurses with similar characteristics. The model "applies" each of its career factors subroutines to all cohort groups for each year being simulated. Although the model has been exercised numerous times, and estimates of future shortages and surpluses in nursing specialties have been observed and reported, time has not permitted extensive research of the effects of changing parameters which would operate under contract incentive scenarios.

- Preliminary Trends in Simulations with Specific "Reduction in Force" Scenarios

In preliminary testing runs a scenario of "reduction in force" for the next several years with low recruitment levels created a small initial decrease in the number of officers with less than one year of service. It was found that in the model's graphical outputs, which display the force structure (number of officers vs. years of service) for each year being simulated, there appeared a "valley" which "moved" along the horizontal axis (years of service) as the graphs were viewed in chronological order. When the initial (1972) profile of these simulation runs was compared with profiles obtained for 1975 the most pronounced effects of the reduction in force appeared in the 1975 profile for officers with less than seven years of service. The profile of officers with more than seven years of service was relatively unaffected.

- Use of Model in Projection

Output from the model is of two forms, namely tabular and graphical, for each year being simulated. At present, the output describes the predicted yearly force structures by rank and service component, by MOS. With minor changes in the computer program any combination of cohort group characteristics can be selected, and the corresponding force structure description can be output in similar year-by-year form. 
6.6.2 The Worldwide Questionnaire

The analysis of the worldwide questionnaire revealed the principal issues associated with Army nurses' decisions to 1eave or remain in the service.

- Staying or Leaving

Over two-thirds of the younger nurses (20-24 year age group) indicated a high expectation of leaving the service on completion of their obligation. The highest retention rate, by an overwhelming margin, is among RN's who enter the service through direct appointment from civilian status.

- Student Nurse Programs

Army student nurse degree programs reflect the higher mobility of baccalaureate nurses, who have lower retention rates after the initial service obligation has been met.

- Policy Proposals

Of the 48 policy proposals on which Army nurses were asked to give their opinion, the most important issues to the Corps are: (1) basic pay, allowances, and benefits; (2) nursing professiona1ism; and (3) inequities based on sex, marital status, and dependents.

- Professionalism in the MEDDAC

A dominant issue in attitudinal responses was a conflict between professional nursing and military bureaucracy in the MEDDAC environment. The higher the level of professional orientation of an Army nurse the more difficult it becomes to adapt to the system of rank, seniority, and authority in a military organization, especially when that system overrides the nurse's professional judgment.

- The Generation Gap

One major theme that emerges in the attitudinal responses is a "generation gap." Younger nurses tend to agree that there is a conflict between professional competence, and rank and authority of senior nurses.

- Administration and Facilities

Over half of those who expressed an opinion feel that the Army hospital administration is generally competent, but not particularly responsive to patients' needs. About the same proportion tend to agree that the Army medical facilities and equipment are often obsolete. 
- Reputation of the ANC

Most nurses agree that the Nurse Corps enjoys a good reputation and that the quality of patient care is generally good.

- Expanded Nursing Role

The nurses gave strong support to the expanded role of the nurse and showed an interest in nurse clinician programs.

- Skil1 and Assignments

About two-thirds of the Corps believe that their assignments utilize their skills. Most of the Corps are satisfied with their present work assignments and geographic locations, although a significant proportion indicated they were neither consulted nor given their preference in their current assignments.

6.6.3 The MEDDAC

The analysis of the MEDDAC data base revealed relationships among workloads, staff sizes, indicators of the quality of patient care, and other MEDDAC-related variables.

- MOS Mismatches

Data supplied in the survey of over 70 U. S. Army hospitals worldwide indicate a number of mismatches between hospital duty MOS's and ANC primary MOS's. Projections of the ANC force structure model indicate that this degree of mismatch will widen in the next few years unless appropriate policies of recruitment, training, and retention are instituted.

- Staff Workload Relationships

A range of simple, easy to use fitted relationships between staff and workload variables in U. S. Army hospitals was derived.

- Staff Indicators

A single indicator of staff requirements is the number of bed occupied days at a given hospital. An improved weighting of the four factors used in calculating the Medical Care Composite Unit resulted in a markedly increased correlation with the nursing staff.

- Patient Care and Hospital Size

The overall quality of patient care, as measured by the indicators of this study, increases, in general, with decreasing hospital size. 
- Patient Care and Nurses

The observed shortages or surpluses in nurses have 1ittle influence on, or correlation with, the indicators of the quality of patient care.

This account started with a description of study goals centered on nursing personnel attitudes, nursing environment, ANC force structure; and it concluded with wel1-defined sets of study findings. The study was concerned very early with team development and utilization of certain procedures, methods, and interrelated concepts. The concepts are interdisciplinary in nature, consisting of elements borrowed from nursing, behavioral science, survey instrument methodology, statistics, computer programming, and the simulation modeling characteristic of the field of operations research.

The study project generated:

- A large, functional, easily accessible computerized data base; - An analysis of a salient portion of this data base; and

- Quantitative relationships of the MEDDAC-the nursing environment.

The data of the attitudinal analysis and the numbers derived from the MEDDAC relationships served both as inputs and outputs of the various interdisciplinary efforts including the regression and force structure model.

In conclusion it is noted that the results of the attitudinal analysis, the relationships resulting from the MEDDAC statistics, and the force structure model, simulate for management planners the future characteristics of the ANC as specified by certain inputs and policies. It is anticipated that management functions will encompass a wide range of military as well as civilian manpower planning decisions with respect to recruitment, training, retention, promotion, separation, and retirement. 


\begin{tabular}{|c|c|c|c|}
\hline $\begin{array}{l}\text { L.S. DEPT. OF COMM. } \\
\text { BIBLIOGRAPHIC DATA } \\
\text { SHEET }\end{array}$ & $\begin{array}{l}\text { 1. PUBLICATION OR REPORT NO. } \\
\text { NBSIR } 73-285\end{array}$ & $\begin{array}{l}\text { 2. Gov"t Accession } \\
\text { No. }\end{array}$ & 3. Recipient's Accession No. \\
\hline \multirow{2}{*}{\multicolumn{3}{|c|}{$\begin{array}{l}\text { 4. TIT LE AND SUBTITLE } \\
\text { Structure Analysis and Program Planning Study of the } \\
\text { Army Nurse Corps (ANC): Part I }\end{array}$}} & $\begin{array}{l}\text { 5. Publication Date } \\
\text { October } 1973 \\
\end{array}$ \\
\hline & & & 6. Performing Organization Code \\
\hline \multicolumn{3}{|c|}{$\begin{array}{l}\text { 7. AUTHOR(S) } \\
\text { John W. Rowen, Ralph B. Swisher, Patsy B. Saunders }\end{array}$} & $\begin{array}{l}\text { 8. Performing Organization } \\
\text { NBS IR } 73-285\end{array}$ \\
\hline \multirow{2}{*}{\multicolumn{3}{|c|}{$\begin{array}{l}\text { 9. PERF ORMING ORGANIZATION NAME AND ADDRESS } \\
\text { NATIONAL BUREAU OF STAND ARDS } \\
\text { DEPARTMENT OF COMMERCE } \\
\text { WASHINGTON, D.C. } 20234\end{array}$}} & $\begin{array}{l}\text { 10. Project/Task/Work Unit No. } \\
4314487\end{array}$ \\
\hline & & & $\begin{array}{l}\text { 11. Contract/Grant No. } \\
\text { Ltr. Jan. } 72\end{array}$ \\
\hline \multirow{2}{*}{\multicolumn{3}{|c|}{$\begin{array}{l}\text { 12. Sponsoring Organization Name and Address } \\
\qquad \begin{array}{l}\text { Office of The Surgeon Genera1 } \\
\text { Department of the Army } \\
\text { Washington, D.C. } 20314\end{array}\end{array}$}} & $\begin{array}{l}\text { 13. Type of Report \& Period } \\
\text { Covered } \\
\text { Final } 1 / 72-10 / 73\end{array}$ \\
\hline & & & 14. Sponsoring Agency Code \\
\hline
\end{tabular}

15. SUPPLEMENTARY NOTES

16. ABSTRACT (A 200-word or less factual summary of most significant information. If document includes a significant bibliography or literature survey, mention it here.)

This report presents the results of a study of the U.S. Army Nurse Corps (ANC) conducted by the Technical Analysis Division (TAD) of the National Bureau of Standards (NBS) and sponsored by the Office of The Surgeon General (OTSG). The study focuses on nurses' attitudes, working environment, and ANC force structure. It documents the following study products: A new computer model simulates the ANC force struc alternative policies. The study contains analyses of individual and organizational survey questionnaires distributed to approximately 3500 Army nurses and 70 Army hospitals worldwide. The project developed an extensive computerized data base and a quantitative description of the operating environments of the hospitals in terms of staff, workloads, quality of patient care and other variables. The attitudinal analysis focuses on issues associated with staying in the ANC and professional interests of Army Nurses.

17. KEY WORDS (Alphabetical order, separated by semicolons) Activities; ANC, Army Nurse Corps; Army hospitals; attitudes; attrition; education; force structure; forecasting; manpower; MEDDAC; modeling; nursing staff; personnel; quality of care; simulation; survey; training

\begin{tabular}{|c|c|c|}
\hline $\begin{array}{l}\text { 18. AVAILABILITY STATEMENT } \\
\square \text { UNLIMITED. }\end{array}$ & $\begin{array}{l}\text { 19. SECURITY CLASS } \\
\text { (THIS REPURT) } \\
\text { UNCL ASSIF IED }\end{array}$ & $\begin{array}{l}\text { 21. NO. OF PAGES } \\
\text { Pt. I - } 208 \\
\text { Annex - } 416\end{array}$ \\
\hline $\begin{array}{l}\mathrm{X} \text { FOR OFFICIAL DISTRIBUTION. DO NOT RELEASE } \\
\text { TO NTIS. }\end{array}$ & $\begin{array}{l}\text { 20. SECURITY CLASS } \\
\text { (THIS PAGE) } \\
\text { UNCL ASSIFIED }\end{array}$ & 22. Price \\
\hline
\end{tabular}





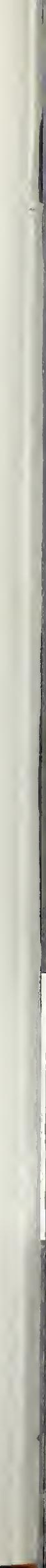

